\title{
Effects of the PRACHAR project's reproductive health training programme for adolescents: Findings from a longitudinal study
}

\author{
Neelanjana Pandey \\ Population Council \\ Shireen J. Jejeebhoy \\ Rajib Acharya \\ Population Council \\ Santosh Kumar Singh \\ Population Council \\ Mahesh Srinivas
}

Follow this and additional works at: https://knowledgecommons.popcouncil.org/departments_sbsr-pgy

Part of the Demography, Population, and Ecology Commons, Family, Life Course, and Society Commons, Gender and Sexuality Commons, and the International Public Health Commons How does access to this work benefit you? Let us know!

\section{Recommended Citation}

Pandey, Neelanjana, Shireen J. Jejeebhoy, Rajib Acharya, Santosh Kumar Singh, and Mahesh Srinivas. 2016. "Effects of the PRACHAR project's reproductive health training programme for adolescents:

Findings from a longitudinal study." New Delhi: Population Council. 


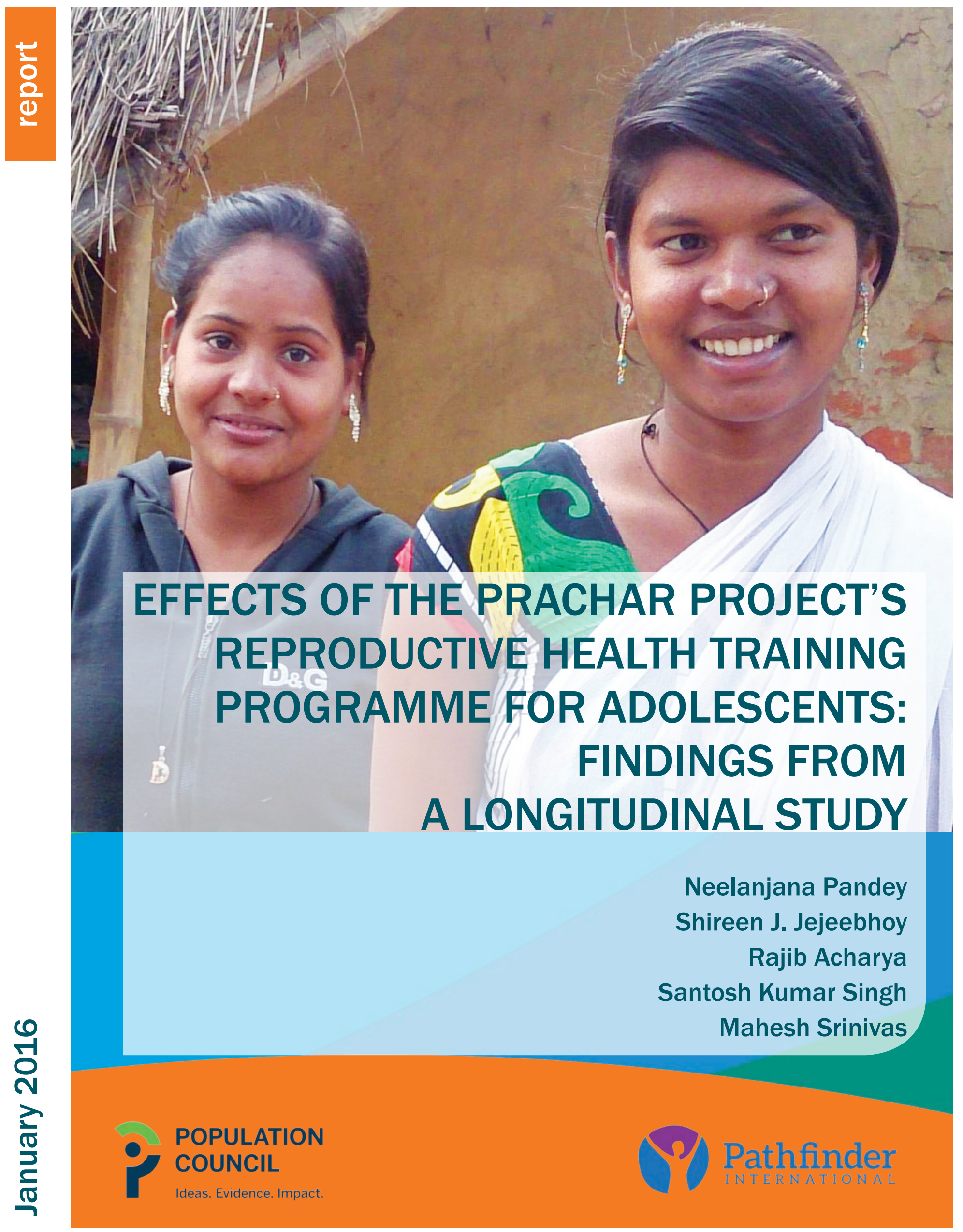




\section{Poovlation COUNCIL \\ Ideas. Evidence. Impact.}

The Population Council confronts critical health and development issues-from stopping the spread of HIV to improving reproductive health and ensuring that young people lead full and productive lives. Through biomedical, social science, and public health research in 50 countries, we work with our partners to deliver solutions that lead to more effective policies, programs, and technologies that improve lives around the world. Established in 1952 and headquartered in New York, the Council is a nongovernmental, nonprofit organization governed by an international board of trustees.

The information and views expressed in this report do not necessarily reflect the views of the Population Council.

\section{Population Council}

Zone 5A, Ground Floor India Habitat Centre, Lodi Road

New Delhi, India 110003

Phone: +91-11-2464 2901

Email: info.india@popcouncil.org

Website: www.popcouncil.org

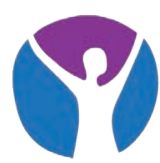

Sexual and reproductive health without fear or boundary.

\section{Pathfinder International}

B7-Extn./110A

Harsukh Marg

Safdarjung Enclave

New Delhi 110029

Phone: +91-11-4769 0900

Wesbite: http://www.pathfinder.org/

Suggested Citation: Pandey, N., S. J. Jejeebhoy, R. Acharya et al. 2016. Effects of the PRACHAR Project's Reproductive Health Training Programme For Adolescents: Findings From A Longitudinal Study. New Delhi: Population Council. 


\section{EFFECTS OF THE PRACHAR PROJECT'S REPRODUCTIVE HEALTH TRAINING PROGRAMME FOR ADOLESCENTS: FINDINGS FROM A LONGITUDINAL STUDY}

Neelanjana Pandey

Shireen J. Jejeebhoy

Rajib Acharya

Santosh Kumar Singh Mahesh Srinivas 


\section{Table of Contents}

List of Tables

List of Figures

Acknowledgements $\quad$ vii

Executive summary

Chapter 1 Introduction 1

Chapter 2 Socio-demographic profile of youth 10

Chapter 3 The intervention and participants' experiences and perceptions about its acceptability 18

Chapter 4 Young people's awareness about sexual and reproductive health matters 23

Chapter 5 Age at marriage and marriage related planning 36

Chapter 6 Contraceptive practice in pre-marital and extra-marital relations and within marriage 42

Chapter 7 Young people's agency and gender role attitudes 53

Chapter 8 Pregnancy related care and nature of married life 62

Chapter 9 Summary 65

$\begin{array}{ll}\text { References } & 70\end{array}$

$\begin{array}{ll}\text { Authors } & 71\end{array}$

$\begin{array}{ll}\text { List of Investigators } & 72\end{array}$ 


\section{List of Tables}

Table 1.1: Profile of young population and selected indicators of reproductive health in Rural Bihar and study district, Gaya

Table 1.2: $\quad$ Follow-up rate in intervention blocks 6

Table 1.3: $\quad$ Response rates and reasons of non-response in intervention and control blocks 7

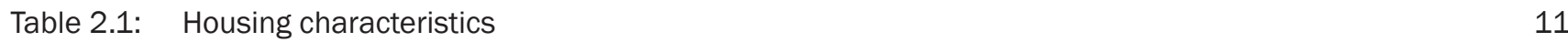

Table 2.2: Social and demographic profile of respondents 12

Table 2.3: Educational attainment, economic activity, and mass media and mobile phone exposure 14

Table 2.4: Extent of pre-marital and extra-marital sexual relations among young people 16

Table 3.1: Participation in the entire three-day programme and size of the group 19

Table 3.2: Recall of themes addressed in the training programme, and perceptions about the importance of these themes $\quad 20$

Table 3.3: Communication with family and friends about the training programme 21

Table 3.4: Perceptions about the usefulness of the training programme in subsequent life decisions 22

Table 4.1: $\quad$ Awareness about becoming pregnant 23

Table 4.2: $\quad$ Awareness about ideal pace of childbearing 24

Table 4.3: $\quad$ Awareness about contraceptive methods 25

Table 4.4: Correct specific knowledge about non-terminal methods of contraception 26

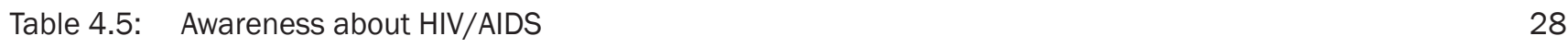

Table 4.6: $\quad$ Awareness about the legal minimum age at marriage for males and females 29

Table 4.7: $\quad$ Awareness of risks for the mother associated with early childbearing 30

Table 4.8: Awareness of risks for the child associated with early childbearing 31

Table 4.9: Exposure to family life or sexuality education programmes 32

Table 4.10: Association between exposure to the PRACHAR programme and awareness of Contraception and HIV/AIDS: Results of multivariate analysis

Table 5.1: Cumulative percentages of young men and women who were married by specific ages, according to study arms $\quad 36$

Table 5.2: Preferred and actual age at marriage among the married 38

Table 5.3: Marriage related planning among unmarried young people 39 
Table 5.4: $\quad$ Marriage related planning among married young people

Table 6.1: Extent of safe pre-marital and extra-marital sexual relations experienced by young people reporting any pre-marital or extra-marital sexual experiences

Table 6.2: $\quad$ Preparedness for married life

Table 6.3: Percentage of currently married young men and women reporting current contraceptive use by parity according to study arm

Table 6.4: Contraception to delay the first birth

Table 6.5: Non-use of contraception among married young women who had at least one live birth and reasons for non-use of contraception

Table 6.6: Percentage of currently married young men and women who have had at least one birth, reporting current contraceptive use according to study arm

Table 6.7: Pace of childbearing, married young women

Table 6.8: Association between exposure to PRACHAR programme and safe sex practices:

Results of multivariate analysis

Table 6.9: Association between exposure to the PRACHAR programme and contraception practices:

Results from multivariate analysis

Table 7.1: Decision-making

Table 7.2: $\quad$ Self-efficacy

Table 7.3: Access to economic resources 56

$\begin{array}{llr}\text { Table 7.4: } & \text { Mobility } & 57\end{array}$

$\begin{array}{lll}\text { Table 7.5: } & \text { Gender role attitudes } & 58\end{array}$

Table 7.6: Association between exposure to the PRACHAR programme and agency and gender attitudes: Results of multivariate analysis

Table 8.1: Pregnancy related care, all births in the three years preceding the survey to married young women

\section{List of Figures}

Figure 5.1: Life table hazard curve showing probability of getting married at various ages for young men and women according to study arms 


\section{Acknowledgements}

This study was undertaken by the Population Council to evaluate the longer term effects of the PRACHAR project implemented by Pathfinder International to equip and empower adolescent boys and girls with reproductive health related information as well as related communication and negotiation skills.

This study would not have been possible without the insights, cooperation and support of many. Above all, we are grateful to the David and Lucile Packard Foundation for recognizing the need to explore the effects of a programme delivered to adolescents on knowledge of reproductive health matters and practice of contraception, especially to delay first pregnancy some years following exposure, and for supporting authors to conduct the evaluation. We are grateful to Lana Dakan and Anand Sinha of the Packard Foundation, and former Packard Foundation colleagues Lester Coutinho, V.S. Chandrashekhar, and Anupam Shukla for their comments and suggestions at various points during the evaluation. We gratefully acknowledge, moreover, the guidance and insights of Pathfinder International colleagues, and especially Dr E.E. Daniel, the architect of the intervention. Dr Daniel and Pathfinder International colleagues provided the sampling frame that we used to select trainees and villages for the evaluation, gave us valuable insights into the design of the intervention, ways of tracking the trainees and finally, critically and constructively reviewed earlier drafts of this report.

At the Population Council, several colleagues have supported us in both the technical and administrative aspects of this study. We are grateful to M.A. Jose for overseeing the administration of the project, Shilpi Rampal for her support in preparing tables and figures, and Komal Saxena for reviewing and making inputs in editing the manuscript, correcting discrepancies, and ably coordinating its publication. Their support is gratefully acknowledged. We would also like to acknowledge support from colleagues at the Population Council's New York office, A.J. Melnikas, Sarah Engebretsen, and Ann Blanc who also reviewed and made valuable comments on the report; and Christine Tse for their inputs in editing the manuscript.

We also appreciate the efforts of our team of interviewers, who painstakingly collected quality data in difficult areas and in challenging weather. Finally, we would like to record our deep appreciation of the young men and women who generously gave us their time and shared their views and experiences with us.

Neelanjana Pandey

Shireen J Jejeebhoy

Rajib Acharya

Santosh Kumar Singh

Mahesh Srinivas 


\section{Executive summary}

Although a number of programmes have been implemented in India to support adolescents in making a successful transition to marriage and parenthood, evaluations of these programmes have typically comprised investigations of adolescents' knowledge, attitudes, and practices at the conclusion of the intervention, sometimes compared to a similar investigation at its initiation. Not a single evaluation, to our knowledge, has assessed the situation of those exposed to the programme in comparison with those not exposed, some years following the conclusion of the programme.

The objective of our study was to better understand the longer-term effects of one such programme, namely a three-day training programme offered by Phase III of Pathfinder's PRACHAR (Promoting Change in Reproductive Behaviour)programme among adolescents in rural areas of selected districts of Bihar. Pathfinder's PRACHAR programme was implemented in various districts of Bihar, and focused on addressing adolescents' need for information, contraceptive supplies, parental and community support, and a youth-friendly health system. Briefly, in 2010-11, Pathfinder International implemented three-day non-residential training programmes for a total of almost 40,000 adolescents aged 13 to 21 years in selected villages of Gaya district. The project aimed specifically at raising awareness and understanding of sexual and reproductive matters, the importance of delayed childbearing and spacing of pregnancies, and sources of services among unmarried adolescents. Adolescents were also taught communication skills to negotiate with partners and parents in order to achieve their reproductive goals.

With support from the David and Lucile Packard Foundation, the Population Council followed up adolescents aged 13-21 trained in this programme some 3-4 years following its conclusion- that is, when they were aged 17-25 years - to assess whether their reproductive health situation differed from that of a cohort of similar young people not exposed to the programme.

We note that the training programme was short, but reached large proportions of young people in project settings. It focused directly on raising awareness and changing attitudes and practices with regard to such specific outcomes as delaying marriage and promoting contraception, including contraception to delay the first pregnancy. It did not aim to build girls' agency, promote gender egalitarian attitudes among girls and boys, or address safe pre-marital sex and pregnancy related care. Hence, the direct longer-term effects of the programme should be viewed in terms of changes in young people's awareness of reproductive health matters, their marriage-related experiences (and specifically marriage age), and their contraception behaviours. While our report also discusses other outcomesagency, marital relations, and pregnancy-related care-these are presented as likely indirect outcomes; that is, those attributable to the improved communication and negotiation skills, on the one hand, and the emphasis on contact with the health system for obtaining contraceptives, on the other, which were imparted by the programme.

The study, conducted in 2014, tracked adolescent trainees aged 13-21 in 2010-11 and aged 17-25 in 2014, and compared them in 2014 to a matched sample of similarly aged youth not exposed to the training programme. A survey was conducted of 371 and 679 young men and women from control areas, and 789 and 1382, respectively, from intervention areas. In all, data were collected from 40 selected intervention villages and 20 selected control villages.

\section{Findings}

Findings confirm that the training programme was acceptable and useful to the young people exposed to it, and that it had a number of notable longer term effects, observed even four years following its implementation.

\section{Acceptability of the programme}

The overwhelming majority-more young women than men-had attended the entire three-day session, recalled every topic covered in the programme, and believed that the training had been useful in enabling them to make subsequent decisions in their life, ranging from the timing of marriage and childbearing to contraception and health-seeking. 


\section{Direct effects of the programme: reproductive health awareness, marriage practices, contraception and pace of childbearing}

The training programme focused directly on raising awareness about reproductive health matters, and notably about delaying marriage and appropriate use of contraception. Comparisons between young people trained in the PRACHAR programme and those in control sites suggest that young people exposed to the PRACHAR intervention were more likely than those not so exposed to be aware of all sexual and reproductive health matters about which we probed, ranging from how pregnancy happens to contraception, HIV/AIDS and the risks of early childbearing for mothers and infants. Multivariate analyses controlling for a range of potentially confounding factors provide strong evidence suggesting that the greater levels of awareness about contraception and HIV/AIDS reported by young people from intervention areas compared to comparison areas can be attributed to their exposure to the training programme.

Differences in contraceptive practice were also evident. Contraceptive use and consistent condom use in pre- and extra-marital sexual relations was more likely to be reported by both young men and young women in intervention than control sites; and there was strong evidence that such differences were attributable to the intervention programme, even once confounding factors were controlled.

With regard to contraception in married life, more young men and women from intervention than control sites reported that prior to or around the time of their marriage, someone had discussed with them the importance of delaying the first pregnancy, and more of those from intervention than control sites had intended, around the time of their marriage, to delay the first pregnancy. Exposure to the PRACHAR intervention also had a strong effect on the practice of contraception (largely oral contraceptives and condoms) by young women at the time of the interview even after confounding factors were controlled. No such evidence of the effect of the programme on young men's contraceptive practice was observed.

A similar picture emerged with regard to contraceptive practice to postpone higher-order births among women (but not men) with one or more births, with those exposed to the intervention more likely than others to have been practising contraception at the time of the survey, even after confounding factors were controlled. In contrast, there was no more than weak evidence that more women in intervention sites than control sites had practised contraception to postpone the first pregnancy.

Other practices that the training programme had aimed to influence were similar among young people in intervention and control sites. These include the timing of marriage, participation in marriage related planning, and pre-marital acquaintance with their spouse. Also unaffected by the intervention was the pace of childbearing; for example, similar proportions of young women from both intervention and control sites already had one or more births, and of those who had at least one birth, similar proportions had gone on to have a second or higher-order birth.

\section{Indirect effects of the programme; agency, gender role attitudes, marital relations and pregnancy-related care}

Our evaluation also explored several indirect effects of exposure to the training programme-indirect because they were never explicitly addressed in the training programme-on the situation of young people 4-5 years following exposure. We hypothesised that the focus of the training programme in promoting communication and negotiation about marriage and contraception likely had a spillover effect on young people's agency, their gender role attitudes, and husband-wife relations, and that the emphasis on seeking contraceptive services would additionally have influenced their pregnancy related practices.

With regard to agency, findings confirm that young women-and on a few indicators, young men as well-exposed to the PRACHAR intervention were indeed more likely than those not so exposed to display agency in terms of decision-making, self-efficacy, access to economic resources, and freedom of movement. Indeed, differences between young women in intervention and control sites were wide even after controlling for a host of potentially confounding factors such as age, education, and exposure to mass media, on every dimension of agency probed, namely, decision-making authority, self-efficacy, access to and control over economic resources, and freedom of movement. Effects were also observed with regard to gender role attitudes; while young women were more likely than young men, overall, to exhibit egalitarian gender role attitudes, egalitarian attitudes were significantly more 
likely to be expressed by those who had been exposed to the PRACHAR intervention than others, and effects continued to be strong among both young men and young women even after confounding factors were controlled.

Although young men and women from intervention sites were somewhat more likely than those from control sites to have communicated about the number of children to have and whether and when to practise contraception, there was no evidence that exposure to the PRACHAR training programme had affected spousal communication more generally or had reduced women's experience and men's perpetration of physical and sexual violence in marriage. And while young women in intervention sites were considerably more likely than those in control sites to report their husband's involvement in pregnancy related care, exposure to the intervention did not succeed in improving access to pregnancy-related are, namely, timely registration of and initiation of antenatal care, institutional or professionally attended delivery, or postpartum care.

\section{Conclusions and recommendations}

The longer-term effects of the three-day training programme for adolescents suggested that on several issues, even 3-4 years following exposure to the intervention, those who had been exposed to it displayed significantly different experiences than those not exposed. We note however that our sample of youth was not representative of the communities from which they were drawn. They were likely more educated than the rest, and findings, therefore, may not be entirely generalisable to the communities from which the sample of young people was drawn.

Notwithstanding these caveats, findings appear to confirm that even a short-duration programme delivered at scale may create sufficient momentum among the young to sustain differences in some behaviours between those exposed to the training and other youth even several years following such exposure. Sustained differences were observed only in some aspects of youth life-knowledge about reproductive health matters, contraceptive practice following the birth of the first child, and agency of young women. No differences were observed in other and perhaps more intransigent key practices that the programme attempted to address, namely delaying marriage and delaying the first pregnancy. Nor were differences observed in all aspects of young women's agency, for example, their role in marriage-related decision-making or the perpetration of violence by husbands on their wife.

Findings demonstrate the promise of a scaled intervention implemented among large proportions of adolescent and young people, but suggest that a training programme lasting just three days or one focused only on adolescents may not be sufficient to sustain longer-term effects in the more difficult-to-change aspects of young people's reproductive health-child marriage and early pregnancy-in a conservative setting such as Bihar. Findings relating to the failure of the intervention in effecting changes in these behaviours call into question the need for a more sustained intervention on the one hand, and for programmes that address other stakeholders as well, notably parents, community leaders, and the health system more generally, on the other. 


\section{Chapter 1 Introduction}

\section{Rationale}

The State of the World's Children 2011 focuses on adolescence, observing that 'major gaps in data on adolescents pose one of the biggest challenges to promoting their rights' and that 'a deeper level of disaggregation [of data on adolescents] and causal analysis are required as a foundation for programmes and policies and as a measure of progress' (UNICEF, 2011). Indeed, programming in the area of young people's transitions to adulthood in several countries, including India, has been thwarted by the paucity of evidence on programmes that have had a long-term impact on behaviours rather than on attitudes, knowledge, and intentions alone. Without evidence on the impact of programmes on healthy transitions to adulthood, it is difficult to establish which kinds are most successful in changing young people's behaviours, including in the area of sexual and reproductive health. Indeed, inferences drawn from shorter-term evaluations are limited in enabling understanding of how programme investments in adolescence influence young people's life course by the time they reach young adulthood, and in making evidencebased decisions on the types of programmes worthy of scale-up.

The advantages of a longer-term follow-up are well known; such evaluations have been recognised as essential for the kind of advocacy that results in evidence-based investment in the health of adolescents, the setting of youth-oriented priorities for resource allocation and programming, and, ultimately, sustaining an agenda that focuses on protecting and promoting adolescents' health and well-being (see, for example, Bea ringer et al., 2007). Likewise, an expert consultation held by the Population Council in 2010 and supported by the Packard Foundation, concluded that longitudinal and longer-term follow-up studies are essential for assessing behaviour change and its determinants and drawing the kind of causal inferences that are critical for programmes (Population Council, 2010).

Programmes to support young people in making a successful transition to marriage and parenthood have been implemented by several NGOs in India. One such example is Pathfinder's PRACHAR (Promoting Change in Reproductive Behaviour) project. Located in various districts of Bihar, the project was multi phased and multi pronged. It was implemented over three phases, during 2001-05, 2005-09, and 2009-12, respectively, and focused on addressing young people's need for information, contraceptive supplies, parental and community support, and a youth-friendly health system. Phases I and II were implemented through NGOs, and evaluations of these two phases (Pathfinder International, 2011; Daniel and Nanda, 2012) have suggested that the project indeed enriched the sexual and reproductive health $(\mathrm{SRH})$ field by providing workable models for enhancing young people's SRH. In its third phase, implemented in Gaya district during 2009-12 with support from the Packard Foundation and UNFPA, a public-private partnership model was implemented. Such a model, if effective, holds great promise for replication and sustainability.

Few programmes intended to promote sexual and reproductive health, to our knowledge, have been tested for their sustainability, that is, the extent to which the successes observed over the course of the project among those exposed to the intervention were sustained some years following the completion of the project among new cohorts. An exception was an evaluation of the longer-term effects of PRACHAR's Phases I and II some 5-8 years following the completion of the programme (Prakash, Jejeebhoy, and Acharya, 2013a; 2013b). This evaluation found that adolescents growing up in project sites were indeed more likely than those in comparison sites to be aware of sexual and reproductive health matters and express egalitarian gender-role attitudes and self-efficacy; however, since baseline data were not collected, findings are suggestive and it is difficult to attribute observed differences to the PRACHAR programme (Prakash, Jejeebhoy, and Acharya, 2013c). A key remaining gap, both with regard to the PRACHAR programme and the field in general is an understanding of the longer-term effects of participation in adolescent programmes on trajectories of young people's life as they transition into adulthood. Given that most evaluations have been conducted shortly after the completion of the intervention, opportunities to explore longerterm behavioural outcomes among those exposed to programmes have been restricted. As a result, assessments of whether effects in terms of changes in knowledge, attitudes, and self-efficacy are translated into changes in sexual and reproductive health behaviours such as the timing of marriage, the practice of contraception, the exercise of 
informed choice in reproductive decision-making, as well as in other life events cannot be made (see, for example, Acharya, Kalyanwala, and Jejeebhoy, 2009). This is a significant limitation, hampering efforts towards evidencebased up-scaling. The PRACHAR Phase III experience, in which details of adolescents trained in 2010-11 have been maintained and allow for tracking and follow-up, offers a unique opportunity to fill this gap.

\section{Study objectives}

Recognising the need to better understand longer-term effects of programmes for adolescents, the Population Council, with support from the Packard Foundation, undertook a follow-up study in 2014 of girls and boys aged 15-19 who were exposed to the adolescent training component of the PRACHAR Phase III programme between September 2010 and March 2011 in Gaya district, Bihar. Specific objectives were to explore, an average of 3.5 years after their graduation from the programme, young people's awareness of sexual and reproductive health matters, their gender role attitudes and such behaviours as delayed marriage and postponement of the first birth; the extent of safe and wanted pre-marital sexual experiences, where undertaken; agency (particularly among young women), notably with regard to participation in marriage related decision-making and other life choices (education, work, control over resources); and timely access to sexual and reproductive health services. Outcomes observed among those trained in PRACHAR's programme are compared with outcomes reported by a comparison group not exposed to the programme. We also explore whether outcomes among those exposed to the programme differed according to whether they resided in a village in which PRACHAR activities for communities at large were also conducted or in which PRACHAR implemented only the adolescent training programme.

We note that the PRACHAR project focused directly on raising awareness and changing attitudes with regard to delaying marriage and promoting contraception. It did not directly address such issues as safe sex, gender-based violence, antenatal care, or skilled attendance at delivery. However, it is likely that these behaviours have been affected indirectly, through the project's focus on building agency and negotiating skills, and promoting more egalitarian gender role attitudes. Hence, our objective is to assess both the longer-term effects of the programme on marriage age and contraceptive behaviours, as well as on other issues not directly addressed in the training programme.

Findings are expected to shed light on the extent to which the PRACHAR model may be considered a best practice and respond to questions raised by the Government of Bihar about its potential up-scaling.

\section{Background}

The PRACHAR project is one of the few interventions that has made concerted efforts to promote RH/FP and birth spacing among younger women, and more specifically, to empower young people and their families to postpone marriage and the first birth, ensure that births are wanted, and space subsequent births. The programme, located in several districts of Bihar, was implemented over three phases, during 2001-12, and focused on addressing young people's need for information, contraceptive supplies, parental and community support, and a youth-friendly health system. Its Phases I and II were implemented through NGOs, and in the third phase, the programme was implemented through a public-private partnership (PPP) arrangement. In this model, PRACHAR programme activities were woven into the activities of government health workers including accredited social health activists (ASHAs).

The interventions targeted several participants. The primary targets were unmarried adolescents (ages 15-19), newly married young people, and those with one child. Parents, husbands, and the community at large, as well as healthcare providers, were also targeted. Intervention activities comprised Behaviour Change Communication (BCC) activities imparted through training programmes and sensitisation sessions with various groups; cultural teams presented messages on project themes through plays, songs, and puppet shows. In home visits, moreover, young couples were encouraged to improve their interpersonal communication skills. Separate sessions were held for women and men. In addition, the project trained healthcare providers of various categories in providing youth-friendly services.

In addition to the above, the PRACHAR Phase III programme focused on unmarried adolescents aged 15-19 years. The programme comprised a three-day non-residential training programme (five hours a day) aimed at raising awareness and understanding of SRH issues, the importance of delayed childbearing and spacing of pregnancies, and sources of services among unmarried adolescents. Adolescents were also taught communication skills to 
negotiate with partners and parents in order to achieve their reproductive goals. Training sessions were provided for five hours a day over the three-day period to same-sex batches of approximately 30 boys and 30 girls; two female trainers implemented the programme for girls, and one male and one female did so for boys. Frontline health workers (ASHAs) and Male Communicators were engaged in identifying and mobilising adolescent trainees, and trainers were responsible for ensuring that adolescents attended the entire programme. Trainers themselves underwent training using Pathfinder's 'Reproductive Health Guide for Educators of 15-19 Year-Old Adolescents.' Training was participatory, and included dialogue, stories/case studies, and other activities. Topics covered included the male and female reproductive systems; the menstrual cycle and hygiene; nutrition; conception and contraception; transmission, prevention, and treatment of RTIS/STIs and HIV/AIDS; myths and misconceptions related to sexual behaviour, reproduction, and sexually transmitted infections; sexual harassment and abuse; reproductive rights and responsibilities, communication, negotiation, assertion and joint decision-making skills; the availability of reproductive health and contraception services; and the need to use services (Daniel, personal communication). A total of 39,223 adolescents were trained in this programme in the seven months from September 2010 to March 2011.

The three-day programme for adolescents was implemented in two types of project settings: one in which no other PRACHAR Phase III activities were conducted (standalone settings) and a second (comprehensive settings) in which the adolescent training programme was conducted along with other activities of PRACHAR Phase III among married women and men more generally.

\section{Project setting}

The state of Bihar was purposively selected by Pathfinder International for this intervention as it represents one of the most poorly developed states in India. The state comprises nine percent of India's population: containing a population of 104.1 million, it is the third largest state in the country (Office of the Registrar General and Census Commissioner, India, 2013); and 34 percent of the state's population was estimated to be living below the poverty line (Planning Commission, 2013). A significant proportion of the population, moreover, remains illiterate; just 49 percent of women were literate in Bihar (Office of the Registrar General and Census Commissioner, India, 2013). Adolescents' reproductive health situation is particularly compromised in the state (IIPS and Population Council, 2009). For example, the prevalence of child marriage is higher in Bihar than in any other state in the country: in 2005-06, 69 percent of 20-24-year-old women were married before age 18, 33 percent below age 15, and 10 percent below age 13 (IIPS and Macro International, 2007).

The PRACHAR programme's Phase III was implemented in rural areas of Gaya district. A socio-demographic profile of rural Gaya district compared to rural Bihar more generally suggests that, by and large, characteristics were similar, although some notable differences were evident. For example, economic activity profiles of young people suggest that 50 percent of young men and 36 percent of young women were working in rural Gaya, compared with 46 percent of young men and 22 percent of young women in rural Bihar. At the same time, one-quarter of young men $(25 \%-26 \%)$ and about one-sixth of young women (16\%-18\%) were seeking work in both rural Gaya and rural Bihar.

Reproductive health profiles differed considerably with regard to marriage and childbearing. Early marriage was far more likely to take place in rural Gaya than in rural Bihar: for example, while 72 percent of young women aged 20-24 from rural Gaya were married below age 18, 54 percent of those from rural Bihar were married below age 18 , and correspondingly, among males aged 25-29, percentages married below the legal minimum age at marriage ranged from 72 in Gaya to 42 in rural Bihar.

Childbearing profiles suggest however that similar proportions of young women aged 15-19 had already experienced pregnancy or motherhood (52\% in Gaya, compared to $47 \%$ in rural Bihar) (Office of the Registrar General and Census Commissioner, India, n.d., a). Highlighting the rapid pace of childbearing in the state among young ever-married women aged 20-24, 51 percent of those in rural Bihar and 60 percent of those in rural Gaya had two or more births.

With regard to pregnancy-related care, few young women (4\%) in both rural Gaya and rural Bihar had received complete antenatal care (at least three ANC visits, one TT injection, and 100 iron and folic acid tablets). However, with regard to safe deliveries (institutional or conducted by a trained attendant), considerably fewer women aged 15-19 in Gaya than in rural Bihar more generally had experienced a safe delivery (14\% in rural Gaya and 39\% in rural Bihar) (see Table 1.1). 
Contraceptive use was also limited among the young. According to the District Level Household and Facility Survey, 2007-08, moreover, ever-use of modern methods of family planning by currently married women aged 15-19 was negligible in both Gaya and Bihar on the whole (4-5\%), and just two percent were using a modern method of contraception at the time of the survey (International Institute for Population Sciences, 2010a).

Table 1.1: Profile of young population and selected indicators of reproductive health in Rural Bihar and study district, Gaya

\begin{tabular}{|c|c|c|}
\hline & Rural Bihar & Rural Gaya \\
\hline Youth population $\left(15-24\right.$ years) ${ }^{\mathrm{a}}(\%)$ & 16.5 & 16.9 \\
\hline Young men to the total population & 17.2 & 17.0 \\
\hline Young women to the total population & 15.8 & 16.9 \\
\hline \multicolumn{3}{|l|}{ Economic activity ${ }^{\mathrm{a}}(\%)$} \\
\hline Youth working (\%) & 35.4 & 42.9 \\
\hline Young men working & 46.1 & 49.5 \\
\hline Young women working & 22.8 & 35.9 \\
\hline Youth seeking a job (\%) & 21.2 & 21.6 \\
\hline Young men seeking job & 25.6 & 25.1 \\
\hline Young women seeking job & 15.9 & 17.9 \\
\hline \multicolumn{3}{|l|}{ Age at marriage ${ }^{b}(\%)$} \\
\hline Currently married men aged $25-29$ married before legal age ( 21 years) & 41.8 & 66.5 \\
\hline Currently married women aged $20-24$ married before legal age (18 years) & 53.5 & 71.9 \\
\hline \multicolumn{3}{|l|}{ Childbearing $^{b}(\%)$} \\
\hline $\begin{array}{l}\text { Young ever married women } 15-19 \text { years who were pregnant or already } \\
\text { mothers (\%) }\end{array}$ & 47.3 & 52.3 \\
\hline Young ever married women aged $20-24$ reported two or higher-order birth & 50.9 & 60.3 \\
\hline \multicolumn{3}{|l|}{ Pregnancy-related care ${ }^{c}(\%)$} \\
\hline $\begin{array}{l}\text { Young women who gave live/still birth since January, 2004, aged 15-19 years, } \\
\text { had full ANC }\end{array}$ & 4.1 & 4.0 \\
\hline $\begin{array}{l}\text { Young women who gave live/still birth since January, 2004, aged 15-19 years, } \\
\text { had safe delivery }\end{array}$ & 39.4 & 13.8 \\
\hline \multicolumn{3}{|l|}{ Contraception ${ }^{\mathrm{c}}(\%)$} \\
\hline $\begin{array}{l}\text { Young currently married women aged 15-19 who had ever used a modern method of } \\
\text { family planning }\end{array}$ & 4.5 & 4.3 \\
\hline $\begin{array}{l}\text { Young currently married women aged } 15-19 \text { who were currently using a modern method } \\
\text { of family planning }\end{array}$ & 1.8 & 1.6 \\
\hline
\end{tabular}

Sources: ${ }^{a}$ Office of the Registrar General and Census Commissioner, India, n.d., a; ${ }^{b}$ Office of the Registrar General and Census Commissioner, India, n.d., b; 'International Institute for Population Sciences (IIPS), $2010 b$.

The PRACHAR Phase III adolescent training programme was undertaken in four blocks of Gaya-Belaganj and Khijersarai blocks-in which no other PRACHAR activities were conducted, and Mohanpur and Bodhgaya in which other activities at the community level were also implemented. As such, we refer to Belaganj and Khijesarai blocks as standalone blocks, and Mohanpur and Bodhgaya as comprehensive blocks. Gurua block, in which no PRACHAR programme activities were conducted, was selected as the control block for the purpose of comparison. The study was conducted in a total of 40 intervention villages ( 21 standalone and 19 comprehensive) and 20 control villages. 


\section{Study design}

We note that evaluation activities associated with PRACHAR's adolescent training programme comprised just a short pre- and post-intervention assessment undertaken on the first and third days of the training programme, respectively. The training programme was not evaluated and hence no baseline data were available for assessing longer-term changes among trainees. Our design therefore relied on comparisons of youth who had been trained as adolescents in the PRACHAR III programme and a matched group of youth residing in the control (non-intervention) block (Gurua), who had not been exposed to such training.

We note that although the training programme was focused on adolescents aged 15-19 in 2010-11, younger and older individuals were not turned away, hence, effectively, the intervention focused on those aged 13-21, and were aged $17-25$ at the time of the survey in 2014.

The study included two phases, namely (a) a tracking exercise of adolescents aged 13-21 in 2010-11 and aged 17-25 in 2014 in intervention villages to obtain their current locations and consent for being approached by the survey team; and a corresponding matching exercise to identify comparable youth in control villages; and (b) a survey of tracked (intervention sites) and matched (control sites) individuals to assess their marriage and childbearing experiences, as well as their current status (working, in school or college, etc.), agency, gender role attitudes, and communication and negotiation skills.

Tracking and matching phases: Lists had been maintained by Pathfinder International on each adolescent who participated in the training programmes; these lists included the name of the adolescent and household head;the address of the household and its location in each selected intervention community;and the age, educational status, and marital status of each adolescent at the time of training. From these lists, we excluded villages in which fewer than 18 unmarried boys and 35 unmarried girls had participated in the training programme; the remaining 101 villages from 4 blocks were stratified by available socio-demographic characteristics-village size, female literacy rate, percentage from scheduled castes/tribes)-and a total of 40 villages were selected by systematic sampling ( 21 from the standalone arm and 19 from the comprehensive arm). All trainees in the selected villages were then tracked.

For the tracking exercise, teams of investigators visited each selected village, equipped with available sociodemographic information of all trainees. They contacted the head or any adult member of the household in which the individual trainee to be interviewed resided in 2010-11, and administered a short questionnaire to identify the young woman or man who had been trained in the PRACHAR project. If a selected trainee was not available at the time of tracking, tracking team members requested the adult member to contact the respondent and obtain oral consent for sharing his/her contact information with team members (including phone numbers of trainees who had moved out of their original villages) and conducting an interview with him/her, if selected, in the following month.

The matching exercise in the control area aimed to identify and select young men and women who were aged 13-21 in 2010-11 and whose socio-demographic profiles matched those of the tracked sample in the intervention areas. To do so, lists of villages in the control block were first stratified by available socio-demographic characteristics (village size, female literacy rate, percentage from scheduled castes/tribes), and a number of villages were selected from each stratum so as to represent the overall characteristics of the block as well as those of the selected intervention villages. A rapid household listing exercise was then conducted in which investigators visited all households in 20 selected villages (or selected segments of these villages in the case of large villages) and identified those who were aged 13-21 and had resided in the village in 2010-11, and broadly in the age group 17-25 years at the time of house-listing, irrespective of whether they had since moved away from the village. The investigators also collected information on the educational attainment levels and marital status of those aged 17-25. We acknowledge that house-listers were not always proficient in assessing correct ages and youth and their families were sometimes unable to provide ages accurately, requiring investigators to reconfirm age prior to the interview and exclude those falling outside this age range. For those who had migrated into the village in the period 2010-14, we ascertained their place of residence in 2010-11 in order to ensure that selected youth represented those residing in the control block during 2010-11; it also enabled us to exclude from selection any male or female who had resided in an intervention village during 2010-11 but later moved into one of the villages in the control block. The listing data were entered into computers and lists were prepared of all young men and women eligible for interview (currently aged 17-25 and who had resided in the village in 2010-11). 
We identified three matching variables on which the control area sample was to be matched with the intervention area sample. These included educational attainment, migration status, and current marital status (whether currently married), and were chosen because they represented key markers of the transition to adulthood. Matching was done sequentially, first by educational attainment, then by migration status, and,finally, by current marital status. In the matching exercise, we aimed to select a sample from the control area that resembled those from the intervention area in the following ways: the mean number of years of schooling would not differ by more than two years, percentages who had migrated out of the village would not differ by more than six percent, and finally, percentages married would not differ by more than six percent. Our matching exercise resulted in differences between the control and intervention samples for young men and women of 0.5-0.9 years for educational attainment, 3.0-5.8 percent for the proportion of youth who had migrated out in the intervening period, and 5.4-5.5 percent for the proportion of youth who were unmarried at the time of household listing.

We note that the trainee sample (intervention areas) on which the control sample was matched was likely selfselected as better-educated youth or youth who were in school in 2010-11 were more likely to have participated in the training programme. As a result, both the intervention and control samples in the analysis were somewhat different from the general population of youth of aged 17-25.

Survey of young men and women aged 17-25: A survey was conducted with a sample of young men and women listed in the 40 selected intervention villages and 20 selected control villages. The survey focused on their education and work profiles, marriage and childbearing experiences, pre-marital sexual experiences, contraception practices, awareness of reproductive health matters, and their agency. Also probed were the perceptions of those who had undergone the training about the usefulness and acceptability of the programme.

\section{Study samples and coverage}

Tracked sample: A total of 3,980 unmarried young men and women were selected for tracking from the lists of trainees supplied by Pathfinder International (Table 1.2). Of these, 3,488 young men and women (2,159 young women and 1,329 young men) were successfully followed up, irrespective of whether they continued to reside in the household in which they had resided at the time of the PRACHAR training or whether they had moved away (for marriage, work, education, etc.) to other parts of the state or country. We were able to track 86 percent and 89 percent, respectively, of young men and women trained in 2010-11 from selected intervention villages.

Table 1.2: Follow-up rate in intervention blocks

\begin{tabular}{lccccccc}
\hline & \multicolumn{2}{c}{ Combined } & \multicolumn{2}{c}{ Standalone } & \multicolumn{2}{c}{ Comprehensive } \\
\cline { 2 - 7 } & Male & Female & Male & Female & Male & Female \\
\hline Selected sample for follow-up (a) & 1,548 & 2,432 & 745 & 1,267 & 803 & 1,165 \\
Total tracked (b) & 1,329 & 2,159 & 621 & 1,125 & 708 & 1,034 \\
Follow-up rate $\left(\frac{\mathbf{b}}{\mathbf{a}} * \mathbf{1 0 0}\right)$ & $\mathbf{8 5 . 9}$ & $\mathbf{8 8 . 8}$ & $\mathbf{8 3 . 4}$ & $\mathbf{8 8 . 8}$ & $\mathbf{8 8 . 2}$ & $\mathbf{8 8 . 8}$ \\
\hline
\end{tabular}

Matched sample, control sites: A total matched sample of 700 young men and 815 young women who were eligible for interview were identified from control villages. All those listed as aged 17-25 were considered, as were all those who had resided in the study village in 2010-11 but had migrated out by 2014 to any other location within Bihar. We excluded those who had migrated out of study villages into another state, and since the evaluation focused on experiences of unmarried youth trained in 2010-11, we also excluded any who were married before 2011.

Although villages selected as control sites resembled those from which the intervention sample was drawn in terms of various population-level socio-demographic characteristics, we noted considerable differences between the background characteristics of the control and intervention samples before matching. The sample of youth listed in control sites tended to be less educated, more likely to have been married, and more likely to have migrated out of the village in the period 2010-11 to 2014. As such, it was evident that the sample of young people trained in the PRACHAR project were self-selected among the better off in intervention villages. Thus, it was important that our matching exercise ensured that the control sample resembled the background characteristics of the intervention sample. 
We note therefore that as a result of the matching exercise, the sample selected from the control areas was slightly better educated, less likely to have included out-migrants, and less likely to have included married youth than the pre-matched house-listed sample.

Survey of young men and women in control and intervention villages: Our study design included three arms: the control arm comprising the matched sample, and two intervention arms comprising those trained from standalone and comprehensive intervention villages, respectively. As such, our design called for a sample of 700 young women and 400 young men from each arm;that is, a total sample of 2,100 young women and 1,200 young men. As trainees included fewer males than females, we selected all tracked male trainees and a randomly selected sample of tracked female trainees from intervention villages; likewise, the male and female samples from control villages were selected randomly from matched lists. Given the mobility of youth, we made efforts to interview all youth who had moved away from the villages in which they had resided in 2010-11 provided they continued to reside in the state in 2014; resources did not permit us to access those who had moved away from the state.

A total of 789 young men (of 942 identified) and 1,382 young women (of 1,582 identified) from intervention sites, and 371 young men (of 459 identified) and 679 young women (of 815 identified) from control sites were successfully interviewed, suggesting response rates of 81-83 percent in control sites, and 84-87 percent in intervention sites (Table 1.3). Reasons for non-response fell into three categories: the individual had moved outside the state, the individual was tracked but could not be traced at the new address at the time of the survey, and the individual was not at home despite three visits made by the interviewer.

Table 1.3: Response rates and reasons of non-response in intervention and control blocks

\begin{tabular}{|c|c|c|c|c|c|c|c|c|}
\hline & \multirow{2}{*}{\multicolumn{2}{|c|}{ Control }} & \multicolumn{6}{|c|}{ Intervention } \\
\hline & & & \multicolumn{2}{|c|}{ Combined } & \multicolumn{2}{|c|}{ Standalone } & \multicolumn{2}{|c|}{ Comprehensive } \\
\hline & Male & Female & Male & Female & Male & Female & Male & Female \\
\hline $\begin{array}{l}\text { Number of randomly } \\
\text { selected youth }\end{array}$ & 459 & 815 & 942 & 1,582 & 486 & 810 & 456 & 772 \\
\hline $\begin{array}{l}\text { Number of interviews } \\
\text { completed }\end{array}$ & 371 & 679 & 789 & 1,382 & 404 & 695 & 385 & 687 \\
\hline Response rate & 80.8 & 83.3 & 83.8 & 87.4 & 83.1 & 85.8 & 84.4 & 89.0 \\
\hline \multicolumn{9}{|l|}{$\begin{array}{l}\text { Reasons for non- response } \\
\text { (Number) }\end{array}$} \\
\hline Not at home & 10 & 26 & 43 & 50 & 24 & 31 & 19 & 19 \\
\hline Postponed & 0 & 7 & 0 & 1 & 0 & 1 & 0 & 0 \\
\hline Respondent refused & 4 & 0 & 4 & 7 & 1 & 3 & 3 & 4 \\
\hline Parent refused & 1 & 6 & 0 & 7 & 0 & 5 & 0 & 2 \\
\hline Partly completed & 0 & 0 & 0 & 2 & 0 & 0 & 0 & 2 \\
\hline Incapacitated & 2 & 3 & 4 & 3 & 2 & 1 & 2 & 2 \\
\hline Current address not found & 33 & 38 & 30 & 54 & 18 & 35 & 12 & 19 \\
\hline Out of state & 33 & 51 & 61 & 59 & 32 & 25 & 29 & 34 \\
\hline Others & 5 & 5 & 11 & 17 & 5 & 14 & 6 & 3 \\
\hline
\end{tabular}

\section{Data collection}

Data collection took place during August-December, 2014. During August-October, the tracking and listing exercise was undertaken, followed by the selection of the sample for the survey. The survey took place during November-December, 2014.

For the tracking exercise, a short tracking form was administered to an adult household member to provide updated information about those trained in 2010-11. After confirming the age and education status information at the time of the training programme to ensure that the trainee had been correctly identified, we collected information about 
their current residence and new address (if migrated), current marital status, educational attainment, religion, and caste. During the tracking exercise, moreover, consent was taken from the trainee for research teams to visit them at a later date for a detailed interview.

In control villages, a house-listing exercise was undertaken, in which information was obtained on the age, sex, marital status, and year of marriage for all those aged 17-25. Moreover, in order to match control and intervention samples with respect to migration status, information was also collected about those aged 13-21 in 2010-11 who may have moved away from the village.

For the survey, separate questionnaires were prepared for young men and women; however most of the questions were identical. Survey questionnaires were designed to gather background information of the respondent and his/ her household, as well as an extensive set of questions relating to the key outcomes we sought to explore. These included respondents' agency, gender role attitudes, parental communication, as well as their pre-marital sexual experiences (if any, including age at sexual initiation, partners, and contraception and condom use), and awareness about sexual and reproductive health matters. For the married, the questionnaire also obtained information about their marriage age and related decision-making, and married life, including spousal communication, social isolation of married young women, contraception, wanted and unwanted pregnancy and childbearing (including maternal age at first birth; planning about first child; and antenatal, delivery, and post-partum experiences).

Study instruments were prepared in English, translated into Hindi, and pre-tested. A team of 28 interviewers, trained by Population Council staff, conducted the survey. Interviewers underwent four days of training that comprised a combination of classroom sessions, mock interviews, and field practice. Training focused on interviewing methods, the details of the questionnaire and research ethics including issues of confidentiality and privacy. Interviewers were divided into four teams, each including one supervisor, responsible for the overall management of fieldwork and team-related logistics, and one field editor who was responsible for field editing, back-checks, and quality control of interviews. Principal investigators made visits to monitor and supervise data collection operations. Each team filled quality control sheets regularly, giving the team and principal investigators a quick view of the quality of ongoing fieldwork.

\section{Ethical considerations}

To allay fears of adverse repercussions, we assured respondents that all the data gathered were entirely anonymous; that the interviewers would not share their responses with anyone, including their family members, the authorities, or healthcare providers;and that names would never be recorded on the questionnaire. The following strategies were adopted, moreover, to maintain privacy and confidentiality.

The interviewers underwent extensive training in ethical issues. Emphasis was laid on explaining the content of the questionnaire, the respondent's right to refuse to participate or answer any question, and informed consent. At the same time, we trained interviewers on how to ask sensitive questions-regarding pre-marital sex and physical and sexual violence for example-in empathetic and non-judgemental ways, and emphasised the importance of offering to refer those in need to appropriate nearby organisations. Third, before entering a PSU, interviewer teams were instructed to apprise community leaders of the study and seek their support for its implementation in the community. This step ensured that community support was forthcoming and enabled team members to build rapport easily within the community.

Every effort was made to maintain privacy in the course of the interview. To ensure that the interviews were not overheard by family members or others, the interviewers conducted the interview in a separate room in the respondent's home, asked questions in whispers, called on a co-interviewer designated for this purpose to hold parallel discussions with adults or others interested in listening to the interview, or rescheduled the interview so as to enable full confidentiality. Interviewers were permitted to skip to relatively non-sensitive sections in case the interview was observed by others. Each team was trained to assign one interviewer to conduct parallel discussion sessions with bystanders, thereby providing privacy to the interview. Finally, the interviewers were instructed that if privacy could not be ensured, the interview must be terminated without asking sensitive questions. Notwithstanding these efforts, we acknowledge that sensitive issues such as pre-marital and extra-marital sexual experiences, the experience of marital violence, or the termination of a pregnancy carrying a female foetus may not have been reported accurately during the interview. 
All the questionnaires were anonymous and names were never recorded on them. In order to preserve the confidentiality of the respondent, signing the consent form was optional; however, the interviewer was required to sign that she or he had explained the content of the consent form to the respondent. Consent forms were detached and stored separately from the questionnaires.

The protocol for this study was approved by the Population Council's Institutional Review Board.

\section{Data processing}

All completed questionnaires were sent to the Population Council's office in New Delhi for editing and data processing. Completed questionnaires were rechecked and further edited in the office for omissions and consistency. For entering the edited data, a special software package was developed using CSPro 5.1. Data were entered twice by different entry operators to minimise entry problems. The raw data were validated and cleaned to remove possible inconsistencies. All data were suitably weighted to enable comparison between the intervention and control sites overall, as well as between the standalone and comprehensive intervention sites, and between each of these and the control sites. The analysis of data was carried out using STATA 13.0.

\section{Structure of the report}

The report is divided into nine chapters, including this introductory chapter. Chapter 2 presents a profile of young men and women in both intervention and control arms, including their socio-demographic and housing characteristics. Chapter 3 briefly describes the objectives and content of the PRACHAR training programme and its assessment by participants in intervention arms. Chapters 4,5 , and 6 assess the effect of the intervention on issues that the intervention had directly sought to address, namely sexual and reproductive health-related awareness (Chapter 4), age at marriage and marriage related planning (Chapter 5), and contraceptive use in pre-marital and extra-marital sexual relations as well as within marriage (Chapter 6). Chapters 7 and 8 then describe the effect, if any, of the intervention on issues that the intervention did not directly address but may have influenced indirectly, such as young people's agency, gender-role attitudes, and communication with their parents (Chapter 7); and pregnancy-related practices (Chapter 8). Chapter 9 summarises the main findings of the study and highlights lesson learned for future programme implementation. 


\section{Chapter 2 Socio-demographic profile of youth}

This chapter presents a socio-demographic profile of the households in which youth who participated in the training programme and those from control areas resided as well as a socio-demographic profile of youth who participated in the survey.

\subsection{Characteristics of the households in which youth resided}

Table 2.1 provides information on the household characteristics of surveyed youth. Household size was identical for youth in intervention and control villages: 6.3-6.4 among young men, and somewhat higher, 7.2, among young women. While almost all women from both intervention and control villages reported that a member of their household owned the structure in which they resided (96-97\%), somewhat fewer young men so reported (78-81\%), perhaps reflecting the fact that several young men had migrated away and were residing in rented accommodations.

Differences were observed in housing characteristics of youth from intervention and control villages. More youth from intervention than control villages resided in pucca houses (constructed from brick, cement, or other high-quality materials): 42 percent as compared to 32 percent among young men, and 42 percent versus 27 percent among young women. On average, households from intervention villages contained more rooms than did those in control villages ( 4.0 versus 3.5 among young men; 4.9 versus 4.0 among young women). Correspondingly, the average number of persons per room was significantly higher among young men and young women residing in control villages compared to intervention villages (1.8 versus 1.6 for young men; 2.0 versus 1.6 among young women).

Differences were also observed with regard to access to electricity, with those residing in intervention villages significantly more likely than those residing in control villages to have electricity (92\% versus $77 \%$ among young men; $88 \%$ versus $74 \%$ among young women). Access to a toilet facility of any kind was reported by 39-40 percent of young men and women in control villages, and somewhat larger percentages of those from intervention villages (43-47\%) in general, and significantly larger percentages of those living in standalone intervention sites (49\% of young men and $51 \%$ of young women). Indeed, in intervention sites, significantly fewer women from comprehensive sites had reported access to a toilet facility than had those from standalone sites. With regard to cooking fuel, slightly more young men and significantly more young women from intervention than control villages reported the use of safe cooking fuel (LPG/bio-gas/electricity) in their household (29\% versus $25 \%$ among young men; $18 \%$ versus $12 \%$ among young women). As in the case of toilet facilities, significantly more of those from standalone than both comprehensive intervention sites and control sites reported the use of safe cooking fuel.

Household economic status was measured using a wealth index composed of household asset data on ownership of selected durable goods, including means of transportation, as well as data on access to a number of amenities. ${ }^{1}$ Index scores, so constructed, ranged from 0 to 54. The households were then ranked according to the index score. This ranked sample was divided into quintiles-that is, five groups, each containing an equal number of

\footnotetext{
${ }^{1}$ The wealth index was constructed by allocating the following scores to a household's reported assets or amenities: Type of house: 2 for pucca; 1 for semi-pucca; 0 for kachcha.

Agricultural land owned: 4 for more than 10 acres; 3 for 5.1-10.0 acres; 2 for 2.6-5.0 acres; 1 for less than 2.6 acres, or if the household owns some land but does not know how much; 0 for no land.

Access to a toilet facility: 4 for own flush toilet; 2 for shared flush toilet or own pit toilet; 1 for shared pit toilet or other types of toilet; 0 for no toilet facility.

Cooking fuel used: 2 for liquid petroleum gas, electricity, or bio-gas; 1 for kerosene, wood, crop residue, dung cakes, coal, or charcoal; 0 for other types of cooking fuel, for example, straw, shrubs, or grass.

Access to a drinking water facility: 4 for own piped water, hand-pump, or covered well; 3 for own open well; 2 for public or shared piped water, hand-pump, or covered well; 1 for public or shared open well; 0 for other sources of drinking water, for example, surface water, tanker/truck, or rain water.

Access to electricity: 3 for electricity; 0 for no electricity.

Ownership of household assets: 4 for car or truck or tractor; 3 each for motorcycle or scooter, refrigerator, computer/laptop, telephone (landline or mobile); 2 each for television, bicycle, electric fan, radio or transistor, sewing machine, water pump, animal-drawn cart; 1 for watch or clock; 0 for each of the above items that the household does not possess.
} 
respondents - with the first quintile representing respondents of the lowest (poorest) wealth status and the fifth quintile representing respondents with the highest (wealthiest) status. Mean scores, presented in Table 2.1 confirm that young men and women from intervention were economically better off than were their counterparts in control villages (23 versus 20 among young men; 23 versus 21 among young women).

Table 2.1: Housing characteristics

Percentage of households of surveyed young men and women by selected housing characteristics, according to study arm

\begin{tabular}{|c|c|c|c|c|}
\hline \multirow[t]{2}{*}{ Characteristics } & \multirow[t]{2}{*}{ Control } & \multicolumn{3}{|c|}{ Intervention } \\
\hline & & Combined & Standalone & Comprehensive \\
\hline \multicolumn{5}{|c|}{ Young men } \\
\hline \multicolumn{5}{|l|}{ Household characteristics } \\
\hline Household size (mean number of persons) & 6.3 & 6.4 & 6.1 & 6.6 \\
\hline Owns a house & 77.5 & 81.2 & $77.8^{* *}$ & 84.9 \\
\hline Lives in a pucca house & 31.7 & $41.9^{*}$ & $42.1^{*}$ & 41.8 \\
\hline Mean number of rooms in a house & 3.5 & $4.0^{* *}$ & $4.0^{* * *}$ & $4.5^{* * *+}$ \\
\hline Mean number of persons per room & 1.8 & $1.6^{* *}$ & $1.6^{* *}$ & $1.6^{\star *}$ \\
\hline \multicolumn{5}{|l|}{ Household amenities } \\
\hline Has electricity & 76.9 & $91.6^{* *}$ & 88.6 & $95.0^{* * *}$ \\
\hline Has access to a toilet facility & 39.7 & $46.6^{*}$ & $49.2^{* *}$ & 43.6 \\
\hline Using LPG/electricity/bio-gas for cooking & 25.3 & 29.0 & $32.7^{*}$ & $25.2^{+}$ \\
\hline \multicolumn{5}{|l|}{ Household economic status } \\
\hline Mean household wealth index & 20.2 & $23.1^{* * *}$ & $22.9^{* * *}$ & $23.3^{* * *}$ \\
\hline Number of respondents & 371 & 789 & 404 & 385 \\
\hline \multicolumn{5}{|c|}{ Young women } \\
\hline \multicolumn{5}{|l|}{ Household characteristics } \\
\hline Household size (mean number of persons) & 7.2 & 7.2 & 7.2 & 7.2 \\
\hline Owns a house & 96.8 & 96.1 & 94.9 & $97.4^{+}$ \\
\hline Lives in a pucca house & 26.7 & $41.8^{* * *}$ & $46.8^{* * *}$ & $36.9^{*+}$ \\
\hline Mean number of rooms in a house & 4.0 & $4.9^{* * *}$ & $5.0^{* * *}$ & $4.7^{* *+}$ \\
\hline Mean number of persons per room & 2.0 & $1.6^{* \star *}$ & $1.5^{* * *}$ & $1.6^{* * *}$ \\
\hline \multicolumn{5}{|l|}{ Household amenities } \\
\hline Has electricity & 74.0 & $88.0^{* *}$ & $88.5^{* *}$ & $87.6^{* *}$ \\
\hline Has access to a toilet facility & 39.0 & 42.8 & $51.1^{* * *}$ & $34.5^{+++}$ \\
\hline Using LPG/electricity/bio-gas for cooking & 11.9 & $17.6^{* * *}$ & $22.8^{* * *}$ & $12.2^{+++}$ \\
\hline \multicolumn{5}{|l|}{ Household economic status } \\
\hline Mean household wealth index & 20.8 & $22.8^{* * *}$ & $24.0^{* * *}$ & $21.7^{*+++}$ \\
\hline Number of respondents & 679 & 1382 & 695 & 687 \\
\hline
\end{tabular}

Notes: Differences between control and intervention (combined) blocks, control and standalone blocks, and control and comprehensive blocks are significant at ${ }^{*} p<0.05,{ }^{* *} p<0.01,{ }^{* *} p<0.001$; Differences between standalone and comprehensive blocks are significant at ${ }^{+} p<0.05,{ }^{+++} p<0.001$. 


\subsection{Profile of surveyed young men and women: Socio-demographic characteristics}

Table 2.2 presents the socio-demographic characteristics of surveyed youth. Age profiles suggest that on average, young men were one year older than young women. Among both young men and young women, however, those in control villages were older than those in intervention villages (20 versus 19 among young men; 19 versus 18 among young women). Marriage age profiles show that about four-fifths of young men (81-82\%), and half of young women $(50-51 \%)$ remained unmarried at the time of the interview; the only difference between those in intervention and control sites was that more young men and young women from intervention sites than control sites were married but had not started cohabiting (gauna) at the time of the interview.

The distribution of young men and women by religion suggests that there was a greater concentration of Hindus in intervention than in control villages. For example, among young men, 96 percent of those in intervention villages, compared to 87 percent of those in control villages were Hindu; corresponding percentages were 90 and 79 among young women. While 12 percent of young men and 22 percent of young women in control villages were Muslim, just four percent and ten percent, respectively, of those from intervention villages were Muslim.

Table 2.2: Social and demographic profile of respondents

Percent distribution of surveyed young men and women by selected socio-demographic characteristics, according to study arm

\begin{tabular}{|c|c|c|c|c|}
\hline \multirow[t]{2}{*}{ Background Characteristics } & \multirow[t]{2}{*}{ Control } & \multicolumn{3}{|c|}{ Intervention } \\
\hline & & Combined & Standalone & Comprehensive \\
\hline \multicolumn{5}{|c|}{ Young men } \\
\hline \multicolumn{5}{|l|}{ Age (in years) } \\
\hline 17 & 13.8 & 16.9 & 18.4 & 15.3 \\
\hline 18 & 20.3 & 24.6 & 24.5 & 24.8 \\
\hline 19 & 15.6 & 18.5 & 17.6 & 19.5 \\
\hline 20 & 11.8 & 13.2 & 13.1 & 13.3 \\
\hline $21-23$ & 28.5 & 20.6 & 20.5 & 20.7 \\
\hline $24-25$ & 9.9 & 6.1 & 5.9 & 6.4 \\
\hline Significance level & & * & & \\
\hline Median age & 20 & 19 & 19 & 19 \\
\hline \multicolumn{5}{|l|}{ Marital status } \\
\hline Unmarried & 80.7 & 82.3 & 82.8 & 81.8 \\
\hline Currently married & 18.5 & 13.3 & 12.8 & 13.7 \\
\hline Married but gauna not performed & 0.5 & 4.1 & 3.7 & 4.5 \\
\hline Widow/divorced/separated & 0.3 & 0.4 & 0.7 & 0.0 \\
\hline Significance level & & ** & ** & ** \\
\hline \multicolumn{5}{|l|}{ Religion } \\
\hline Hindu & 87.3 & 96.0 & 95.0 & 97.2 \\
\hline Muslim & 12.4 & 3.9 & 4.8 & 2.8 \\
\hline Others & 0.3 & 0.1 & 0.2 & 0.0 \\
\hline Significance level & & * & & ** \\
\hline \multicolumn{5}{|l|}{ Caste } \\
\hline Scheduled caste & 29.3 & 23.8 & 23.5 & 24.1 \\
\hline $\mathrm{OBC}$ & 58.8 & 67.2 & 62.7 & 72.3 \\
\hline Non ST/SC/OBC & 11.8 & 9.0 & 13.8 & 3.6 \\
\hline \multicolumn{5}{|l|}{ Significance level } \\
\hline Number of respondents & 371 & 789 & 404 & 385 \\
\hline
\end{tabular}




\begin{tabular}{|c|c|c|c|c|}
\hline \multirow[t]{2}{*}{ Background Characteristics } & \multirow[t]{2}{*}{ Control } & \multicolumn{3}{|c|}{ Intervention } \\
\hline & & Combined & Standalone & Comprehensive \\
\hline \multicolumn{5}{|c|}{ Young women } \\
\hline \multicolumn{5}{|l|}{ Age (in years) } \\
\hline 17 & 22.3 & 27.0 & 23.7 & 30.3 \\
\hline 18 & 25.0 & 26.7 & 27.7 & 25.8 \\
\hline 19 & 16.6 & 17.9 & 17.7 & 18.0 \\
\hline 20 & 15.4 & 12.2 & 11.5 & 12.8 \\
\hline $21-23$ & 16.8 & 14.3 & 16.1 & 12.5 \\
\hline $24-25$ & 4.0 & 1.9 & 3.3 & 0.6 \\
\hline Significance level & & * & & $* * *$ \\
\hline Median age & 19 & 18 & 18 & 18 \\
\hline \multicolumn{5}{|l|}{ Marital status } \\
\hline Unmarried & 51.4 & 50.4 & 53.8 & 47.2 \\
\hline Currently married & 48.5 & 44.8 & 42.5 & 47.0 \\
\hline Married but gauna not performed & 0.2 & 4.5 & 3.6 & 5.4 \\
\hline Widow/divorced/separated & 0.0 & 0.3 & 0.1 & 0.4 \\
\hline Significance level & & $* * *$ & $* * *$ & \\
\hline \multicolumn{5}{|l|}{ Religion } \\
\hline Hindu & 78.5 & 90.3 & 92.3 & 88.2 \\
\hline Muslim & 21.5 & 9.7 & 7.6 & 11.8 \\
\hline Others & 0.0 & 0.1 & 0.1 & 0.0 \\
\hline Significance level & & & * & \\
\hline \multicolumn{5}{|l|}{ Caste } \\
\hline Scheduled caste & 26.9 & 24.9 & 23.4 & 26.3 \\
\hline OBC & 56.4 & 63.9 & 59.4 & 68.4 \\
\hline Non ST/SC/OBC & 16.7 & 11.2 & 17.2 & 5.3 \\
\hline Significance level & & & & ${ }^{* *+}$ \\
\hline Number of respondents & 679 & 1,382 & 695 & 687 \\
\hline
\end{tabular}

Notes: Differences between control and intervention (combined) blocks, control and standalone blocks, and control and comprehensive blocks are significant at ${ }^{*} p<0.05,{ }^{* *} p<0.01,{ }^{* *} p<0.001$; Differences between standalone and comprehensive blocks are significant at ${ }^{+} p<0.05$.

The distribution of young men and women by caste was generally similar among young men and women from both intervention and control villages. About one-quarter of all groups belonged to scheduled castes, between three-fifths and two-thirds belonged to other backward castes, and some 10-17 percent came from general castes. Among young women, however, somewhat more of those from control than intervention villages came from general castes (17\% versus $11 \%)$.

\subsection{Profile of surveyed young men and women: Educational attainment, economic activity, and mass media and mobile phone exposure}

Table 2.3 presents educational attainment levels, economic activity status, and mass media exposure and access to mobile phones. Gender differences were pronounced, with young men from both intervention and control villages reporting higher levels of educational attainment and economic activity, as well as exposure to the mass media and 
access to and ownership of a mobile phone. While differences between the two intervention groups were negligible, significant differences were observed between youth in intervention and control villages.

Educational attainment levels were significantly higher among young men and young women from intervention villages than control villages (11.6 years versus 10.8 years among young men; 9.7 years versus 9.1 years among young women) and more were in school or college at the time of the interview (82\% versus $63 \%$ among young men, $59 \%$ versus $50 \%$ among young women). Conversely, fewer young men from intervention than control villages were working for wages in the year preceding the interview ( $42 \%$ versus $52 \%$ among young men); differences were negligible among young women (24-26\%). While similar percentages of young men from intervention and control villages were seeking employment at the time of the survey (47-49\%), significantly more young women from intervention than control villages were doing so (17\% versus $8 \%$ ). More young men and women from intervention than control sites were exposed, moreover, to various media, notably television ( $79 \%$ versus $66 \%$ among young men, $57 \%$ versus $37 \%$ among young women) and newspapers and books (89\% versus $83 \%$; $37 \%$ versus $30 \%$, respectively), and in the case of young men, the internet as well (49\% versus $39 \%)$. Access to mobile phones was reported by almost all young men and women; even so, those from intervention villages were more likely than those

Table 2.3: Educational attainment, economic activity, and mass media and mobile phone exposure Percent distribution of surveyed young men and women by educational attainment levels, and percentage of young men and women by economic activity and mass media and mobile phone exposure, according to study arm

\begin{tabular}{|c|c|c|c|c|}
\hline \multirow{2}{*}{$\begin{array}{l}\text { Education, work status and } \\
\text { exposure to mass media }\end{array}$} & \multirow[t]{2}{*}{ Control } & \multicolumn{3}{|c|}{ Intervention } \\
\hline & & Combined & Standalone & Comprehensive \\
\hline \multicolumn{5}{|c|}{ Young men } \\
\hline \multicolumn{5}{|l|}{ Education (years of schooling) } \\
\hline None & 1.9 & 0.1 & 0.0 & 0.2 \\
\hline $1-5$ years & 5.3 & 1.8 & 0.7 & 3.1 \\
\hline $6-8$ years & 8.6 & 4.1 & 3.2 & 5.2 \\
\hline $9-10$ years & 26.5 & 19.3 & 19.8 & 18.7 \\
\hline $11-12$ years & 28.5 & 44.1 & 47.8 & 39.9 \\
\hline More than 12 years & 29.2 & 30.6 & 28.5 & 32.9 \\
\hline Significance level & & *** & $* * *$ & ** \\
\hline Mean years of schooling & 10.8 & $11.6^{* * *}$ & $11.7^{* * *}$ & $11.5^{*}$ \\
\hline \% Currently studying & 63.0 & $82.3^{* * *}$ & $83.2^{* * *}$ & $81.3^{* * *}$ \\
\hline \multicolumn{5}{|l|}{ Work status } \\
\hline Paid work in last 12 months & 51.7 & $41.9^{*}$ & $38.7^{* \star}$ & 45.5 \\
\hline Currently seeking job & 47.3 & 48.6 & 48.4 & 48.8 \\
\hline \multicolumn{5}{|l|}{ Mass media exposure ${ }^{a}$} \\
\hline Television & 66.1 & $79.1^{* * *}$ & $77.3^{*}$ & $81.1^{* * *}$ \\
\hline Movie (in theatre) & 5.2 & 8.4 & 8.9 & 7.8 \\
\hline Newspaper/magazine/books ${ }^{b}$ & 82.6 & $88.8^{* *}$ & $89.6^{*}$ & $87.9^{*}$ \\
\hline Internet ${ }^{\mathrm{b}}$ & 39.2 & $49.2^{*}$ & 45.6 & $53.2^{* *}$ \\
\hline \multicolumn{5}{|l|}{ Access to mobile phone } \\
\hline Yes, own & 87.3 & 93.4 & 94.0 & 92.6 \\
\hline Yes, not own & 11.9 & 5.8 & 5.0 & 6.6 \\
\hline Do not have access & 0.8 & 0.8 & 1.0 & 0.8 \\
\hline Significance level & & ** & $* *$ & \\
\hline Number of respondents & 371 & 789 & 404 & 385 \\
\hline
\end{tabular}


Table 2.3: (Cont'd)

\begin{tabular}{|c|c|c|c|c|}
\hline \multirow{2}{*}{$\begin{array}{l}\text { Education, work status and } \\
\text { exposure to mass media }\end{array}$} & \multirow[t]{2}{*}{ Control } & \multicolumn{3}{|c|}{ Intervention } \\
\hline & & Combined & Standalone & Comprehensive \\
\hline \multicolumn{5}{|c|}{ Young women } \\
\hline \multicolumn{5}{|l|}{ Education (years of schooling) } \\
\hline None & 8.9 & 5.2 & 3.3 & 7.1 \\
\hline $1-5$ years & 10.5 & 7.1 & 6.2 & 8.0 \\
\hline $6-8$ years & 11.0 & 10.4 & 7.5 & 13.4 \\
\hline $9-10$ years & 27.2 & 33.6 & 32.6 & 34.6 \\
\hline $11-12$ years & 26.5 & 28.2 & 31.4 & 24.9 \\
\hline More than 12 years & 15.9 & 15.5 & 19.0 & 12.1 \\
\hline Significance level & & & ** & ++ \\
\hline Mean years of schooling & 9.1 & $9.7^{* * *}$ & $10.2^{* \star *}$ & 9.2 \\
\hline \% Currently studying & 49.6 & $58.5^{*}$ & $59.6^{*}$ & 57.3 \\
\hline \multicolumn{5}{|l|}{ Work status } \\
\hline Paid work in last 12 months & 24.1 & 25.6 & 23.8 & 27.5 \\
\hline \multicolumn{5}{|l|}{ Significance level } \\
\hline Currently seeking job & 7.6 & $16.9^{* * *}$ & $17.6^{* * *}$ & $16.3^{* * *}$ \\
\hline \multicolumn{5}{|l|}{ Mass media exposure ${ }^{a}$} \\
\hline Television & 37.2 & $56.8^{* * *}$ & $60.5^{* * *}$ & $53.1^{* *}$ \\
\hline Movie (in theatre) & 0.3 & 0.6 & 0.9 & 0.4 \\
\hline Newspaper/magazine/books ${ }^{b}$ & 30.4 & $36.5^{*}$ & $39.2^{*}$ & 33.6 \\
\hline Internet $^{\mathrm{b}}$ & 5.4 & 4.2 & 4.4 & 3.9 \\
\hline \multicolumn{5}{|l|}{ Access to mobile phone } \\
\hline Yes, own & 30.6 & 36.5 & 38.3 & 34.7 \\
\hline Yes, not own & 68.3 & 62.2 & 60.8 & 63.5 \\
\hline Do not have access & 1.1 & 1.3 & 0.9 & 1.8 \\
\hline Significance level & & * & * & \\
\hline Number of respondents & 679 & 1,382 & 695 & 687 \\
\hline
\end{tabular}

Notes: Differences between control and intervention (combined) blocks, control and standalone blocks, and control and comprehensive blocks are significant at ${ }^{*} p<0.05,{ }^{* *} p<0.01,{ }^{* *} p<0.001$; ${ }^{a}$ Includes almost every day/at least once a week/at least once a month; ${ }^{b}$ Includes respondents with five or more years of education.

from control villages to own a mobile phone (93\% versus $87 \%$ among young men; $37 \%$ versus $31 \%$ among young women) and correspondingly, less likely to just have access to a phone owned by someone else in the family.

Table 2.4 sheds light on the extent of pre- and extra-marital relations reported by young men and women. ${ }^{2}$ Several young people had engaged in pre-marital sex, and in the case of the married, extra-marital, with their romantic partners, as well as, in some cases, as a result of a forced encounter (with a non-romantic partner), sex in exchange

\footnotetext{
2 The survey probed young people's romantic relationships through a number of questions (whether they had accepted a proposal or a proposal they had made was accepted, whether they had met someone from the opposite sex alone and in secret, and more directly, whether they had a boyfriend). Questions for the married referred to their pre-marital life. Young people who responded positively to any of these questions were considered to have experienced a pre-marital romantic relationship. Further questions were posed to those who had experienced a pre-marital romantic relationship that focused on whether sexual relations were protected and consensual. The survey posed questions to all young people about whether they had experienced pre-marital sex in any such situation, and to married young people also about whether they had experienced extra-marital sex in any such situation. We note therefore that percentages reporting forced, paid, sex worker, casual sex relations or sexual relations with a married woman refer to the situation before and after marriage for the married. The married were also asked about their age at first sex, and those reporting that their age at first sex preceded their age at marriage were considered to have experienced premarital sex.
} 
for money or favours, a casual sex encounter, and in the case of young men, sex worker relations and relations with a married woman. Findings confirm that the majority of those who had experienced pre-marital (or extra-marital) sex had done so with a romantic partner. With regard to young men, overall, 29 percent of those from intervention sites, compared to 20 percent of those from control sites reported pre-marital sex with a romantic partner. In addition, sexual relations had been experienced in other situations, and differences between those in intervention and control sites were not observed. Fewer young women reported sexual relations in most situations about which we probed (ranging from $4 \%$ to $9 \%$ for relations with a romantic partner, and from $0 \%$ to $4 \%$ in other situations about which we probed). Differences between young women in intervention than control sites were not observed.

A summary measure of the percentage of young people who had engaged in pre-marital and extra-marital sex reveals that among young men, 34 percent of those from intervention sites and significantly fewer-23 percent-of those from control sites had experienced premarital sex. Among young women, too, a similar pattern emerged, although levels of pre-marital sex were far lower than among young men. Overall, eight percent of young women

Table 2.4: Extent of pre-marital and extra-marital sexual relations among young people

Percentage of young men and women reporting pre-marital and extra-marital sexual relations, and situations in which such relations were experienced, by marital status, according to study arm

\begin{tabular}{|c|c|c|c|c|}
\hline \multirow{2}{*}{$\begin{array}{l}\text { Pre-marital and extra-marital } \\
\text { sexual experiences }\end{array}$} & \multirow[t]{2}{*}{ Control } & \multicolumn{3}{|c|}{ Intervention } \\
\hline & & Combined & Standalone & Comprehensive \\
\hline \multicolumn{5}{|c|}{ Young men } \\
\hline \multicolumn{5}{|l|}{ Reported sexual relations with: } \\
\hline An opposite-sex romantic partner & 20.1 & 28.7 & 28.2 & 29.2 \\
\hline Someone who forced the respondent to have sex & 1.4 & 1.9 & 2.0 & 1.9 \\
\hline A girl/woman whom the respondent forced & 0.3 & 2.3 & 3.2 & 1.3 \\
\hline Someone in exchange for money/favour & 2.2 & 2.8 & 3.4 & 2.1 \\
\hline Sex worker & 2.2 & 4.4 & 4.9 & 3.9 \\
\hline Married woman & 1.3 & 2.3 & 3.2 & 1.3 \\
\hline Casual partner & 2.0 & 6.2 & 6.7 & 5.6 \\
\hline Any pre-marital sexual experience ${ }^{1}$ & 23.2 & $33.6^{* * *}$ & $9.6^{* *}$ & $33.8^{* * *}$ \\
\hline Number of respondents & 371 & 789 & 404 & 385 \\
\hline Any extra-marital sexual experience & 17.7 & 17.8 & 21.2 & 14.3 \\
\hline Number of married respondents & 72 & 140 & 70 & 70 \\
\hline
\end{tabular}

\section{Young women}

\section{Reported sexual experience with:}

An opposite-sex romantic partner

Someone who forced the respondent to have sex

Someone in exchange for money/favour

Casual partner

Any pre-marital sexual experience ${ }^{1}$

Number of respondents

Any extra-marital sexual experience

Number of married respondents

$\begin{array}{rrrl}4.3 & 7.7 & 6.8 & 8.7 \\ 0.9 & 3.0 & 1.7 & 4.3^{++} \\ 0.3 & 0.4 & 0.3 & 0.6 \\ 0.2 & 0.4 & 0.3 & 0.4 \\ 4.9 & 8.3^{* *} & 7.1 & 9.6^{* *} \\ \mathbf{6 7 9} & \mathbf{1 3 8 2} & \mathbf{6 9 5} & \mathbf{6 8 7} \\ 1.8 & 2.5 & 1.9 & 3.0 \\ \mathbf{3 2 9} & \mathbf{6 8 3} & \mathbf{3 2 1} & \mathbf{3 6 2}\end{array}$

Notes: Differences between control and intervention (combined) blocks, control and standalone blocks, and control and comprehensive blocks are significant at ${ }^{*} p<0.05,{ }^{* *} p<0.01,{ }^{* \star} p<0.001$; Differences between standalone and comprehensive blocks are significant at ${ }^{+} p<0.05,{ }^{++} p<0.01$; ${ }^{1}$ Pre-martial sex among the married is the proportion of respondents whose reported age at first sex with any romantic/other partner (excluding spouse) was lower than their age at marriage. 
from intervention sites, compared with five percent of those from control sites had experienced pre-marital sex. Married young men and women also reported extra-marital sexual relations; however, differences between those in comparison and intervention areas were not observed (18\% among young men and $2 \%-3 \%$ among young women, irrespective of exposure to the PRACHAR training programme). Only in one instance was a difference observed in the experiences those in standalone and comprehensive intervention sites, respectively: significantly more young women in comprehensive than standalone sites reported that they had been forced to engage in sexual relations ( $4 \%$ versus $2 \%$ overall).

\section{Summary}

Findings generally suggest that many study participants had completed a high school education (Class 10), although gender differences were evident, and large proportions of young men, and somewhat fewer young women were pursuing their education at the time of the interview. At the same time, many young people-more young men than young women-were working for wages at the time of the survey. Young men were, moreover, far more likely to report exposure to various media, as well as to own a mobile phone. Finally, notable minorities of young people-particularly young men-reported pre-marital or extra-marital sexual experience, mostly with a romantic partner.

Findings indicate that while largely similar, despite village- as well as sample-level matching on educational attainment, young people in intervention areas were marginally better off in terms of household economic status, educational attainments, and economic activity than those in control areas. 


\section{Chapter 3}

\section{The intervention and participants' experiences and perceptions about its acceptability}

In this chapter, we provide a brief description of the PRACHAR project's three-day training programme for adolescents, and the perceptions of young men and women who had undergone the training programme about both its acceptability and how the training programme may have affected their life over the intervening period.

\section{The intervention}

The PRACHAR Phase III intervention for unmarried adolescents sought to fill a key need among this under served group in Bihar. It recognised that adolescents in the state were denied information about sexual and reproductive health matters, yet desired this information, and that although significant minorities were sexually active, they were poorly equipped to make informed reproductive health decisions and ensure safe and wanted sexual relations. Responding to these needs, the PRACHAR programme focused on the provision of sexual and reproductive health education to unmarried adolescents.

The programme focused on unmarried adolescents aged 15-19 (although younger adolescents and older youth were not turned away) and was imparted as a non-residential, 15-hour programme delivered over three days. Sessions for boys and girls were delivered separately. Training was imparted by local non-governmental organisations identified and oriented by Pathfinder International using the facilitator's guide developed by Pathfinder International for the reproductive health training of adolescents (Pathfinder International, 2007a, 2007b). Two pairs of female trainers trained girls, and two teams comprising one female and one male trainer trained boys. Female trainers were deliberately included in the boys' training programme to encourage a culture of respect for girls and women.

A total of 39,223 adolescents were trained over the course of the PRACHAR III project. Batches of up to 30 adolescents were trained in each three-day programme, and job aids, flip charts, pictorials, aprons, and models were used to explain reproduction, disease transmission and prevention, and contraceptive methods and their use.

Training encompassed a range of issues related to reproduction, family planning, and responsible decision-making in the area of reproductive health. Specific themes encompassed male and female reproductive systems, the menstrual cycle and hygiene; nutrition; conception and contraception; transmission, prevention, and treatment of STIs, RTIs, and HIV/ AIDS; myths and misconceptions related to sexuality, reproduction, and STIs; recognising and protecting against sexual harassment and abuse; spousal negotiation; gender-egalitarian sexual decision-making; the availability of reproductive health and family planning services; and the need to use services. Sessions for both girls and boys also addressed sexual abuse and violence, respect for women and girls, and actions to take in case of harassment and abuse. Communication skills were also imparted, with particular reference to negotiating with partners and guardians about personal and sensitive matters, including making safe and wanted reproductive decisions.

In view of widespread child marriage in the area, the training programme included a special emphasis on the dangers of early marriage and childbirth; the need to delay first pregnancy and space subsequent ones; social and family well-being; and economic benefits of delaying marriage to 18 years or more and delaying first birth until age 21 years. Stress was placed on equitable partner relations, for example, the importance, for newlyweds in particular, of spending time together, getting to know and enjoy each other's company, developing mutual understanding, and ensuring sufficient savings before taking on the responsibilities of childbearing. Groups also discussed how to resist family and community pressures to marry and conceive at a young age. 
Gender role attitudes and the importance of gender egalitarian relations were cross-cutting issues imparted throughout the training programme. Efforts were made to help boys and girls think about their own notions of the equality of men and women, about women's rights, and about sexual harassment of women and girls.

When launched, the project faced considerable opposition from parents and other adults in the community. In order to allay concerns about exposing adolescents, especially girls, to information about sex and sexuality, reproductive organs and condom use, the project, led by local NGO partners, held community-level meetings in project villages. Meetings were addressed by influential community leaders, including, in addition to local NGO representatives, community leaders, trainers, and even some particularly articulate adolescents. These efforts went a long way towards gaining community acceptance for the training programme.

\section{Participation in the training programme}

Study respondents from intervention villages who had attended the training programme in 2010-11 were asked whether they had attended the entire programme, and the number of adolescents who had attended the training programme with them. Findings (Table 3.1) suggest that 88 percent of young men and significantly more-94 percent-of young women had attended all three days of the programme. While similarly large proportions of young women from standalone and comprehensive PRACHAR sites reported having attended the entire programme, significantly more boys from the standalone than the comprehensive sites had done so (91\% versus $84 \%$ ).

The majority reported that the group in which they were trained comprised an average of 11-20 (29-36\%) or 21-30 (37-41\%) participants; even so more girls than boys reported that the group in which they were trained included more than 30 participants (30\% versus $16 \%$ ). The size of the group was similar for boys in comprehensive and standalone sites; however, among girls, those in standalone sites reported larger group size than did those in comprehensive sites (37\% versus $24 \%$ ). On average, young men reported that the group in which they had been trained had 23 participants (22-23 in both standalone and comprehensive sites), while young women reported a somewhat larger group size-27 participants, and ranging from 24 in comprehensive intervention sites to 30 in standalone sites.

Table 3.1: Participation in the entire three-day programme and size of the group

Percentage of young men and women who attended the entire programme, and percent distribution of training group size, and median number of trainees per session, young men and women, according to study arm

\begin{tabular}{lcccccc}
\hline Participation in programme & \multicolumn{3}{c}{ Young men } & \multicolumn{3}{c}{ Young women } \\
\cline { 2 - 6 } & Combined & Standalone & Comprehensive & Combined & Standalone & Comprehensive \\
\hline $\begin{array}{l}\text { Participated in the entire } \\
\text { three-day programme }\end{array}$ & 87.8 & 91.1 & $84.2^{++}$ & $94.0^{\# \# \#}$ & 95.4 & 92.6 \\
$\begin{array}{l}\text { Number of participants in the } \\
\text { training (\%) }\end{array}$ & & & & & & \\
1-10 & 1.9 & 2.7 & 1.0 & 1.0 & 0.7 & 1.3 \\
11-20 & 36.1 & 34.5 & 37.9 & 28.5 & 24.1 & 32.9 \\
$21-30$ & 40.5 & 38.4 & 42.7 & 36.8 & 35.1 & 38.5 \\
More than 30 & 16.0 & 17.7 & 14.1 & 30.2 & 36.8 & 23.6 \\
Do not remember & 5.5 & 6.7 & 4.2 & 3.5 & 3.3 & 3.7 \\
Median number of participants & $\mathbf{2 2 . 5}$ & $\mathbf{2 2 . 7}$ & $\mathbf{2 2 . 3}$ & $\mathbf{2 6 . 6}$ & $\mathbf{2 9 . 8}$ & $\mathbf{2 4 . 2}$ \\
in a training session & $\mathbf{7 8 9}$ & $\mathbf{4 0 4}$ & $\mathbf{3 8 5}$ & $\mathbf{1 , 3 8 2}$ & $\mathbf{6 9 5}$ & $\mathbf{6 8 7}$ \\
Number of respondents &
\end{tabular}

Notes: Differences between standalone and comprehensive intervention blocks are significant at ${ }^{++} p<0.01$; Differences between young men and women are significant at ${ }^{\# \# \#<<0.001 . ~}$ 


\section{Perceptions about the intervention}

In order to understand young people's perceptions about the intervention, we probed about their recall of themes covered, the themes they found most important, whether they had discussed the intervention with family and friends, and whether participation in the training had been useful in their subsequent life. Findings are presented in Tables 3.2-3.4.

For the most part, more than 90 percent of young people recalled the topics covered in the training programme (Table 3.2). Young men were significantly more likely than young women to recall sessions on RTI/HIV/STI ( $97 \%$ versus $84 \%$ ) and young women were significantly more likely than young men to recall sessions on most other topics, notably delaying marriage and childbearing ( $98 \%$ versus $90 \%$; $97 \%$ versus $89 \%$, respectively). Differences between

Table 3.2: Recall of themes addressed in the training programme, and perceptions about the importance of these themes

Percentage of young men and women recalling various themes addressed in the training programme, and perceiving the importance of these themes, according to study arm

\begin{tabular}{|c|c|c|c|c|c|c|}
\hline \multirow[t]{2}{*}{ Topics } & \multicolumn{3}{|c|}{ Young men } & \multicolumn{3}{|c|}{ Young women } \\
\hline & Combined & Standalone & Comprehensive & Combined & Standalone & Comprehensive \\
\hline \multicolumn{7}{|l|}{$\begin{array}{l}\text { Exposure to various topics } \\
\text { during training }\end{array}$} \\
\hline $\begin{array}{l}\text { Reproductive anatomy, human } \\
\text { body }\end{array}$ & 94.9 & 96.1 & 93.7 & 93.5 & 95.1 & $91.9^{+}$ \\
\hline How pregnancy happens & 91.1 & 92.3 & 89.9 & $93.5^{\#}$ & 95.9 & $91.1^{+++}$ \\
\hline Contraception & 97.1 & 97.3 & 96.9 & 95.9 & 97.1 & $94.8^{+}$ \\
\hline RTI, HIV/AIDS & 96.7 & 97.6 & 95.6 & $83.6^{\# \# \#}$ & 86.3 & $80.9^{++}$ \\
\hline $\begin{array}{l}\text { Place to get family planning/ } \\
\text { reproductive health services }\end{array}$ & 91.0 & 93.6 & $88.2^{++}$ & 89.4 & 92.3 & $86.5^{+++}$ \\
\hline Importance of delaying marriage & 90.4 & 90.1 & 90.7 & $98.4^{\# \# \#}$ & 99.4 & $97.4^{++}$ \\
\hline $\begin{array}{l}\text { Importance of delaying first } \\
\text { birth }\end{array}$ & 89.4 & 89.6 & 89.2 & $96.9^{\# \# \#}$ & 98.3 & $95.5^{+}$ \\
\hline Equality of men and women & 90.5 & 91.9 & 88.9 & $93.2^{\#}$ & 94.5 & 92.0 \\
\hline \multicolumn{7}{|l|}{$\begin{array}{l}\text { Topics perceived to be most } \\
\text { important }^{\text {a }}\end{array}$} \\
\hline $\begin{array}{l}\text { Reproductive anatomy, human } \\
\text { body }\end{array}$ & 18.7 & 16.7 & 20.9 & 18.1 & 16.8 & 19.4 \\
\hline How pregnancy happens & 12.7 & 14.5 & 10.7 & 11.9 & 10.9 & 12.8 \\
\hline Contraception & 50.4 & 53.4 & 47.0 & $35.4^{\# \# \#}$ & 34.4 & 36.4 \\
\hline RTI, HIV/AIDS & 66.8 & 69.0 & 64.4 & $19.8^{\# \# \#}$ & 21.4 & 18.2 \\
\hline $\begin{array}{l}\text { Place to get family planning/ } \\
\text { reproductive health services }\end{array}$ & 14.4 & 14.9 & 13.7 & $18.6^{\# \#}$ & 19.4 & 17.8 \\
\hline Importance of delaying marriage & 46.3 & 43.1 & 49.9 & $69.8^{\# \# \#}$ & 68.9 & 70.7 \\
\hline $\begin{array}{l}\text { Importance of delaying first } \\
\text { birth }\end{array}$ & 29.6 & 25.8 & $33.8^{+}$ & $53.5^{\# \# \#}$ & 54.9 & 52.1 \\
\hline Equality of men and women & 13.5 & 15.0 & 11.9 & 14.7 & 15.7 & 13.7 \\
\hline Number of respondents & 789 & 404 & 385 & 1,382 & 695 & 687 \\
\hline
\end{tabular}

Notes: Differences between standalone and comprehensive intervention blocks are significant at ${ }^{+} p<0.05,{ }^{++} p<0.01,{ }^{+++} p<0.001$;

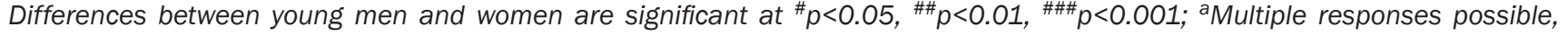
hence percentages add up to more than 100. 
young men in standalone and comprehensive sites were negligible, with one exception: significantly more young men from standalone than comprehensive settings recalled exposure to information about the location of family planning or reproductive health services ( $94 \%$ versus $88 \%$ ). In contrast, significantly more young women from standalone than comprehensive sites reported exposure to almost every topic about which we probed.

Table 3.2 also presents young people's assessment of topics they found most important. Gender differences were notable. Young men reported sessions on RTI/HIV/STIs, contraception and delaying marriage to be of greatest importance $(67 \%, 50 \%$, and $46 \%$, respectively), while young women reported delaying marriage, delaying childbearing, and contraception to be most important (70\%, 54\%, and 35\%, respectively). Also notable are the small percentages, in contrast, of young men and women who found sessions about gender equality to have been important (14-15\%).

Differences between young men and women, respectively, in comprehensive and standalone areas were negligible.

With regard to whether they had discussed what they had learned in the course of the intervention with family and friends, a different pattern emerges for young men and young women (Table 3.3). Almost all young men (94\%) had discussed what they learned during the training programme with their friends, but fewer than ten percent had discussed these matters with a family member or even a spouse or girlfriend. In contrast, young women had discussed the training programme with an array of family and friends: two-thirds (67\%) with friends, and one-third or more with parents or grandparents, siblings, and other relatives (34-37\%). Differences in reports of communication about the training among those in standalone and comprehensive settings were negligible.

Almost all young people-young men and young women and those from standalone and comprehensive sites-found the training useful in their subsequent life (95-98\%) (Table 3.4). Between one-third and half of young men found the training useful in making subsequent decisions about marriage timing (54\%), health care-seeking (48\%), and contraceptive use (33\%). In contrast, young women-between one-third and two-thirds-found the training useful in making subsequent decisions about health care-seeking (65\%), marriage timing (45\%), contraceptive use (36\%), and pregnancy planning (35\%). Differences between those in standalone and comprehensive sites were negligible.

Table 3.3: Communication with family and friends about the training programme

Percentage of young men and women reporting discussion with selected individuals about what was imparted in the training programme, according to study arm

\begin{tabular}{|c|c|c|c|c|c|c|}
\hline \multirow{2}{*}{$\begin{array}{l}\text { Discussed with selected } \\
\text { individuals about what was } \\
\text { imparted in the training } \\
\text { programme }^{\mathrm{a}}\end{array}$} & \multicolumn{3}{|c|}{ Young men } & \multicolumn{3}{|c|}{ Young women } \\
\hline & Combined & Standalone & Comprehensive & Combined & Standalone & Comprehensive \\
\hline Parents/grandparents & 1.2 & 0.8 & 1.8 & $37.1^{\# \# \#}$ & 38.5 & 35.6 \\
\hline Siblings & 1.8 & 2.5 & 1.0 & $33.8^{\# \# \#}$ & 33.6 & 33.9 \\
\hline Other relatives & 3.4 & 4.2 & 2.5 & $34.8^{\# \# \#}$ & 36.1 & 33.5 \\
\hline Friends & 93.7 & 95.1 & 92.3 & $66.7^{\# \# \#}$ & 63.4 & $69.9^{+}$ \\
\hline Husband/wife/girlfriend & 8.2 & 8.4 & 7.9 & $4.7^{\# \#}$ & 4.4 & 5.1 \\
\hline No one & 4.6 & 2.7 & $6.7^{++}$ & 4.4 & 3.9 & 4.8 \\
\hline Number of respondents & 789 & 404 & 385 & 1,382 & 695 & 687 \\
\hline
\end{tabular}

Notes: Differences between standalone and comprehensive intervention blocks are significant at ${ }^{++} p<0.01$; Differences between

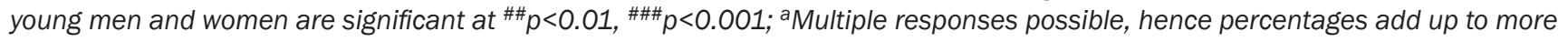
than 100. 
Table 3.4: Perceptions about the usefulness of the training programme in subsequent life decisions

Percentage of young men and women reporting that the training programme had been useful, and the ways in which it had been useful, according to study arm

\begin{tabular}{lcccccc}
\hline Decisions & \multicolumn{3}{c}{ Young men } & \multicolumn{3}{c}{ Young women } \\
\cline { 2 - 7 } & Combined & Standalone & Comprehensive & Combined & Standalone & Comprehensive \\
\hline Reported that training was & 94.8 & 95.3 & 94.2 & 98.2 & 99.0 & $97.4^{+}$ \\
useful & \multicolumn{7}{c}{} & & & & & \\
Reported that training helped them in taking decisions about: & & & & \\
When to marry & 54.0 & 52.8 & 55.3 & $45.2^{\# \# \#}$ & 44.7 & 45.8 \\
Contraceptive use & 33.0 & 32.2 & 33.9 & 36.4 & 36.6 & 36.2 \\
Health care-seeking & 47.5 & 47.6 & 47.3 & $65.1^{\# \# \#}$ & 67.4 & 62.8 \\
Pregnancy planning & 7.7 & 6.7 & 8.9 & $35.2^{\# \# \#}$ & 36.6 & 33.8 \\
Menstrual hygiene practices & na & na & na & 7.4 & 8.3 & 6.6 \\
Number of respondents & $\mathbf{7 8 9}$ & $\mathbf{4 0 4}$ & $\mathbf{3 8 5}$ & $\mathbf{1 , 3 8 2}$ & $\mathbf{6 9 5}$ & $\mathbf{6 8 7}$ \\
\hline
\end{tabular}

Notes: Differences between standalone and comprehensive intervention blocks are significant at ${ }^{+} p<0.05$; Differences between young men and women are significant at ${ }^{\# \#} p<0.001$; na $=$ not applicable

\section{Summary}

Findings confirm that the PRACHAR programme for adolescents was both acceptable and useful to the young people exposed to it. The overwhelming majority had attended the entire three-day session and recalled every topic covered in the programme. Large proportions found topics relating to RTI/HIV/STIs, contraception, and delaying marriage and childbearing to have been important. However, relatively few found such topics as reproductive anatomy, how pregnancy happens, the location of services, and gender equality to have been important. Almost all young people had discussed the programme with someone, almost entirely friends in the case of young men, and friends and family in the case of young women, and almost all found the training useful in making subsequent decisions in their life, ranging from the timing of marriage and childbearing to contraception and health-seeking.

Gender differences were apparent on many outcomes. More young women than men reported having attended the entire three-day programme. Recall of topics addressed and perceptions of important topics also differed, with young women more likely to recall and consider important such topics as marriage and childbearing, and young men, in contrast, more likely to recall and consider sessions on RTIs and HIV to have been important. Individuals with whom young people shared what they had learned in the training programme also differed, with almost all young men discussing the programme with friends, and hardly any with family, and young women discussing the programme with a mix of family and friends. Also different were young people's assessments about how the programme had helped them make decisions in their subsequent life: while both young men and young women reported that it had helped them in making decisions about health care seeking, marriage timing, and contraception, young women also reported that it helped them to make decisions about pregnancy planning, a perception rarely made by young men.

Differences between the two intervention arms were generally negligible, but where differences were observed, it was young men in standalone sites who were more likely than those in comprehensive sites to report full participation in the programme, and young women in standalone sites who were more likely to recall topics covered in the programme than were those in comprehensive sites. 


\section{Chapter 4 \\ Young people's awareness about sexual and reproductive health matters}

This chapter presents findings with regard to young people's awareness about sexual and reproductive health matters. The intention is to assess the extent to which young men and women who had been exposed to the PRACHAR intervention were more aware, three to four years following the training, about such issues as pregnancy, contraception, and infection than were those in control sites, and the extent to which those in the two intervention arms differed from each other in these respects.

\section{Awareness about becoming pregnant}

In order to measure young people's awareness about becoming pregnant, two statements were provided and young people were asked whether they were correct: a woman can get pregnant at first sex and a woman is most likely to become pregnant if she has sex half-way between her periods. Findings, presented in Table 4.1, show that awareness about pregnancy related matters was far from universal, and while young men who had undergone training were significantly more likely than those who had not to be correctly informed, differences among young women were negligible. For example, just half of young men (51\%) who had received training, compared to 43 percent of those in the control sites, were aware that a woman can become pregnant at first sex, and four-fifths (81\%) of young men compared to two-thirds $(66 \%)$ of those from control sites were aware that a woman is most likely to become pregnant if she has sex midway between her periods. Corresponding differences among young women were negligible (72-74\% and $76-80 \%$, respectively). Differences between standalone and comprehensive intervention sites were largely insignificant, except that young women in standalone sites were significantly better informed about when in the menstrual cycle pregnancy is most likely to occur ( $84 \%$ versus $77 \%$ ).

Table 4.1: Awareness about becoming pregnant

Percentage of young men and women expressing awareness about becoming pregnant, according to study arm

\begin{tabular}{|c|c|c|c|c|}
\hline \multirow[t]{2}{*}{ Pregnancy related matters } & \multirow[t]{2}{*}{ Control } & \multicolumn{3}{|c|}{ Intervention } \\
\hline & & Combined & Standalone & Comprehensive \\
\hline \multicolumn{5}{|c|}{ Young men } \\
\hline \multicolumn{5}{|l|}{ Aware that: } \\
\hline $\begin{array}{l}\text { A women can get pregnant on the very first sexual } \\
\text { intercourse }\end{array}$ & 42.5 & $50.9^{*}$ & 50.2 & $51.7^{*}$ \\
\hline $\begin{array}{l}\text { A women is most likely to get pregnant if she has } \\
\text { sexual intercourse halfway between her periods }\end{array}$ & 66.3 & $80.9^{* * *}$ & $82.6^{* * *}$ & $78.9^{* *}$ \\
\hline Number of respondents & 371 & 789 & 404 & 385 \\
\hline
\end{tabular}

\section{Aware that:}

A women can get pregnant on the very first sexual intercourse

Young women

A women is most likely to get pregnant if she has sexual intercourse halfway between her periods

Number of respondents

$\begin{array}{rrrr}73.8 & 72.3 & 72.9 & 71.7 \\ 76.1 & 80.1 & 83.5^{*} & 76.8^{+} \\ \mathbf{6 7 9} & \mathbf{1 3 8 2} & \mathbf{6 9 5} & \mathbf{6 8 7}\end{array}$

Notes: Differences between control and intervention (combined) blocks, control and standalone blocks, and control and comprehensive blocks are significant at ${ }^{*} p<0.05,{ }^{* *} p<0.01,{ }^{* *} p<0.001$; Differences between standalone and comprehensive blocks are significant at ${ }^{+} p<0.05$. 


\section{Awareness about the ideal pace of childbearing}

The majority of young people believed that the ideal age at first birth for women is 21 years or older, that the first child should be born 2-3 years after marriage, and that the ideal interval between subsequent births is 36 months or more (Table 4.2). Differences between young people who had undergone training and those who had not were significant in some instances. For example, more young men and women who had undergone training reported an ideal age at first birth of 21 or older (77\% versus $64 \%$ among young men, $72 \%$ versus $52 \%$ among young women), and an ideal inter-birth interval of 36 or more months (68\% versus $58 \%$ among young men, $84 \%$ versus $77 \%$ among young women).

Differences between standalone and comprehensive intervention sites were largely insignificant. Significant differences were observed in responses about ideal inter-birth intervals; while fewer young men from standalone than comprehensive intervention sites reported an ideal interval of 36 months or more (63\% versus $72 \%$ ), more young women from standalone than comprehensive intervention sites so reported ( $86 \%$ versus $81 \%$ ).

Table 4.2: Awareness about ideal pace of childbearing

Percentage of young men and women reporting that childbearing should not be initiated till age 21, that the first child should be born only 2-3 years following marriage, and that inter-birth intervals should be 36 months or more, according to study arm

\begin{tabular}{|c|c|c|c|c|}
\hline \multirow[t]{2}{*}{ Ideal pace of child baring } & \multirow[t]{2}{*}{ Control } & \multicolumn{3}{|c|}{ Intervention } \\
\hline & & Combined & Standalone & Comprehensive \\
\hline \multicolumn{5}{|c|}{ Young men } \\
\hline $\begin{array}{l}\text { Ideal age of women at first birth should be } \\
21 \text { years or more }\end{array}$ & 63.5 & $76.8^{* \star \star}$ & $74.4^{* *}$ & $79.6^{\star \star *}$ \\
\hline $\begin{array}{l}\text { First child should born after } 2-3 \text { years of } \\
\text { marriage or more }\end{array}$ & 75.5 & $80.6^{*}$ & 80.7 & 80.5 \\
\hline $\begin{array}{l}\text { Ideal birth interval between first and second } \\
\text { birth should be at least } 36 \text { months }\end{array}$ & 58.4 & $67.5^{\star *}$ & 63.2 & $72.3^{* * *+}$ \\
\hline Number of respondents & 371 & 789 & 404 & 385 \\
\hline \multicolumn{5}{|c|}{ Young women } \\
\hline $\begin{array}{l}\text { Ideal age of women at first birth should be } \\
21 \text { years or more }\end{array}$ & 51.5 & $72.0^{* * *}$ & $73.0^{* * *}$ & $71.1^{* * *}$ \\
\hline $\begin{array}{l}\text { First child should born after } 2-3 \text { years of } \\
\text { marriage or more }\end{array}$ & 77.4 & 79.2 & 78.8 & 79.5 \\
\hline $\begin{array}{l}\text { Ideal birth interval between first and second } \\
\text { birth should be at least } 36 \text { months }\end{array}$ & 77.4 & $83.6^{\star * \star}$ & $86.4^{* \star *}$ & $80.9^{++}$ \\
\hline Number of respondents & 679 & 1,382 & 695 & 687 \\
\hline
\end{tabular}

Notes: Differences between control and intervention (combined) blocks, control and standalone blocks, and control and comprehensive blocks are significant at ${ }^{*} p<0.05,{ }^{* *} p<0.01,{ }^{* * *} p<0.001$; Differences between standalone and comprehensive blocks are significant at ${ }^{+} p<0.05,{ }^{++} p<0.01$.

\section{Awareness about contraception}

As is evident from Table 4.3, awareness of at least one contraceptive method, at least one terminal method, and at least one non-terminal method was virtually universal among young men and women (although significantly more young men and women from intervention than control sites were aware of at least one non-terminal method of contraception (100\% versus 97\%; 99\% versus 93\%). Awareness of individual non-terminal methods of contraception was, however, significantly greater among young men and women who had undergone training than among those from the control sites. More specifically, significantly more young men from intervention than control sites were aware of oral contraceptive pills (OCPs) (90\% versus $65 \%$ ), emergency contraceptive pills (53\% versus $41 \%$ ), 
IUCDs ( $78 \%$ versus $37 \%$ ), and injectables (53\% versus $28 \%$ ). Among young women, too, significantly more of those from intervention than control sites reported awareness of almost every non-terminal contraceptive method: oral contraceptive pills (96\% versus $86 \%$ ), emergency contraceptive pills (30\% versus $19 \%$ ), condoms (96\% versus $78 \%$ ), IUCDs ( $83 \%$ versus $62 \%$ ), and injectables (77\% versus $54 \%$ ). Significant differences were also observed, among both young men and women, with regard to male sterilisation and traditional methods.

Table 4.3: Awareness about contraceptive methods

Percentage of young men and women expressing awareness about contraceptive methods, according to study arm

\begin{tabular}{|c|c|c|c|c|}
\hline \multirow{2}{*}{ Contraceptive method } & \multirow[t]{2}{*}{ Control } & \multicolumn{3}{|c|}{ Intervention } \\
\hline & & Combined & Standalone & Comprehensive \\
\hline \multicolumn{5}{|c|}{ Young men } \\
\hline Any method & 99.7 & 100.0 & 100.0 & 100.0 \\
\hline Any modern method & 99.7 & 100.0 & 100.0 & 100.0 \\
\hline Oral contraceptive pills & 64.7 & $89.6^{* * *}$ & $89.8^{* * *}$ & $89.3^{* * *}$ \\
\hline Emergency contraceptive pills & 41.0 & $52.9^{* *}$ & $53.7^{* *}$ & $52.0^{*}$ \\
\hline Condom & 96.2 & $99.8^{* * *}$ & $100.0^{* * *}$ & $99.5^{* *}$ \\
\hline IUCD/Copper-T & 37.3 & $77.6^{* * *}$ & $78.3^{* * *}$ & $76.8^{* \star *}$ \\
\hline Injectables & 28.1 & $53.2^{* * *}$ & $52.1^{* * *}$ & $54.4^{\star \star *}$ \\
\hline Female sterilisation & 98.7 & 99.4 & 99.5 & 99.2 \\
\hline Male sterilisation & 85.0 & $94.4^{* *}$ & $93.8^{* *}$ & $95.1^{* * *}$ \\
\hline Any traditional method & 51.2 & $83.4^{* * *}$ & $85.0^{* *}$ & $81.6^{* * *}$ \\
\hline Safe-day method & 39.3 & $74.1^{* * *}$ & $76.1^{* * *}$ & $71.9^{\star \star *}$ \\
\hline Withdrawal & 37.5 & $59.0^{* * *}$ & $59.8^{* * *}$ & $58.2^{* * *}$ \\
\hline Any modern spacing method & 97.3 & $99.9^{* * *}$ & $100.0^{* *}$ & $99.7^{* *}$ \\
\hline Any permanent method & 98.7 & 99.4 & 99.5 & 99.2 \\
\hline Number of respondents & 371 & 789 & 404 & 385 \\
\hline \multicolumn{5}{|c|}{ Young women } \\
\hline Any method & 99.7 & 99.9 & 99.9 & 100.0 \\
\hline Any modern method & 99.7 & 99.9 & 99.9 & 100.0 \\
\hline Oral contraceptive pills & 85.7 & $96.2^{* * *}$ & $96.4^{* * *}$ & $96.1^{* * *}$ \\
\hline Emergency contraceptive pills & 18.6 & $29.7^{* * *}$ & $34.4^{* * *}$ & $25.0^{\star *+++}$ \\
\hline Condom & 78.1 & $96.3^{* * *}$ & $97.4^{* * *}$ & $95.3^{* * *}$ \\
\hline IUCD/Copper-T & 62.0 & $82.9^{* * *}$ & $87.0^{* * \star}$ & $78.9^{\star * *+}$ \\
\hline Injectables & 54.0 & $76.8^{* * *}$ & $78.0^{* * *}$ & $75.5^{\star \star *}$ \\
\hline Female sterilisation & 99.2 & 99.6 & 99.7 & 99.6 \\
\hline Male sterilisation & 89.7 & $95.7^{* * *}$ & $96.2^{\star \star \star}$ & $95.2^{* *}$ \\
\hline Any traditional method & 57.5 & $80.6^{* * *}$ & $80.9^{* * *}$ & $80.3^{* * *}$ \\
\hline Safe-day method & 48.1 & $73.6^{* * *}$ & $74.6^{* * *}$ & $72.6^{* * *}$ \\
\hline Withdrawal & 41.5 & $56.6^{* * *}$ & $56.3^{* \star *}$ & $56.9^{* * *}$ \\
\hline Any modern spacing method & 93.4 & $99.1^{* * *}$ & $99.4^{* * *}$ & $98.8^{* * *}$ \\
\hline Any permanent method & 99.4 & 99.7 & 99.7 & 99.7 \\
\hline Number of respondents & 679 & 1,382 & 695 & 687 \\
\hline
\end{tabular}

Notes: Differences between control and intervention (combined) blocks, control and standalone block, and control and comprehensive blocks are significant at ${ }^{*} p<0.05,{ }^{* *} p<0.01,{ }^{* *} p<0.001$; Differences between standalone and comprehensive blocks are significant at ${ }^{+} p<0.05,{ }^{++} p<0.001$. 
Correct specific knowledge of various non-terminal methods was also probed, and found to vary considerably by method. With regard to oral contraceptive pills, we probed awareness of three issues that had been addressed during the training programme: that OCPs are taken daily or weekly, that women should start a new packet of OCPs from the fifth day of their menstrual cycle, and that if they forget to take the pills one day, they should take two pills together on the following day. With regard to other contraceptive methods, a single question was posed for each: that ECPs should be taken within 72 hours of unprotected sex, that one (male) condom may be used just once; that the IUCD is placed in the woman's uterus; and that injectables must be taken within the first five days of the menstrual cycle. A composite index was created that summed the number of issues about which a respondent expressed correct specific knowledge; this index ranged from 0 if the respondent was unaware of all the issues about which we probed, to 7 if the respondent was aware of all the issues. Findings are presented in Table 4.4.

Gender differences in correct specific knowledge of non-terminal methods were notable. While considerably more young men than women were aware that one male condom may be used just once, and that ECPs must be taken within 72 hours of unprotected sex, more young women than men had correct specific knowledge of the three remaining non-terminal methods about which we probed (OCPs, IUCD, injectables). Notwithstanding these gender differences, correct specific knowledge of every single method was significantly more likely to be expressed by those from the intervention than the control group.

The summary index suggests, however, that correct specific knowledge of contraceptive methods was limited. On average, young people, irrespective of sex or training status, were aware of just 1-2 issues about which we probed. Nevertheless, those who had undergone PRACHAR training were aware, on average, of significantly more issues than were those in the control group (1.9 versus 1.1 among young men; 2.2 versus 1.0 among young women.

Findings from Tables 4.3 and 4.4 suggest moreover that among young people who had undergone training, differences between those in standalone and comprehensive settings were typically mild. Among young men, for example, significant differences in overall awareness and specific knowledge were not observed with regard to a single issue. Among young women, significant differences were observed in just a few instances, and in all of these, those in the standalone arm were better informed than those in the comprehensive arm (awareness about ECPs, $34 \%$ versus $25 \%$ ); awareness of IUCD, $87 \%$ versus $79 \%$; correct specific knowledge about ECPs, $7 \%$ versus $4 \%$ ).

Table 4.4: Correct specific knowledge about non-terminal methods of contraception Percentage of young men and women reporting correct specific knowledge about various non-terminal methods of contraception, according to study arm

\begin{tabular}{|c|c|c|c|c|}
\hline \multirow[t]{2}{*}{ Correct specific knowledge } & \multirow[t]{2}{*}{ Control } & \multicolumn{3}{|c|}{ Intervention } \\
\hline & & Combined & Standalone & Comprehensive \\
\hline \multicolumn{5}{|c|}{ Young men } \\
\hline A woman should take OCPs everyday/weekly & 11.1 & $31.3^{* * *}$ & $31.8^{* * *}$ & $30.8^{* * *}$ \\
\hline $\begin{array}{l}\text { A woman should start taking OCPs from the fifth } \\
\text { day of her menstrual cycle }\end{array}$ & 2.7 & $8.4^{* *}$ & $7.7^{*}$ & $9.2^{* *}$ \\
\hline $\begin{array}{l}\text { If a woman forgets to take OCPs on any day, she } \\
\text { should take two pills on the following day }\end{array}$ & 1.9 & $9.6^{* * *}$ & $7.9^{* *}$ & $11.5^{* * *}$ \\
\hline $\begin{array}{l}\text { ECPs should be taken within } 72 \text { hours of } \\
\text { unprotected sexual intercourse }\end{array}$ & 5.5 & $21.1^{* * *}$ & $22.7^{* * *}$ & $19.3^{* * *}$ \\
\hline One condom can be used for only one sexual act & 80.6 & $96.2^{* * *}$ & $96.8^{* * *}$ & $95.4^{* *}$ \\
\hline IUCD/Copper-T is placed in the uterus & 6.9 & $27.6^{* * *}$ & $29.7^{* * *}$ & $25.2^{* * *}$ \\
\hline $\begin{array}{l}\text { Injectables should be taken within the first five } \\
\text { days of the menstrual cycle }\end{array}$ & 1.6 & $4.8^{*}$ & $4.7^{*}$ & $4.9^{*}$ \\
\hline $\begin{array}{l}\text { Index of correct specific knowledge }{ }^{\text {a }} \text { (Average } \\
\text { score) (range 0-7, Cronbach's alpha: } 0.71 \text { ) }\end{array}$ & 1.1 & $1.9^{* * *}$ & $2.0^{* * *}$ & $1.9^{* * *}$ \\
\hline Number of respondents & 371 & 789 & 404 & 385 \\
\hline
\end{tabular}




\begin{tabular}{|c|c|c|c|c|}
\hline \multirow[t]{2}{*}{ Correct specific knowledge } & \multirow[t]{2}{*}{ Control } & \multicolumn{3}{|c|}{ Intervention } \\
\hline & & Combined & Standalone & Comprehensive \\
\hline \multicolumn{5}{|c|}{ Young women } \\
\hline A woman should take OCPs everyday/weekly & 20.7 & $49.6^{* * *}$ & $48.2^{* * *}$ & $51.0^{* * *}$ \\
\hline $\begin{array}{l}\text { A woman should start taking OCPs from the fifth } \\
\text { day of her menstrual cycle }\end{array}$ & 5.6 & $19.4^{* * *}$ & $19.7^{* \star *}$ & $19.0^{* * *}$ \\
\hline $\begin{array}{l}\text { If a woman forgets to take OCPs on any day, she } \\
\text { should take two pills on the following day }\end{array}$ & 9.3 & $28.2^{* * *}$ & $29.2^{\star * \star}$ & $27.2^{* * *}$ \\
\hline $\begin{array}{l}\text { ECPs should be taken within } 72 \text { hours of } \\
\text { unprotected sexual intercourse }\end{array}$ & 2.8 & $5.5^{*}$ & $6.9^{* *}$ & $4.1^{+}$ \\
\hline One condom can be used for only one sexual act & 46.7 & $74.0^{* * *}$ & $76.3^{* * *}$ & $71.6^{* * *}$ \\
\hline IUCD/Copper-T is placed in the uterus & 14.7 & $32.1^{* * *}$ & $34.6^{* * *}$ & $29.6^{* *}$ \\
\hline $\begin{array}{l}\text { Injectables should be taken within the first five } \\
\text { days of the menstrual cycle }\end{array}$ & 2.3 & $10.7^{* * *}$ & $10.2^{* * *}$ & $11.3^{* * *}$ \\
\hline $\begin{array}{l}\text { Index of correct specific knowledge }{ }^{\text {a }} \text { (Average } \\
\text { score) (range } 0-7 \text {, Cronbach's alpha: } 0.78 \text { ) }\end{array}$ & 1.0 & $2.2^{* * *}$ & $2.3^{* * *}$ & $2.1^{* * *}$ \\
\hline Number of respondents & 679 & 1,382 & 695 & 687 \\
\hline
\end{tabular}

Notes: Differences between control and intervention (combined) blocks, control and standalone blocks, and control and comprehensive blocks are significant at ${ }^{*} p<0.05,{ }^{* *} p<0.01,{ }^{* \star *} p<0.001$; Differences between standalone and comprehensive blocks are significant at ${ }^{+} p<0.05$; ${ }^{a}$ Correct specific awareness score sums correct responses on each of the above seven issues regarding correct knowledge of modern methods of contraception for delaying and spacing births.

\section{Awareness about HIV/AIDS}

Awareness of HIV/AIDS was assessed through questions that probed whether young people had heard about HIV/ AIDS, and if so, had comprehensive awareness of HIV/AIDS, that is, they were aware of the protective nature of condom use and single partner relations, and rejected such misconceptions about HIV transmission as HIV can be transmitted through mosquito bites, sharing food or hugging, or that one can tell by looking at a person whether he or she has HIV. A summary measure was created that assessed comprehensive awareness about all questions relating to protective behaviours and common misconceptions.

Findings, presented in Table 4.5, confirm that more young men than young women had heard about HIV/AIDS, and, among those aware of HIV/AIDS, young men were more likely than young women to know about modes of transmission, and to have dispelled misconceptions.

Differences between young people in intervention and control sites in comprehensive knowledge about HIV/AIDS were significant for almost every indicator. For example, while 99 percent of young men and 84 percent of young women who had undergone training had heard about HIV/AIDS, significantly fewer-92 percent and 56 percent, respectively-from control sites had heard about HIV/AIDS. Far fewer were aware of protective behaviours or rejected common misconceptions, but even so, significantly more young men and women, respectively, in intervention than in control sites reported comprehensive knowledge on four of the six issues about which we probed, and overall, significantly more young men and young women from intervention than control sites reported comprehensive knowledge: 43 percent versus 26 percent of young men, and 26 percent versus 10 percent of young women, respectively.

Again, differences between young people in standalone and comprehensive intervention sites were negligible for the most part. The only exception was that significantly larger percentages of young men in standalone than comprehensive intervention sites reported comprehensive awareness about HIV/AIDS (47\% versus 38\%). 
Table 4.5: Awareness about HIV/AIDS

Percentage of young men and women who had heard about HIV/AIDS and who had comprehensive awareness about modes of transmission of HIV and common misconceptions, according to study arm

\begin{tabular}{|c|c|c|c|c|}
\hline \multirow[t]{2}{*}{ HIV/AIDS awareness } & \multirow[t]{2}{*}{ Control } & \multicolumn{3}{|c|}{ Intervention } \\
\hline & & Combined & Standalone & Comprehensive \\
\hline \multicolumn{5}{|c|}{ Young men } \\
\hline Had heard about HIV/AIDS & 91.6 & $98.6^{* * *}$ & $98.8^{* *}$ & $98.4^{* *}$ \\
\hline Had comprehensive awareness about HIV/AIDS ${ }^{a}$ & 26.1 & $42.8^{* * *}$ & $47.1^{* * *}$ & $38.1^{* *++}$ \\
\hline Number of respondents & 371 & 789 & 404 & 385 \\
\hline \multicolumn{5}{|l|}{$\begin{array}{l}\text { Of respondents who heard about HIV/AIDs, those } \\
\text { reporting that: }\end{array}$} \\
\hline $\begin{array}{l}\text { one can reduce chances of getting HIV by having } \\
\text { only one sexual partner }\end{array}$ & 95.3 & $98.2^{* *}$ & 97.5 & $99.0^{* *}$ \\
\hline one cannot get HIV through mosquito bites & 63.3 & 68.1 & 70.4 & 65.6 \\
\hline $\begin{array}{l}\text { one can reduce chances of getting HIV by consistent } \\
\text { use of condoms }\end{array}$ & 89.5 & $96.1^{* \star *}$ & $96.8^{* * *}$ & $95.4^{*}$ \\
\hline $\begin{array}{l}\text { one cannot become infected by sharing food with a } \\
\text { person who has AIDS }\end{array}$ & 54.1 & $65.7^{* *}$ & $68.0^{* *}$ & $63.2^{*}$ \\
\hline one cannot get HIV by hugging an HIV-positive person & 68.1 & $81.3^{* * *}$ & $83.0^{* *}$ & $79.5^{* *}$ \\
\hline $\begin{array}{l}\text { one cannot tell if a person is HIV-positive by just } \\
\text { looking at him/her }\end{array}$ & 80.0 & 82.7 & 82.7 & 82.8 \\
\hline \multicolumn{5}{|l|}{ Number of respondents who had heard about } \\
\hline \multicolumn{5}{|c|}{ Young women } \\
\hline Had heard about HIV/AIDS & 56.2 & $84.2^{* * *}$ & $85.7^{* * *}$ & $82.8^{* * *}$ \\
\hline Had comprehensive awareness about HIV/AIDS ${ }^{a}$ & 10.4 & $25.5^{* * *}$ & $27.5^{* * *}$ & $23.4^{* * *}$ \\
\hline Number of respondents & 679 & 1,382 & 695 & 687 \\
\hline \multicolumn{5}{|l|}{$\begin{array}{l}\text { Of respondents who heard about HIV/AIDs, those } \\
\text { reporting that: }\end{array}$} \\
\hline $\begin{array}{l}\text { one can reduce chances of getting HIV by having } \\
\text { only one sexual partner }\end{array}$ & 82.9 & 86.8 & 87.2 & 86.4 \\
\hline one cannot get HIV through mosquito bites & 41.1 & $50.8^{*}$ & $53.6^{*}$ & 47.9 \\
\hline $\begin{array}{l}\text { one can reduce chances of getting HIV by consistent } \\
\text { use of condoms }\end{array}$ & 62.9 & $78.3^{* * *}$ & $79.8^{* * *}$ & $76.7^{* * *}$ \\
\hline $\begin{array}{l}\text { one cannot become infected by sharing food with a } \\
\text { person who has AIDS }\end{array}$ & 45.0 & $59.3^{* * *}$ & $60.9^{* * *}$ & $57.6^{* *}$ \\
\hline one cannot get HIV by hugging an HIV-positive person & 68.5 & $79.2^{* *}$ & $80.8^{* * *}$ & $77.7^{*}$ \\
\hline $\begin{array}{l}\text { one cannot tell if a person is HIV-positive by just } \\
\text { looking at him/her }\end{array}$ & 89.1 & 91.7 & 91.3 & 92.1 \\
\hline \multicolumn{5}{|l|}{ Number of respondents who had heard about } \\
\hline HIV/AIDS & 381 & 1,166 & 596 & 570 \\
\hline
\end{tabular}

Notes: Differences between control and intervention (combined) blocks, control and standalone blocks, and control and comprehensive blocks are significant at ${ }^{*} p<0.05$, ${ }^{* *} p<0.01$, ${ }^{* *} p<0.001$; Differences between standalone and comprehensive blocks are significant at ${ }^{++} p<0.01$; ${ }^{a}$ Comprehensive knowledge of HIV/AIDS includes awareness that consistent condom use and having just one uninfected and faithful partner can reduce the chance of getting the HIV/AIDS, that a healthy-looking person can be HIV+, and rejection of two common misconceptions. 


\section{Awareness about the legal minimum age at marriage}

The survey also gauged young people's awareness of the legal minimum age at marriage for males (21 years) and females (18 years). As evident from Table 4.6, gender differences in awareness were negligible, but more young people were correctly informed about the legal minimum age at marriage for females than for males. Differences between young people in intervention and control sites were significant. For example, while 94-95 percent of young men and women from intervention sites were aware of the legal minimum age at marriage for females, significantly fewer-82-85 percent-of those from control sites so reported. Correspondingly, with regard to awareness of the legal minimum age at marriage for males, while 77 percent of both young men and young women from intervention sites were correctly informed, just 51-56 percent of those from control sites were so informed.

Differences between young women in standalone and comprehensive intervention sites were negligible, but among young men, significantly more of those from standalone than comprehensive programme settings reported awareness of both the legal minimum age at marriage for males ( $81 \%$ versus $73 \%$ ) and for females (96\% versus $92 \%$ ).

Table 4.6: Awareness about the legal minimum age at marriage for males and females

Percentage of young men and women who were aware of the legal minimum age at marriage for males and females, according to study arm

\begin{tabular}{|c|c|c|c|c|}
\hline \multirow{2}{*}{$\begin{array}{l}\text { Awareness about the } \\
\text { legal age at marriage }\end{array}$} & \multirow[t]{2}{*}{ Control } & \multicolumn{3}{|c|}{ Intervention } \\
\hline & & Combined & Standalone & Comprehensive \\
\hline \multicolumn{5}{|c|}{ Young men } \\
\hline $\begin{array}{l}\text { Aware of the legal minimum age at } \\
\text { marriage for males ( } 21 \text { years) }\end{array}$ & 56.1 & $77.1^{* \star *}$ & $80.7^{* * *}$ & $73.2^{* * *+}$ \\
\hline $\begin{array}{l}\text { Aware of the legal minimum age at } \\
\text { marriage for females ( } 18 \text { years) }\end{array}$ & 85.0 & $94.0^{* * *}$ & $96.0^{* * *}$ & $91.9^{* *+}$ \\
\hline Number of respondents & 371 & 789 & 404 & 385 \\
\hline \multicolumn{5}{|c|}{ Young women } \\
\hline $\begin{array}{l}\text { Aware of the legal minimum age at } \\
\text { marriage for males ( } 21 \text { years) }\end{array}$ & 50.6 & $76.8^{* \star *}$ & $79.1^{* \star *}$ & $74.4^{* *}$ \\
\hline $\begin{array}{l}\text { Aware of the legal minimum age at } \\
\text { marriage for females (18 years) }\end{array}$ & 82.1 & $94.7^{* * *}$ & $95.1^{* * *}$ & $94.3^{* * *}$ \\
\hline Number of respondents & 679 & 1,382 & 695 & 687 \\
\hline
\end{tabular}

Notes: Differences between control and intervention (combined) blocks, control and standalone blocks, and control and comprehensive blocks are significant at ${ }^{*} p<0.05,{ }^{* *} p<0.01,{ }^{* *} p<0.001$; Differences between standalone and comprehensive blocks are significant at ${ }^{+} p<0.05$.

\section{Awareness of risks associated with early childbearing}

In order to explore young people's awareness about the risks associated with early childbearing, we asked them whether there were any risks associated with giving birth at ages 15-16 to the mother or the child. Findings are presented in Tables 5.7 and 5.8 and suggest that most young people, particularly young women, were aware that early childbearing carried risks to both the mother and the child, although percentages reporting awareness of particular risks varied. Overall, respondents had a general awareness about risks, but relatively smaller proportions from both intervention and control sites could identify specific risks, including those related to maternal and infant mortality. Even so, notable differences were observed between those in intervention and control sites.

With regard to awareness of risks to the mother's health (Table 4.7), significantly more young men and women from intervention than control sites were aware that early pregnancy carried risks for the health of the mother (98\% versus $88 \% ; 99 \%$ versus $96 \%$, respectively). Those from intervention sites were more likely than those from control sites to cite general risks such as illhealth of the mother ( $80 \%$ versus $72 \%$ of young men; $87 \%$ versus $79 \%$ of young women) 
as well as several specific risks. For example, among young men, more of those from intervention than control sites knew that early childbearing was associated with increased risk of miscarriage or stillbirth (20\% versus 9\%), and among young women, more of those from intervention than control sites knew that childbearing at an early age could cause obstructed or prolonged labour (42\% versus 32\%), pregnancy related complications (51\% versus 39\%), and maternal mortality (39\% versus 32\%).

Differences between standalone and comprehensive intervention sites were not observed among young men, and were evident in just two instances among young women. In one, awareness of the elevated risks of maternal mortality associated with early childbearing was reported by more young women from standalone than comprehensive intervention sites (43\% versus 36\%). In the other, awareness of the links between early childbearing and obstructed labour was less likely to have been reported by those from standalone than comprehensive intervention sites (45\% versus 39\%).

Table 4.7: Awareness of risks for the mother associated with early childbearing Percentage of young men and women who reported different risks of early childbearing to the mother, according to study arm

\begin{tabular}{|c|c|c|c|c|}
\hline \multirow{2}{*}{$\begin{array}{l}\text { Awareness of risks associated with early } \\
\text { child bearing }\end{array}$} & \multirow[t]{2}{*}{ Control } & \multicolumn{3}{|c|}{ Intervention } \\
\hline & & Combined & Standalone & Comprehensive \\
\hline \multicolumn{5}{|c|}{ Young men } \\
\hline $\begin{array}{l}\text { Aware of risks that a girl may face if } \\
\text { she gives birth(at age 15-16) during her } \\
\text { adolescence }\end{array}$ & 88.2 & $97.5^{* * *}$ & $97.8^{* * *}$ & $97.2^{* * *}$ \\
\hline $\begin{array}{l}\text { Undeveloped reproductive organs leading } \\
\text { to prolonged or obstructed labour }\end{array}$ & 18.0 & 15.8 & 16.1 & 15.5 \\
\hline $\begin{array}{l}\text { Increased possibilities of complications } \\
\text { during pregnancy and labour/delivery }\end{array}$ & 38.8 & 43.2 & 45.2 & 41.0 \\
\hline Increased risk of maternal mortality & 59.8 & 62.0 & 62.5 & 61.4 \\
\hline Miscarriage/stillbirth & 9.2 & $19.9^{* * *}$ & $19.9^{* * *}$ & $19.8^{* * *}$ \\
\hline III health of the mother & 72.0 & $80.3^{* *}$ & $78.5^{*}$ & $82.2^{* * *}$ \\
\hline Anaemia in women & 0.0 & $2.4^{* *}$ & $1.5^{*}$ & $3.3^{* * *}$ \\
\hline Number of respondents & 371 & 789 & 404 & 385 \\
\hline \multicolumn{5}{|c|}{ Young women } \\
\hline $\begin{array}{l}\text { Aware of risks that a girl may face if } \\
\text { she gives birth(at age 15-16) during her } \\
\text { adolescence }\end{array}$ & 96.4 & $99.1^{* * *}$ & $99.6^{* * *}$ & $98.7^{* *}$ \\
\hline $\begin{array}{l}\text { Undeveloped reproductive organs leading } \\
\text { to prolonged or obstructed labour }\end{array}$ & 31.6 & $41.9^{* * *}$ & $38.8^{* *}$ & $44.9^{* * *+}$ \\
\hline $\begin{array}{l}\text { Increased possibilities of complications } \\
\text { during pregnancy and labour/delivery }\end{array}$ & 38.8 & $51.0^{* * *}$ & $50.2^{* \star *}$ & $51.7^{* * *}$ \\
\hline Increased risk of maternal mortality & 32.4 & $39.4^{* *}$ & $43.0^{* * *}$ & $35.7^{++}$ \\
\hline Miscarriage/stillbirth & 5.0 & 5.9 & 5.7 & 6.1 \\
\hline III health of the mother & 79.0 & $86.9^{* * *}$ & $86.6^{* \star *}$ & $87.1^{* * *}$ \\
\hline Anaemia in women & 0.3 & 0.8 & 1.2 & 0.4 \\
\hline Number of respondents & 679 & 1,382 & 695 & 687 \\
\hline
\end{tabular}

Notes: Differences between control and intervention (combined) blocks, control and standalone blocks, and control and comprehensive blocks are significant at ${ }^{*} p<0.05,{ }^{* *} p<0.01,{ }^{* \star *} p<0.001$; Differences between standalone and comprehensive blocks are significant at ${ }^{+} p<0.05,{ }^{++} p<0.01$. 
With regard to awareness of the risks of early childbearing to the child (Table 4.8), awareness levels were significantly greater among those in intervention than control sites (96\% versus $86 \%$ among young men, $97 \%$ versus $92 \%$ among young women). Significantly more young men and women from intervention than control sites reported that early childbearing increased risks of infant mortality (53\% versus $46 \%$ among young men; $37 \%$ versus $30 \%$ among young women), and that it would lead to the birth of a 'weak' child ( $85 \%$ versus $70 \%$ among young men and $90 \%$ versus $79 \%$ among young women). Young women from intervention sites were, moreover, more likely than those in control sites to report awareness of such risks to the child as low birth weight (33\% versus $21 \%$ ) and susceptibility to ill health(18\% versus $12 \%)$.

Differences between standalone and comprehensive intervention sites were insignificant among young men, but significant among young women. Significantly larger proportions of young women from standalone than comprehensive sites were aware that childbearing at any early age has one or more risks (98\% versus 96\%).

Table 4.8: Awareness of risks for the child associated with early childbearing

Percentage of young men and women who reported different risks of early childbearing to the child, according to study arm

\begin{tabular}{|c|c|c|c|c|}
\hline \multirow{2}{*}{$\begin{array}{l}\text { Awareness of risks that a child of an } \\
\text { adolescent mother may face }\end{array}$} & \multirow[t]{2}{*}{ Control } & \multicolumn{3}{|c|}{ Intervention } \\
\hline & & Combined & Standalone & Comprehensive \\
\hline \multicolumn{5}{|c|}{ Young men } \\
\hline $\begin{array}{l}\text { Aware of risks that a child of adolescent } \\
\text { mother may face }\end{array}$ & 85.8 & $96.3^{* * *}$ & $96.8^{* * *}$ & $95.8^{* * *}$ \\
\hline Increased possibility of underdeveloped child & 21.1 & 23.4 & 24.4 & 22.3 \\
\hline Premature birth/baby & 1.9 & 4.0 & 3.0 & $5.2^{*}$ \\
\hline Risk of weak child & 70.2 & $85.3^{* * *}$ & $84.4^{* * *}$ & $86.3^{* * *}$ \\
\hline Risk of infant death & 46.2 & $52.6^{*}$ & 51.1 & $54.2^{*}$ \\
\hline Low birth-weight baby & 25.8 & 28.2 & 27.6 & 28.9 \\
\hline Risk of a disabled child & 12.1 & $30.9^{* * *}$ & $28.9^{* \star *}$ & $33.2^{* * *}$ \\
\hline Child will be prone to illness & 2.1 & 1.8 & 2.3 & 1.3 \\
\hline Number of respondents & 371 & 789 & 404 & 385 \\
\hline \multicolumn{5}{|c|}{ Young women } \\
\hline $\begin{array}{l}\text { Aware of risks that a child of adolescent } \\
\text { mother may face }\end{array}$ & 92.4 & $97.3^{* * *}$ & $98.4^{* * *}$ & $96.2^{* *+}$ \\
\hline Increased possibility of underdeveloped child & 9.2 & 11.2 & 10.5 & 11.8 \\
\hline Premature birth/baby & 3.4 & 3.6 & 3.0 & 4.2 \\
\hline Risk of weak child & 79.3 & $89.5^{* * *}$ & $90.6^{* * *}$ & $88.5^{* * *}$ \\
\hline Risk of infant death & 29.5 & $37.4^{* * *}$ & $39.5^{* * *}$ & $35.2^{*}$ \\
\hline Low birth-weight baby & 20.7 & $32.7^{* \star *}$ & $32.0^{* * *}$ & $33.4^{* * *}$ \\
\hline Risk of a disabled child & 7.3 & $11.2^{* *}$ & $12.9^{* * *}$ & $9.5^{+}$ \\
\hline Child will be prone to illness & 12.0 & $17.8^{* *}$ & $16.0^{*}$ & $19.5^{* \star *}$ \\
\hline Number of respondents & 679 & 1,382 & 695 & 687 \\
\hline
\end{tabular}

Notes: Differences between control and intervention (combined) blocks, control and standalone blocks, and control and comprehensive blocks are significant at ${ }^{\star} p<0.05,{ }^{\star *} p<0.01,{ }^{\star \star \star} p<0.001$; Differences between standalone and comprehensive blocks are significant at ${ }^{+} p<0.05$. 


\section{Exposure to family life or sexuality education}

The survey also probed young people's exposure to family life or sexuality education. We inquired whether they had been exposed to family life or sexuality education in school or college or any other place (camps, the PRACHAR programme, etc.). Those reporting exposure to any family life or sexuality education programme were asked about the topics addressed during the family life/sexuality education sessions.

Findings reported in Table 4.9 show that, as expected, almost all those from intervention sites recalled the training they had received through the PRACHAR programme (99-100\%). In addition, a similar percentage of young women from intervention and control sites had received such education from schools, colleges, or other programmes (35-36\%). Among young men, in contrast, significantly more of those from intervention than control sites reported having attended such education programmes (50\% versus 38\%).

Topics about which young people had been oriented in any family life or sexuality education programme (including the PRACHAR project) also differed significantly between intervention and control sites. The large majority had been exposed to information about HIV/AIDS, namely, modes of transmission and ways of preventing HIV;and differences between intervention and control sites were negligible (94\%-97\% among young men for both issues; $80 \%-83 \%$ and $71 \%-78 \%$, respectively, among young women). Other topics were significantly more likely to have been reported by those in the intervention than control sites. For example, among young men, significantly more of those from intervention than control sites had been informed about nocturnal emission (90\% versus 32\%), how pregnancy happens (92\% versus 47\%) and boy-girl relationships (93\% versus 35\%). Among young women, a similar pattern was observed, with significantly larger proportions of those from intervention than control sites reporting that such topics as menstruation (100\% versus $81 \%$ ), how pregnancy happens (94\% versus $46 \%$ ), and boy-girl relationships (95\% versus $47 \%$ ) had been covered during the training programmes to which they had been exposed.

Differences between the standalone and comprehensive intervention sites were negligible, with one exception: more young men from standalone than comprehensive sites reported that they had been exposed to discussions about boy girl relationships (96\% versus $90 \%$ ).

Table 4.9: Exposure to family life or sexuality education programmes

Percentage of young men and women who had attended any family life or sexuality education programme, according to study arm

\begin{tabular}{|c|c|c|c|c|}
\hline \multirow{2}{*}{$\begin{array}{l}\text { Attendance at any family life or sexuality } \\
\text { education programme }\end{array}$} & \multirow[t]{2}{*}{ Control } & \multicolumn{3}{|c|}{ Intervention } \\
\hline & & Combined & Standalone & Comprehensive \\
\hline \multicolumn{5}{|c|}{ Young men } \\
\hline $\begin{array}{l}\text { Ever attended a family life/sexuality education } \\
\text { programme }\end{array}$ & 38.8 & $99.6^{* * *}$ & $99.8^{* * *}$ & $99.5^{* * *}$ \\
\hline $\begin{array}{l}\text { Ever attended a family life/sexuality education in } \\
\text { school/college/other places (e.g., camp) }\end{array}$ & 37.8 & $50.4^{* * *}$ & $50.8^{* *}$ & $49.9^{* *}$ \\
\hline Attended PRACHAR training programme & NA & 98.9 & 99.0 & 98.7 \\
\hline Number of respondents & 371 & 789 & 404 & 385 \\
\hline \multicolumn{5}{|l|}{$\begin{array}{l}\text { Topics covered in the course of the family } \\
\text { life/sexuality education or PRACHAR training } \\
\text { programme }\end{array}$} \\
\hline Modes of HIV transmission & 93.7 & 97.2 & 97.6 & 96.9 \\
\hline Ways of preventing HIV infection & 94.4 & 96.7 & 97.1 & 96.3 \\
\hline Nocturnal emission & 31.7 & $89.8^{* * *}$ & $92.3^{* * *}$ & $87.1^{* * *}$ \\
\hline Pregnancy & 47.2 & $92.0^{* * *}$ & $94.0^{* * *}$ & $89.8^{* * *}$ \\
\hline Boy-girl relationships & 34.9 & $93.1^{* * *}$ & $95.8^{* * *}$ & $90.1^{* *+}$ \\
\hline $\begin{array}{l}\text { Number who attended a family life/sexuality } \\
\text { education programme, including the PRACHAR } \\
\text { programme }\end{array}$ & 144 & 786 & 403 & 383 \\
\hline
\end{tabular}




\begin{tabular}{|c|c|c|c|c|}
\hline \multirow{2}{*}{$\begin{array}{l}\text { Attendance at any family life or sexuality } \\
\text { education programme }\end{array}$} & \multirow[t]{2}{*}{ Control } & \multicolumn{3}{|c|}{ Intervention } \\
\hline & & Combined & Standalone & Comprehensive \\
\hline \multicolumn{5}{|c|}{ Young women } \\
\hline $\begin{array}{l}\text { Ever attended a family life/sexuality education } \\
\text { programme }\end{array}$ & 38.9 & $99.9^{* * *}$ & $100.0^{* * *}$ & $99.7^{* * *}$ \\
\hline $\begin{array}{l}\text { Ever attended a family life/sexuality education in } \\
\text { school/college/other places (e.g., camp) }\end{array}$ & 35.0 & 35.5 & 36.9 & 34.2 \\
\hline Attended PRACHAR training programme & NA & 99.6 & 99.9 & 99.4 \\
\hline Number of respondents & 679 & 1,382 & 695 & 687 \\
\hline \multicolumn{5}{|l|}{$\begin{array}{l}\text { Topics covered in the course of the family } \\
\text { life/sexuality education or PRACHAR training } \\
\text { programme }\end{array}$} \\
\hline Modes of HIV transmission & 83.0 & 79.6 & 82.2 & 76.9 \\
\hline Ways of preventing HIV infection & 70.5 & 77.7 & 79.8 & 75.6 \\
\hline Menstruation & 80.6 & $99.5^{* * *}$ & $99.7^{* * *}$ & $99.3^{* * *}$ \\
\hline Pregnancy & 46.1 & $94.2^{* * *}$ & $96.1^{* * *}$ & $92.4^{* * *}$ \\
\hline Boy-girl relationships & 46.7 & $95.2^{* * *}$ & $96.0^{* * *}$ & $94.4^{* * *}$ \\
\hline $\begin{array}{l}\text { Number who attended a family life/sexuality } \\
\text { education programme, including the PRACHAR } \\
\text { programme }\end{array}$ & 264 & 1,380 & 695 & 685 \\
\hline
\end{tabular}

Notes: Differences between control and intervention (combined) blocks, control and standalone blocks, and control and comprehensive blocks are significant at ${ }^{\star} p<0.05,{ }^{* *} p<0.01,{ }^{\star *} p<0.001$. Differences between standalone and comprehensive blocks are significant at ${ }^{+} p<0.05$; NA: not asked.

\section{Multivariate analysis}

The associations between many of the variables discussed above and our outcome variables remained statistically significant even after adjustment for a range of potentially confounding covariates, namely, current age, educational attainment, work status, caste, religion, household wealth status, exposure to mass media, and access to a mobile phone (Table 4.10). Effects were strong and consistent among both young men and young women, irrespective of the indicator. For example, young men and women from intervention areas in general, and standalone and comprehensive areas in particular, were significantly more likely than those from comparison areas to report awareness of at least four modern spacing methods (odds ratios, 4.00 among young men, and 3.18 among young women), and at least one correct way of using oral contraceptive pills (odds ratios, 3.47 among young men, and 4.74 among young women). Effects on the contraceptive awareness index, likewise, remained significantly greater among those in intervention than comparison areas (regression coefficients ranged from 0.78 among young men to 1.07 among young women). Finally, the odds that a young man or woman had comprehensive knowledge about HIV/ AIDS were higher among those from intervention areas than those in comparison areas (odds ratios, 1.87 among young men, 2.97 among young women). We note that similarly significant associations were also observed when responses of those in the control sites were compared with those in standalone and comprehensive intervention sites, respectively.

As in the bivariate association, findings lend no support for the argument that those indicators of awareness differed among young men and women residing in standalone versus comprehensive project areas. 


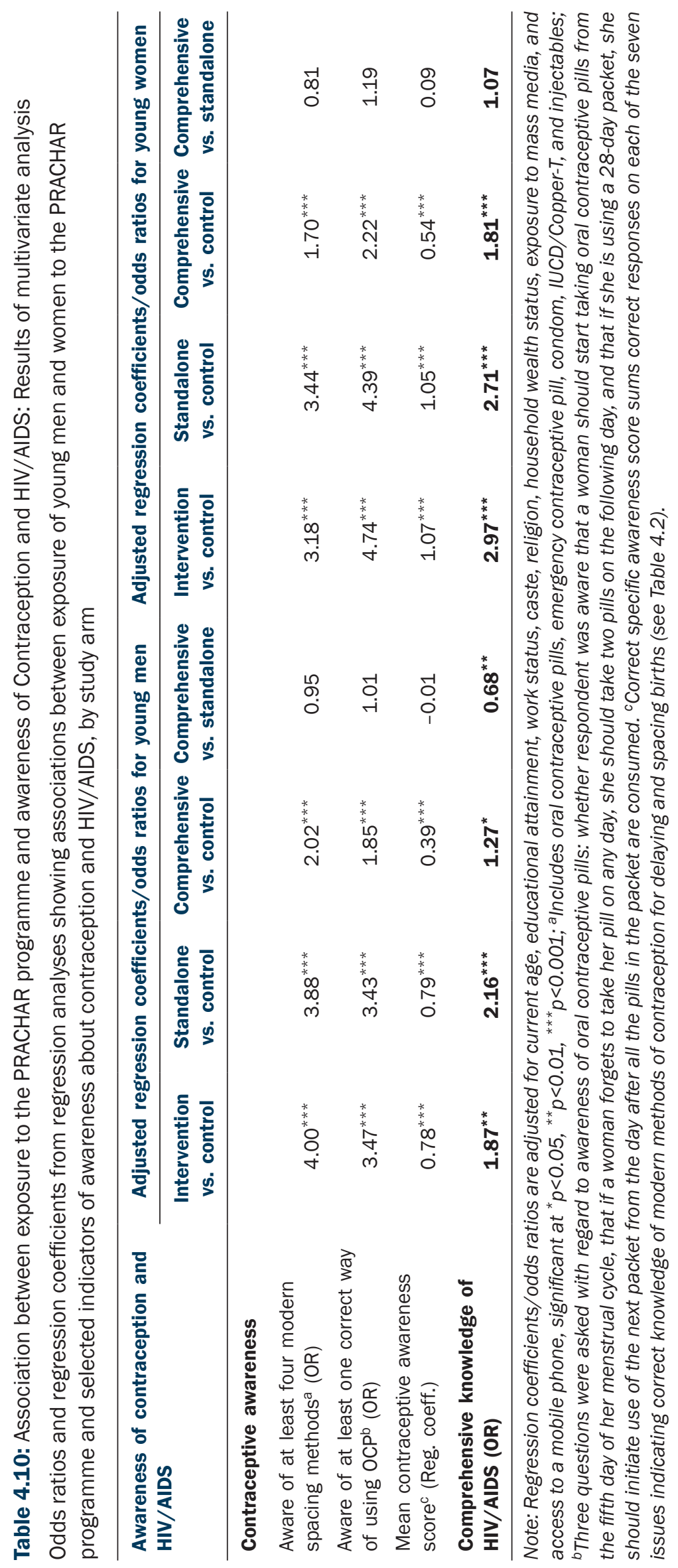




\section{Summary}

Findings confirm that young people exposed to the PRACHAR intervention were consistently and significantly more likely than those not exposed to be aware of all sexual and reproductive health matters about which we probed, namely, how pregnancy happens, ideal ages for initiation of pregnancy and ideal inter-birth intervals, contraception, HIV/AIDS, the legal minimum age at marriage for males and females, and the risks of early childbearing for mothers and infants. We note, in addition, that gender differences in young people's awareness of sexual and reproductive health was evident on several matters: by and large young women were better informed than young men about pregnancy-related matters and the risks associated with early childbearing, while young men were better informed than young women about HIV-related matters. Both young men and young women were similarly informed about the legal minimum age at marriage for males and females, and, in general, about contraception and the ideal pace of childbearing.

Multivariate analyses, controlling for a range of potentially confounding factors, reiterate that those in intervention areas, including both standalone and comprehensive project areas, were more likely to report awareness of contraception and HIV/AIDS than were those in the comparison areas. Findings therefore highlight that the consistently greater knowledge levels of those in intervention than control sites could not be attributed to differences in their background characteristics, and lend support to the argument that exposure to the PRACHAR programme did indeed have a sustained effect on trainees' knowledge of sexual and reproductive health matters.

With regard to exposure to family life or sexuality education, including the PRACHAR programme, as expected, almost all those in the intervention sites recalled their participation in the PRACHAR programme, and were thus exposed to one or more family life or sexuality education programme. In contrast, fewer than two in five young men and women from control sites had been so exposed. Among those exposed to any programme, almost all had been informed about HIV-related matters. However, those from intervention sites were significantly more likely than those from control sites to have been informed about such other key issues as nocturnal emission, menstruation, pregnancy, and boy-girl relationships.

Finally, we note that among those exposed to the intervention, differences between those in standalone versus comprehensive project sites were generally negligible on all issues about which we probed, but in the few instances in which differences were observed, those in the standalone intervention sites reported greater awareness than did those in comprehensive intervention sites. 


\section{Chapter 5}

\section{Age at marriage and marriage related planning}

The intervention programme aimed to prepare adolescents for a healthy transition to marriage and parenthood. Thus, it focused on enabling young people to delay marriage, as well as to negotiate with parents about doing so. This chapter focuses on respondents' age at marriage and marriage related planning. The intention is to assess the extent to which young men and women who had been exposed to the PRACHAR intervention were more likely, three to four years following the training, to have married at a later age and to have played a greater role in marriage related planning than were those in control sites, and the extent to which those in the two intervention arms differed from each other in these respects.

We note that because marital status was one of the factors used in the matching exercise to ensure that young people not exposed to the PRACHAR training programme resembled those so exposed, our study makes no claims to be able to compare percentages of young people married since 2010-11 in the two populations; however, since no effort was made to match samples by age at which young people married, findings are robust with regard to the age at marriage.

\section{Marriage age}

We note that all young men and women in our sample were unmarried and aged 13-21 in 2010-11, and hence findings on age at marriage cannot be compared with already available data on marriage age for rural Bihar or rural Gaya district in general. We present marriage age data in two ways: using life table techniques we present cumulative percentages of young men and women who married below specific ages $15,18,20$, and 21 , as well as the median age at marriage among those who were married at the time of our survey in 2014.

Table 5.1 presents cumulative percentages of young men and women who married at selected ages (among all in the sample-currently married or unmarried) calculated using life table technique, with censoring taking place at the time of interview for unmarried youth. Findings show that almost equal proportions of youth from intervention and control

Table 5.1: Cumulative percentages of young men and women who were married by specific ages, according to study arms

\begin{tabular}{|c|c|c|c|c|}
\hline \multirow[t]{2}{*}{ Age at first marriage } & \multirow[t]{2}{*}{ Control } & \multicolumn{3}{|c|}{ Intervention } \\
\hline & & Combined & Standalone & Comprehensive \\
\hline \multicolumn{5}{|c|}{ Young men } \\
\hline \multicolumn{5}{|c|}{ First married before age (years) ${ }^{1}$ : } \\
\hline 15 & 0.3 & 0.4 & 0.5 & 0.3 \\
\hline 18 & 5.8 & 6.5 & 7.3 & 5.5 \\
\hline 20 & 14.1 & 15.9 & 16.3 & 15.5 \\
\hline 21 & 20.8 & 19.6 & 19.3 & 19.8 \\
\hline Number of respondents & 371 & 789 & 404 & 385 \\
\hline \multicolumn{5}{|c|}{ Young women } \\
\hline \multicolumn{5}{|c|}{ First married before age (years) ${ }^{1}$ : } \\
\hline 15 & 4.8 & 3.9 & 3.6 & 4.3 \\
\hline 18 & 30.5 & 32.4 & 28.6 & 36.1 \\
\hline 20 & 51.8 & 56.5 & 49.1 & 64.5 \\
\hline 21 & 62.1 & 68.2 & 60.5 & 77.0 \\
\hline Number of respondents & 679 & 1,382 & 695 & 687 \\
\hline
\end{tabular}

Note: ${ }^{1}$ Calculated using life table techniques. 
arms got married by specific ages. For example, 21 and 20 percent of young men from control and intervention arms, respectively, had married before legal age of 21 . Similarly 31 percent and 32 percent of young women from control and intervention arms, respectively, got married by age 18-the legal minimum age at marriage for women in India.

Figure 5.1: Life table hazard curve showing probability of getting married at various ages for young men and women according to study arms
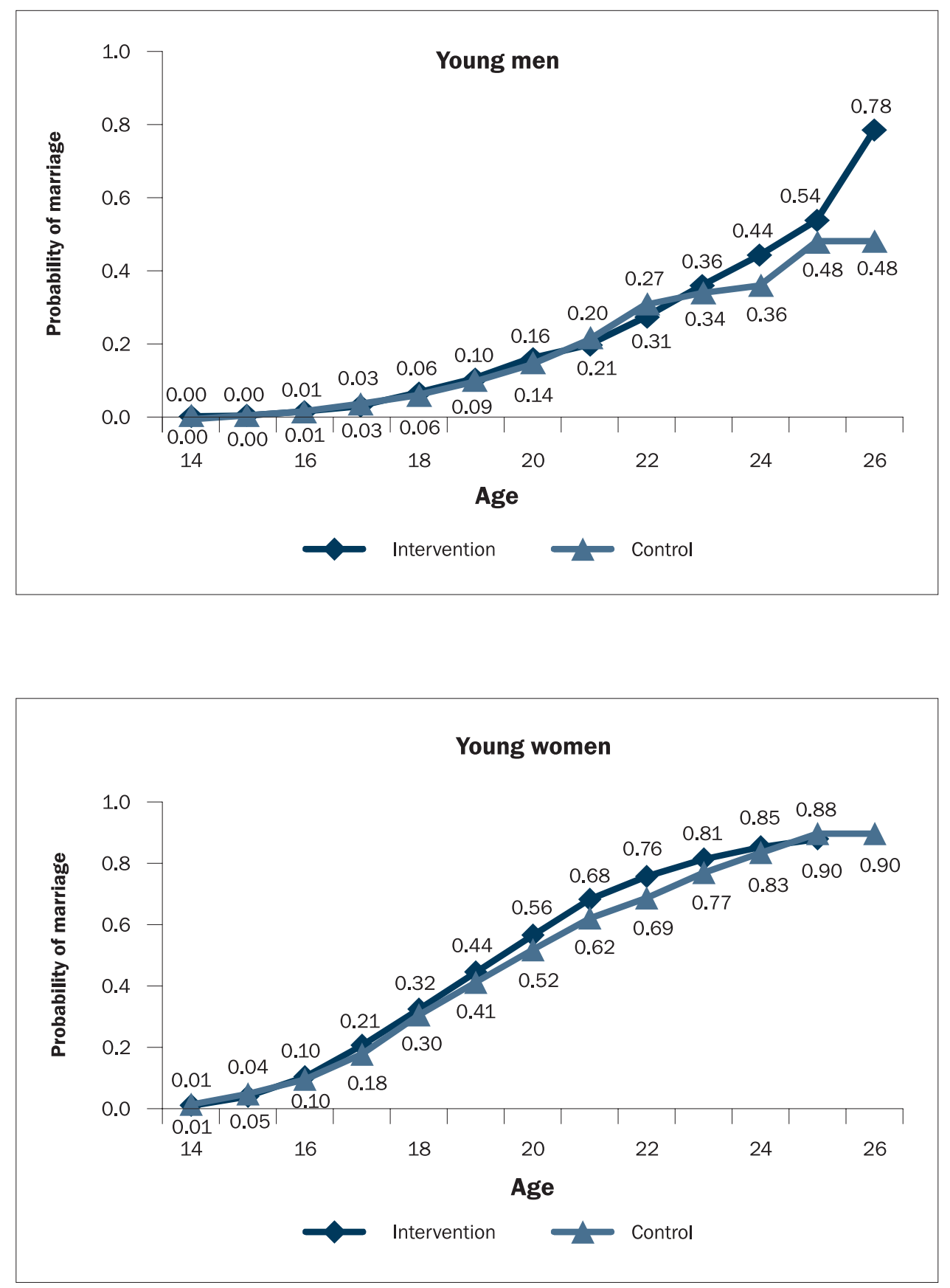

Figure 5.1 presents the cumulative probability of marrying at various ages, and shows equivalence of the probability of marrying between youth from intervention and control arms. This is also confirmed by a non-parametric Log-Rank test. In other words, there were no significant differences between the time when young women and men married in control and intervention sites. 


\section{Preferred and actual age at marriage, married youth}

In addition, we explored, among the married, their average age at marriage and percentages reporting that at the time of their marriage, they had wanted to delay their marriage (Table 5.2). Findings suggest that the median age at marriage was 19 years for both groups of young men, but a year older among young women in control sites than intervention sites (18 versus 17).

We hypothesised that young people trained in the intervention would be more likely than others to communicate and negotiate with parents to delay marriage, and therefore more likely to delay marriage than those in control sites. Findings do not support this hypothesis. Large proportions of those from both intervention and control sites had wanted to delay their marriage but, in both groups, were unsuccessful in doing so. While differences between young men from control and intervention sites were negligible (82-85\%), among young women, significantly more from intervention than control sites considered that they had married too soon (85\% versus $77 \%)$. Differences in marriage age preferences between those in comprehensive and standalone intervention sites were, once again, negligible.

Table 5.2: Preferred and actual age at marriage among the married

Median age at marriage of young men and women and percentage of young men and women who had wanted to marry later, according to study arms

\begin{tabular}{lcccc}
\hline Preferred and actual age at marriage & Control & \multicolumn{3}{c}{ Intervention } \\
\cline { 3 - 5 } & \multicolumn{2}{c}{ Combined } & Standalone & Comprehensive \\
\hline & \multicolumn{2}{c}{ Married young men } \\
\hline Median age at marriage & 19 & 19 & 19 & 19 \\
Percentage who wanted to marry later & 81.6 & 84.5 & 84.4 & 84.6 \\
Number of married young men & $\mathbf{7 2}$ & $\mathbf{1 4 0}$ & $\mathbf{7 0}$ & $\mathbf{7 0}$ \\
\hline & Married young women & & 17 \\
\hline Median age at marriage & 18 & 17 & 18 & $87.0^{* * *}$ \\
Percentage who wanted to marry later & 76.7 & $84.6^{* *}$ & 81.8 & $\mathbf{3 6 2}$ \\
Number of married young women & $\mathbf{3 2 9}$ & $\mathbf{6 8 3}$ & $\mathbf{3 2 1}$ & \\
\hline
\end{tabular}

Notes: Differences between control and intervention (combined) blocks, control and standalone blocks, and control and comprehensive blocks are significant at ${ }^{* *} p<0.01,{ }^{* *} p<0.001$.

\section{Marriage related planning among the unmarried}

In order to assess the marriage planning experiences of unmarried young people, and the extent to which they were involved in such planning, the survey inquired from the unmarried about whether marriage related planning had been initiated, and their own involvement in the planning process. Findings are presented in Table 5.3. They suggest that marriage related discussions had been initiated for sizeable proportions-between one-sixth and one-fifth of young men, and between two-fifths and one-half of young women. About ten percent of young men, and 15-19 percent of young women reported, moreover, that a potential spouse had been proposed for them, and two percent and 6-7 percent, respectively, reported that their marriage had been fixed, that is, that they were engaged to be married. Differences between young men and women, respectively, in intervention and control sites, were negligible, and likewise, among those exposed to the intervention, differences between those in comprehensive and standalone intervention sites were also negligible.

The unmarried were also probed about whether, once married, they wished to practise contraception to delay their first pregnancy. Findings suggest significant differences between the intentions of young people who were exposed to the intervention and those who were from the control sites. For example, among those in intervention sites, 94 percent of young men and 90 percent of young women intended to delay their first pregnancy; in comparison, significantly fewer of their counterparts from control sites intended to do so ( $81 \%$ and $77 \%$, respectively). 
Table 5.3: Marriage related planning among unmarried young people

Median age at which youth would like to marry and percentage of unmarried young men and women reporting that marriage related planning had been initiated, that a potential spouse had been proposed, that their marriage had been fixed, and that they wanted to delay their first pregnancy, according to study arm

\begin{tabular}{|c|c|c|c|c|}
\hline \multirow[t]{2}{*}{ Indicator of marriage planning } & \multirow[t]{2}{*}{ Control } & \multicolumn{3}{|c|}{ Intervention } \\
\hline & & Combined & Standalone & Comprehensive \\
\hline \multicolumn{5}{|c|}{ Unmarried young men } \\
\hline $\begin{array}{l}\text { Age at which unmarried respondents would like } \\
\text { to marry (median) }\end{array}$ & 25.0 & 25.0 & 25.0 & 25.0 \\
\hline Parents initiated discussion on marriage (\%) & 21.3 & 17.4 & 16.2 & 18.7 \\
\hline $\begin{array}{l}\text { A boy/girl had ever been proposed to } \\
\text { respondent (\%) }\end{array}$ & 9.4 & 9.3 & 9.3 & 9.3 \\
\hline $\begin{array}{l}\text { Respondent got engaged or marriage had been } \\
\text { fixed (\%) }\end{array}$ & 2.1 & 2.0 & 2.7 & 1.3 \\
\hline $\begin{array}{l}\text { Unmarried men who intended to practice } \\
\text { contraception to delay their first pregnancy (\%) }\end{array}$ & 80.8 & $93.8^{* * *}$ & $92.8^{* \star *}$ & $95.0^{* * *}$ \\
\hline Number of respondents & 299 & 649 & 334 & 315 \\
\hline \multicolumn{5}{|c|}{ Unmarried young women } \\
\hline $\begin{array}{l}\text { Age at which unmarried respondents would like } \\
\text { to marry (median) }\end{array}$ & 21.0 & 21.0 & 21.0 & 21.0 \\
\hline Parents initiated discussion on marriage (\%) & 40.0 & 47.2 & 48.6 & 45.5 \\
\hline $\begin{array}{l}\text { A boy/girl had ever been proposed to } \\
\text { respondent (\%) }\end{array}$ & 15.4 & 19.4 & 18.9 & 20.0 \\
\hline $\begin{array}{l}\text { Respondent got engaged or marriage had been } \\
\text { fixed }(\%)\end{array}$ & 6.6 & 5.6 & 5.4 & 5.9 \\
\hline $\begin{array}{l}\text { Unmarried women who intended to practice } \\
\text { contraception to delay their first pregnancy (\%) }\end{array}$ & 77.2 & $90.2^{* \star *}$ & $92.5^{* * *}$ & $87.6^{* \star *+}$ \\
\hline Number of respondents & 350 & 699 & 374 & 325 \\
\hline
\end{tabular}

Notes: Differences between control and intervention (combined) blocks, control and standalone blocks, and control and comprehensive blocks are significant at ${ }^{* * *} p<0.001$; Differences between standalone and comprehensive blocks are significant at ${ }^{+} p<0.05$.

\section{Marriage related planning among the married}

Married young people were asked a somewhat different set of questions regarding marriage related planning. They were asked about whether they had been involved in the selection of their spouse, and if they had ever met or been acquainted with their spouse before marriage. Findings, presented in Table 5.4, suggest that for the most part, young people's marriage was arranged by their parents, with no involvement of the young person him- or herself, and young women were particularly unlikely to report any involvement in marriage related decisions. Differences between intervention and control sites were not observed: 47-52 percent of young men, and 72-73 percent of young women reported that they had no say whatsoever in the selection of their spouse, and fewer-44-48 percent of young men and 24-25 percent of young women reported that their marriage had been fixed by their parents but they had been consulted; just 4-5 percent of young men, and three percent of young women reported that they had selected their own spouse. As a result, large majorities of married young people whose marriage was arranged reported that they had met their spouse for the first time on the wedding day (87-89\% of young men; $71-77 \%$ of young women), and hardly any reported that they were well acquainted with their spouse before marriage $(0-3 \%$ and $5-6 \%$ of young men and women, respectively). Differences between intervention and control sites were negligible. As in the case of the unmarried, no differences were discerned between respondents from the two intervention sites. 
Table 5.4: Marriage related planning among married young people

Percent distribution of young men and women by their involvement in marriage related planning and pre-marital acquaintance with their spouse, according to study arm

\begin{tabular}{|c|c|c|c|c|}
\hline \multirow{2}{*}{$\begin{array}{l}\text { Youth involvement in marriage-related } \\
\text { planning }\end{array}$} & \multirow[t]{2}{*}{ Control } & \multicolumn{3}{|c|}{ Intervention } \\
\hline & & Intervention & Standalone & Comprehensive \\
\hline \multicolumn{5}{|c|}{ Currently married young men } \\
\hline $\begin{array}{l}\text { Marriage fixed by respondent himself (love } \\
\text { marriage) }\end{array}$ & 4.0 & 5.0 & 5.9 & 4.1 \\
\hline $\begin{array}{l}\text { Marriage arranged by parents, with } \\
\text { respondent's approval of choice of spouse }\end{array}$ & 44.0 & 48.0 & 46.1 & 50.0 \\
\hline $\begin{array}{l}\text { Marriage fixed by parents without respondent's } \\
\text { approval }\end{array}$ & 51.9 & 47.0 & 48.0 & 46.0 \\
\hline Number of respondents & 71 & 137 & 67 & 70 \\
\hline \multicolumn{5}{|l|}{ Acquaintance with spouse before marriage } \\
\hline Did not know at all/met on wedding day & 86.6 & 88.5 & 85.7 & 91.3 \\
\hline Knew somewhat & 10.2 & 11.5 & 14.3 & 8.7 \\
\hline Knew very well & 3.2 & 0.0 & 0.0 & 0.0 \\
\hline $\begin{array}{l}\text { Number of respondents whose marriage was } \\
\text { arranged }\end{array}$ & 68 & 130 & 63 & 67 \\
\hline \multicolumn{5}{|c|}{ Currently married young women } \\
\hline $\begin{array}{l}\text { Marriage fixed by respondent himself (love } \\
\text { marriage) }\end{array}$ & 2.7 & 2.6 & 4.1 & 1.4 \\
\hline $\begin{array}{l}\text { Marriage arranged by parents, with } \\
\text { respondent's approval of choice of spouse }\end{array}$ & 25.0 & 24.3 & 27.3 & 21.6 \\
\hline $\begin{array}{l}\text { Marriage fixed by parents without respondent's } \\
\text { approval }\end{array}$ & 72.3 & 73.1 & 68.6 & 77.0 \\
\hline Number of respondents & 329 & 679 & 320 & 359 \\
\hline \multicolumn{5}{|l|}{ Acquaintance with spouse before marriage } \\
\hline Did not know at all/met on wedding day & 71.2 & 76.7 & 75.5 & 77.7 \\
\hline Knew somewhat & 23.8 & 16.9 & 18.3 & 15.8 \\
\hline Knew very well & 5.0 & 6.4 & 6.3 & 6.5 \\
\hline $\begin{array}{l}\text { Number of respondents whose marriage was } \\
\text { arranged }\end{array}$ & 320 & 661 & 307 & 354 \\
\hline
\end{tabular}

\section{Summary}

In contrast to the findings of earlier chapters, there is no evidence that young people's exposure to the PRACHAR intervention succeeded in delaying marriage or enhancing young people's participation in marriage-related planning. Indeed, about one-fifth of young men and one-third of young women had married before the minimum legal age at marriage for males and females, respectively. In addition, 4-5 percent of young women had married before they were 15 years old. Median ages at marriage ranged from 19 years among young men and 17 among young women. Differences between intervention and control sites were not observed. 
Among the unmarried, marriage related discussions had been initiated for between one-sixth and one-fifth of young men, and between two-fifths and one-half of young women. Sizeable minorities (10\% of young men, and 15-19\% of young women) reported, moreover, that a potential spouse had been proposed for them, and a few (2\% and $6-7 \%$, respectively) reported that their marriage had been fixed, that is, that they were engaged to be married.

For married young people, marriages had largely been arranged by parents with no involvement of the young person, and this was particularly widespread among young women. About half of young men, and almost three-quarters of young women had no say in the selection of their spouse; fewer than five percent had selected their own spouse. Most young people met their spouse for the first time on the wedding day and hardly any reported that they were well acquainted with their spouse before marriage. Differences in marriage preparation-related indicators between intervention and control sites were negligible for both married and unmarried young men and women.

In two marriage related indicators, those in intervention sites reported significantly different perceptions from those in control sites. For one, while large proportions of married young men and women in both sites had wanted to delay their marriage but were unsuccessful in doing so, among young women, but not young men, significantly more of those from intervention than control sites had wanted to but had not succeeded in delaying their marriage. Second, among the unmarried, while large proportions of young men and young women reported an intention to practise contraception once married to delay their first pregnancy, significantly more of both young men and young women from intervention than control sites reported such an intention.

Finally, we note that among those exposed to the intervention, differences between those in standalone versus comprehensive project sites were generally negligible on both marriage age and all other marriage related indicators. 


\section{Chapter 6}

\section{Contraceptive practice in pre-marital and extra-marital relations and within marriage}

The intervention programme aimed to prepare adolescents for a healthy transition to sexual life, marriage, and parenthood. As such, it included a focus on meeting young people's demand for contraception. We have already seen in Chapter 4 that young people from intervention sites were far better informed about contraception than their counterparts in control sites. This chapter focuses on the contraceptive practices of those in intervention and control sites-among both those who reported pre-marital sexual relations, and those who had married in the period 2010-11 to 2014. The intention is to assess the extent to which young men and women who had been exposed to the PRACHAR intervention were more likely, three to four years following the training, to have experienced safe pre-marital (or extra-marital) sexual relations, and to have been informed and prepared about sexual matters and contraceptive options prior to marriage than those in control sites, and the extent to which those in the two intervention arms differed from each other in these respects.

\section{Contraception in pre-marital and extra-marital sexual relations}

Young people who had engaged in pre-marital or extra-marital sex were probed about whether they had practised contraception the last time they had engaged in pre-marital or extra-marital sexual relations, and whether they had consistently used a condom in all pre-marital and extra-marital sexual encounters. We acknowledge that numbers are small and thus findings are illustrative and not conclusive. Findings suggest that sexual relations were risky for considerable proportions of sexually experienced young men and women from both intervention and control settings (Table 6.1).

Table 6.1: Extent of safe pre-marital and extra-marital sexual relations experienced by young people reporting any pre-marital or extra-marital sexual experiences

Percentage of young men and women who had experienced pre-marital and extra-marital sexual relations reporting contraceptive use in the last sexual encounter, and consistent condom use in all sexual encounters, according to study arm

\begin{tabular}{|c|c|c|c|c|}
\hline \multirow[t]{2}{*}{ Practice of safe sex } & \multirow[t]{2}{*}{ Control } & \multicolumn{3}{|c|}{ Intervention } \\
\hline & & Combined & Stand-alone & Comprehensive \\
\hline \multicolumn{5}{|c|}{ Young men } \\
\hline Mean age at first pre-marital sexual encounter ${ }^{1}$ & 16.9 & 16.6 & 16.5 & 16.7 \\
\hline $\begin{array}{l}\text { Number who reported pre-marital sexual } \\
\text { relationships }\end{array}$ & 81 & 253 & 128 & 125 \\
\hline Had engaged in sex with more than one partner ${ }^{2}$ & 35.0 & 46.4 & 46.7 & 46.0 \\
\hline \multicolumn{5}{|l|}{$\begin{array}{l}\text { Use of contraception in last pre-marital or } \\
\text { extra-marital sexual encounter }\end{array}$} \\
\hline Used any method & 29.0 & $46.0^{* *}$ & $43.0^{* *}$ & $49.1^{* *}$ \\
\hline Used a modern method & 29.0 & $45.2^{* *}$ & 41.5 & $49.1^{* *}$ \\
\hline Used a condom & 29.0 & $42.5^{*}$ & 37.7 & $47.7^{* *}$ \\
\hline Used a traditional method & 0.0 & 1.2 & 1.5 & 0.8 \\
\hline Consistent condom use with all sexual partners ${ }^{3}$ & 16.3 & 25.9 & 25.1 & 26.7 \\
\hline $\begin{array}{l}\text { Number reporting a pre-/extra-marital sexual } \\
\text { relationship }\end{array}$ & 86 & 265 & 135 & 130 \\
\hline
\end{tabular}




\begin{tabular}{lcccc}
\hline Practice of safe sex & Control & \multicolumn{3}{c}{ Intervention } \\
\cline { 3 - 5 } & & Combined & Stand-alone & Comprehensive \\
\hline & Young women & & & \\
\hline Mean age at first pre-marital sex & $\mathbf{1 6 . 1 )}$ & $\mathbf{1 6 . 3}$ & $\mathbf{( 1 6 . 7 )}$ & $\mathbf{1 6 . 0}$ \\
$\begin{array}{l}\text { Number who reported pre-marital sexual } \\
\text { relationship }\end{array}$ & $\mathbf{2 9}$ & $\mathbf{1 0 2}$ & $\mathbf{4 7}$ & $\mathbf{5 4}$ \\
Had engaged in sex with more than one partner & & 12.2 & $(12.6)$ & 12.0 \\
$\begin{array}{l}\text { Use of contraception in last pre-marital or } \\
\text { extra-marital sexual encounter }\end{array}$ & $(8.9)$ & & & \\
$\begin{array}{l}\text { Used any method } \\
\text { Used a modern method }\end{array}$ & $(12.4)$ & $41.4^{* *}$ & $\left(46.7^{* * *}\right)$ & $37.5^{* *}$ \\
$\begin{array}{l}\text { Used a condom } \\
\text { Used a traditional method }\end{array}$ & $(9.2)$ & $38.9^{* *}$ & $\left(44.7^{* * *}\right)$ & $34.6^{* *}$ \\
$\begin{array}{l}\text { Consistent condom use with all sexual partners } \\
\text { N }\end{array}$ & $(9.2)$ & $37.2^{* *}$ & $\left(42.7^{* * *}\right)$ & $33.1^{* *}$ \\
$\begin{array}{l}\text { Number reporting a pre-/extramarital sexual } \\
\text { relationship }\end{array}$ & $(3.2)$ & 2.6 & $(2.0)$ & 3.0 \\
\hline
\end{tabular}

Notes: ${ }^{1}$ Mean age at first sex is computed for those who gave a numeric response for age at first premarital sex; ${ }^{2}$ Multiple partners for married respondents means two or more sexual partner excluding spouse; ${ }^{3}$ Respondents who reported condom use in most recent pre-marital/extra-martial sexual relationship with any of the partner were also asked if they use a condom every time they had sexual relations with any of the partners; ( ) Based on 25-49 unweighted cases; Differences between control and intervention (combined) blocks, control and standalone blocks, and control and comprehensive blocks are significant at * $p<0.05$, ${ }^{* *} p<0.01,{ }^{* *} p<0.001$.

Findings show that among those reporting pre-marital or extra-marital sexual experience, young men in intervention sites were significantly more likely than those in control sites to have used contraception in their last sexual encounter (46\% versus $29 \%$ ); they were also more likely to have used a condom consistently in all their sexual encounters (26\% versus $16 \%$ ). Likewise, young women from intervention sites who had experienced pre-marital or extra-marital sexual relations were significantly more likely than those from control sites to have practised contraception in their last pre-marital or extra-marital sexual encounter ( $41 \%$ versus $12 \%$ ) and to have used a condom consistently in all their sexual encounters ( $24 \%$ versus $3 \%)$.

\section{Pre-marriage awareness of sexual and contraceptive matters and preparedness for married life}

Given that the PRACHAR intervention aimed to prepare adolescents for married life, the survey explored whether, at the time of marriage, young people were aware of what to expect of married life, and whether someone had discussed with them the importance of delaying the first pregnancy. Findings presented in Table 6.2 suggest that far more young women than young men reported that in the early days of their marriage they knew what to expect of married life, specifically about husband-wife relationships, sex and pregnancy, relationship with in-laws, and so on. However, differences between those in intervention and control sites were insignificant for both young women and young men ( $86-87 \%$ of young women; $49 \%$ and $22 \%$ of young men in intervention and control sites, respectively).

Young people were also asked whether someone had discussed with them the importance of delaying the first pregnancy early in married life. Differences between young people in intervention and control sites were significant: among young men, 39 percent of those in intervention sites reported that someone had discussed this issue with them, compared to significantly fewer young men in control sites (14\%). Among young women, likewise, 34 percent of those in intervention sites, compared to significantly fewer, 20 percent of those in control sites, so reported.

Finally, we inquired about young people's intentions, at the time of marriage, about delaying the first pregnancy. While large proportions of all young men and women reported that they had wanted to practise contraception to delay their first birth, significantly more of those from intervention than control sites so desired. Among young men, 
Table 6.2: Preparedness for married life

Percentage of currently married young men and women by different indicators of preparedness for married life, according to study arm

\begin{tabular}{|c|c|c|c|c|}
\hline \multirow[t]{2}{*}{ Indicator of marriage preparedness } & \multirow[t]{2}{*}{ Control } & \multicolumn{3}{|c|}{ Intervention } \\
\hline & & Combined & Standalone & Comprehensive \\
\hline \multicolumn{5}{|c|}{ Currently married young men } \\
\hline $\begin{array}{l}\% \text { respondents who knew what to expect of } \\
\text { married life }\end{array}$ & 22.0 & 49.4 & 51.8 & 46.8 \\
\hline $\begin{array}{l}\% \text { respondents who reported that someone had } \\
\text { discussed the importance of delaying the first } \\
\text { pregnancy with them }\end{array}$ & 14.2 & $39.1^{* * *}$ & $40.2^{* * *}$ & $38.0^{* *}$ \\
\hline $\begin{array}{l}\% \text { respondents who wanted to practise } \\
\text { contraception to delay the first pregnancy }\end{array}$ & 56.5 & $76.2^{* *}$ & $82.7^{* *}$ & 69.8 \\
\hline Number of currently married respondents & 69 & 105 & 52 & 53 \\
\hline \multicolumn{5}{|c|}{ Currently married young women } \\
\hline $\begin{array}{l}\% \text { respondents who knew what to expect of } \\
\text { married life }\end{array}$ & 85.8 & 86.9 & 86.3 & 87.5 \\
\hline $\begin{array}{l}\% \text { respondents who reported that someone had } \\
\text { discussed the importance of delaying the first } \\
\text { pregnancy with them }\end{array}$ & 20.1 & $33.8^{* * *}$ & $33.3^{* * *}$ & $34.3^{* * *}$ \\
\hline $\begin{array}{l}\% \text { respondents who wanted to practise } \\
\text { contraception to delay the first pregnancy }\end{array}$ & 71.0 & $81.1^{* * *}$ & $83.7^{* * *}$ & $78.8^{*}$ \\
\hline Number of currently married respondents & 328 & 617 & 295 & 322 \\
\hline
\end{tabular}

Notes: Differences between control and intervention (combined) blocks, control and standalone blocks, and control and comprehensive blocks are significant at ${ }^{\star} p<0.05,{ }^{* *} p<0.01,{ }^{\star * *} p<0.001$.

while three-quarters of those from intervention sites wished to delay their first pregnancy (76\%), fewer than three-fifths of those from control sites had so desired (57\%). Among young women, corresponding percentages were 81 and 71.

\section{Contraceptive practice in married life}

In this section, we explore contraceptive practices among married young men and women at several stages of their married life: at the time of the interview, preceding the first birth, and following the first birth. We also explore, among those who wanted but failed to practise contraception to postpone the first pregnancy, the challenges they faced in meeting their desire to do so.

\section{Current practice of contraception}

Contraceptive practice at the time of the interview (Table 6.3) among married men and women suggests that exposure to the PRACHAR training programme had little effect on contraceptive prevalence among young men, but a strong effect among young women. Among young men, for example, 34 percent and 33 percent of those from intervention and control sites, respectively, reported contraceptive practice. Those in standalone and comprehensive intervention areas showed that slightly fewer (31\%) and slightly more (38\%), respectively, of young men were practising contraception at the time of the interview. Differences were similarly negligible with regard to the practice of modern spacing methods. 
Among young women, differences between those exposed to the PRACHAR training programme and those in comparison sites were significant. While just 14 percent of married young women from control sites had practised contraception, 25 percent of those from intervention sites had done so; and while just seven percent of those from control sites had used a modern spacing method, 15 percent of those exposed to the intervention had done so.

Table 6.3: Percentage of currently married young men and women reporting current contraceptive use by parity according to study arm

\begin{tabular}{|c|c|c|c|c|c|c|c|c|}
\hline \multirow{3}{*}{$\begin{array}{l}\text { Current } \\
\text { contraceptive use }\end{array}$} & \multicolumn{4}{|c|}{ Currently married young men } & \multicolumn{4}{|c|}{ Currently married young women } \\
\hline & \multirow[t]{2}{*}{ Control } & \multicolumn{3}{|c|}{ Intervention } & \multirow[t]{2}{*}{ Control } & \multicolumn{3}{|c|}{ Intervention } \\
\hline & & Combined & Standalone & Comprehensive & & Combined & Standalone & Comprehensive \\
\hline Any method & 33.4 & 34.2 & 30.9 & 37.5 & 14.3 & $25.1^{* * *}$ & $23.7^{* *}$ & $26.4^{* * *}$ \\
\hline $\begin{array}{l}\text { Any modern } \\
\text { spacing method }\end{array}$ & 17.5 & 22.7 & 25.2 & 20.1 & 7.3 & $14.7^{*}$ & 13.5 & $15.8^{* *}$ \\
\hline $\begin{array}{l}\text { Number of } \\
\text { currently married } \\
\text { respondents }\end{array}$ & 69 & 105 & 52 & 53 & 328 & 617 & 295 & 322 \\
\hline
\end{tabular}

Notes: Includes oral contraceptive pills, emergency contraceptive pill, condom, IUCD/Copper-T, and injectables; Differences between control and standalone blocks are significant at ${ }^{*} p<0.05,{ }^{* *} p<0.01,{ }^{* \star *} p<0.001$; Differences between control and comprehensive blocks are significant at ${ }^{*} p<0.05,{ }^{* *} p<0.01,{ }^{* *} p<0.001$; Differences between control and intervention (combined) block are significant at ${ }^{*} p<0.05,{ }^{* *} p<0.01,{ }^{* *} p<0.001$.

\section{Contraception to postpone the first birth}

The intervention had sensitised adolescents about the importance of delaying the first pregnancy following marriage, and about practising contraception to do so, and the survey probed the extent to which those exposed to the intervention had acted upon this information. We note that our measure of contraception to delay the first pregnancy is conservative: women experiencing their first pregnancy at the time of the interview had not been probed about prior contraception and are included as non-contraceptors in our assessment of the percentage who practised contraception prior to the first pregnancy. Findings, presented in Table 6.4, highlight that the practice of contraception prior to the first pregnancy remains limited. However, young women, but not young men, in intervention sites were significantly more likely than their counterparts in control sites to have practised contraception to delay the first birth (18\% versus $10 \%$ of young women, $22 \%$ versus $17 \%$ among young men).

Restricting the analysis to young men and women at parity zero gives a similar picture. While young men from intervention sites were about as likely as those from control sites to report contraceptive practice, significantly more young women at parity 0 from the intervention arm than the control arm had adopted contraception to delay their first birth (18\% versus $9 \%)$.

Leading methods for delaying the first pregnancy were condoms and/or traditional methods, reported by both young men and young women; a small proportion of young women also reported the use of oral contraceptives (Panel A). Differences between young men in intervention and control sites were negligible (13\% versus $10 \%$ for condoms; $8 \%$ versus $10 \%$ for traditional methods). In contrast, among young women, those from intervention sites were significantly more likely than their counterparts from control sites to have used condoms ( $11 \%$ versus $5 \%$ ) and oral contraceptives ( $2 \%$ versus $<1 \%)$; use of traditional methods was similar among both groups $(5 \%-7 \%)$. Differences in modern spacing method use between those at parity 0 in intervention and control sites were, however, insignificant for both young men ( $8 \%$ versus $10 \%$ ) and young women (10\% versus $5 \%$ ).

As evident from Table 6.5, large proportions of women with one or more births had wanted to postpone their first pregnancy but had failed to do so; even so, significantly fewer young women from intervention than control sites who had wanted to postpone their first birth reported that they had failed to do so ( $79 \%$ and $88 \%$, respectively). In 
Table 6.4: Contraception to delay the first birth

Percentage of all married young men and women and those at parity 0 reporting contraceptive use ${ }^{1}$ to delay first birth, and contraceptive method used, according to study arm

\begin{tabular}{|c|c|c|c|c|}
\hline \multirow[t]{2}{*}{ Use of contraception to delay first birth } & \multirow[t]{2}{*}{ Control } & \multicolumn{3}{|c|}{ Intervention } \\
\hline & & Combined & Standalone & Comprehensive \\
\hline \multicolumn{5}{|c|}{ Currently married young men } \\
\hline \multicolumn{5}{|l|}{ All currently married young men } \\
\hline $\begin{array}{l}\text { Ever used a contraceptive method to delay first } \\
\text { birth (\%) }\end{array}$ & 17.3 & 21.6 & 19.2 & 24.1 \\
\hline $\begin{array}{l}\text { Ever used a modern contraceptive method to } \\
\text { delay first birth (\%) }\end{array}$ & 10.0 & 13.3 & 13.5 & 13.0 \\
\hline Used a condom to delay first birth (\%) & 10.0 & 13.3 & 13.5 & 13.0 \\
\hline Used a traditional method to delay first birth (\%) & 10.3 & 8.4 & 5.7 & 11.1 \\
\hline Number of currently married respondents & 69 & 105 & 52 & 53 \\
\hline \multicolumn{5}{|l|}{ Currently married men at parity 0} \\
\hline Any method & $(25.6)$ & 31.5 & $(24.2)$ & $(38.4)$ \\
\hline Any modern spacing method ${ }^{a}$ & $(9.7)$ & 18.7 & $(16.3)$ & $(20.9)$ \\
\hline Number of currently married respondents & 31 & 53 & 25 & 28 \\
\hline
\end{tabular}

Currently married young women ${ }^{1}$

\section{All currently married young women}

Ever used a contraceptive method to delay first birth (\%)

$\begin{array}{rrrc}9.8 & 18.4^{* * *} & 18.9^{* * *} & 18.0^{* * *} \\ 4.9 & 12.0^{* * *} & 10.8^{* *} & 13.0^{* * *} \\ 0.3 & 1.8^{*} & 1.4 & 2.2^{*} \\ 4.9 & 10.5^{* *} & 9.8^{*} & 11.1^{* *} \\ 5.2 & & & \\ \mathbf{3 2 8} & 7.1 & 8.8 & 5.6 \\ & \mathbf{6 1 7} & \mathbf{2 9 5} & \mathbf{3 2 2} \\ 9.2 & & & \\ 5.2 & 18.3^{* *} & 18.8^{*} & 17.8^{*} \\ \mathbf{1 5 4} & 9.6 & 8.5 & 10.8 \\ & \mathbf{3 2 2} & \mathbf{1 6 4} & \mathbf{1 5 8}\end{array}$

Ever used a modern contraceptive method to delay first birth (\%)

Ever used OCP to delay first birth (\%)

Ever used a condom to delay first birth (\%)

Ever used a traditional method to delay first birth (\%)

Number of currently married respondents

Currently married women at parity 0

\begin{tabular}{|c|c|c|c|c|}
\hline Any method & 9.2 & $18.3^{* *}$ & $18.8^{*}$ & $17.8^{*}$ \\
\hline Any modern spacing method ${ }^{a}$ & 5.2 & 9.6 & 8.5 & 10.8 \\
\hline Number of currently married respondents & 154 & 322 & 164 & 158 \\
\hline
\end{tabular}

Notes: ${ }^{1}$ Those who were pregnant for the first time were not asked about contraception prior to the pregnancy; we assume conservatively that they had not practised contraception to delay their first pregnancy; alncludes oral contraceptive pills, emergency contraceptive pill, condom, IUCD/Copper-T, and injectables; Differences between control and intervention (combined) blocks, control and standalone blocks, and control and comprehensive blocks are significant at ${ }^{*} p<0.05,{ }^{* *} p<0.01,{ }^{* *} p<0.001$.

order to understand the obstacles inhibiting women (with one or more births) who had wanted to postpone their first pregnancy but had failed to do so, we asked for leading reasons underlying their inability to practise contraception at this time. Findings suggest that the leading reason for not practising contraception among these women was pressure from their husband or other family members not to opt for contraception. Indeed, 52-55 percent of young women with one or more birth who had not succeeded in practising contraception to delay their first pregnancy reported that their husband had wanted a child early, and 36-45 percent reported that their family members had wanted them to have a child early. Differences between young women in intervention and control sites, and those in standalone and comprehensive programme sites, respectively, and control sites were negligible (Table 6.5). 
Table 6.5: Non-use of contraception among married young women who had at least one live birth,,$^{1}$ and reasons for non-use of contraception

Percentage of married young women who wanted to delay the birth of their first child but failed to do so, and reasons for non-use, women having at least one child, according to study arm

\begin{tabular}{|c|c|c|c|c|}
\hline \multirow{2}{*}{$\begin{array}{l}\text { Non-use of contraception among those who } \\
\text { wanted to delay their first birth }\end{array}$} & \multirow[t]{2}{*}{ Control } & \multicolumn{3}{|c|}{ Intervention } \\
\hline & & Combined & Standalone & Comprehensive \\
\hline $\begin{array}{l}\text { Women who had wanted to delay their first } \\
\text { birth but did not use any method to do so }\end{array}$ & 88.0 & $78.5^{*}$ & 77.8 & 79.1 \\
\hline $\begin{array}{l}\text { Number who had at least one live birth and } \\
\text { had wished to delay the first pregnancy }\end{array}$ & 92 & 209 & 99 & 110 \\
\hline \multicolumn{5}{|l|}{$\begin{array}{l}\text { Reasons for not using contraceptive to delay } \\
\text { first birth }\end{array}$} \\
\hline $\begin{array}{l}\text { Husband did not approve using contraception/ } \\
\text { Husband wanted child early }\end{array}$ & 55.4 & 52.4 & 47.8 & 56.4 \\
\hline $\begin{array}{l}\text { Other family members did not want us to use } \\
\text { contraception/other family members wanted } \\
\text { child early }\end{array}$ & 44.8 & 36.1 & 45.7 & $27.7^{*}$ \\
\hline Did not know from where to get a method & 3.8 & 6.1 & 5.2 & 6.9 \\
\hline Wanted to use a method that was not available & 3.6 & 1.2 & 1.3 & 1.1 \\
\hline $\begin{array}{l}\text { Number who wanted to delay their first birth } \\
\text { but did not use any method of contraception }\end{array}$ & 81 & 164 & 77 & 87 \\
\hline
\end{tabular}

Notes: ${ }^{1}$ Women who had one or more live births were asked if around the time they became pregnant the first time, they had wanted to have the birth then or later; Differences between control and intervention (combined) blocks, control and standalone blocks, and control and comprehensive blocks are significant at ${ }^{*} p<0.05,{ }^{* *} p<0.01,{ }^{* * *} p<0.001$.

\section{Contraception to postpone higher order births}

Among women who had at least one birth, likewise, significantly more women from the intervention arm than the control arm had practised any form of contraception (32\% versus 19\%) and a modern spacing method of contraception (20\% versus 9\%). Differences among young men were negligible (Table 6.6).

Table 6.6: Percentage of currently married young men and women who have had at least one birth, reporting current contraceptive use according to study arm

\begin{tabular}{|c|c|c|c|c|c|c|c|c|}
\hline \multirow{4}{*}{$\begin{array}{l}\text { Current } \\
\text { contraceptive use }\end{array}$} & \multicolumn{4}{|c|}{ Currently married young men } & \multicolumn{4}{|c|}{ Currently married young women } \\
\hline & \multirow[t]{2}{*}{ Control } & \multicolumn{3}{|c|}{ Intervention } & \multirow[t]{2}{*}{ Control } & \multicolumn{3}{|c|}{ Intervention } \\
\hline & & Combined & Standalone & Comprehensive & & Combined & Standalone & Comprehensive \\
\hline & & & All & & & & All & \\
\hline Any method & $(40.0)$ & 36.9 & $(37.2)$ & $(36.5)$ & 18.9 & $32.4^{* *}$ & $29.7^{*}$ & $34.5^{* *}$ \\
\hline $\begin{array}{l}\text { Any modern } \\
\text { spacing method }\end{array}$ & $(24.1)$ & 26.8 & $(33.5)$ & $(19.3)$ & 9.2 & $20.2^{* *}$ & $19.8^{* *}$ & $20.5^{* *}$ \\
\hline $\begin{array}{l}\text { Number of } \\
\text { currently married } \\
\text { respondents of } \\
\text { parity } 1 \text { or above }\end{array}$ & 38 & 52 & 27 & 25 & 174 & 295 & 131 & 164 \\
\hline
\end{tabular}

Notes: alncludes oral contraceptive pills, emergency contraception, condom, IUCD/Copper-T, and injectables; Differences between control and standalone blocks are significant at ${ }^{*} p<0.05, * \star p<0.01, * \star * p<0.001$; Differences between control and comprehensive blocks are significant at $\star_{p}<0.05, * \star p<0.01, * * \star p<0.001$; Differences between control and intervention (combined) block are significant at ${ }^{*} p<0.05, * * p<0.01, * * * p<0.001$; () based on 25-49 unweighted cases. 


\section{Pace of childbearing}

Important messages conveyed by the PRACHAR intervention related to spacing the first and subsequent pregnancies and maintaining a small family norm. Findings, presented in Table 6.7, show several indicators of the pace of childbearing: the percentage of women who already had one or more live births, the interval between marriage (cohabitation) and the birth of the first child, and percentage of women with at least one birth who had experienced a higher order birth as well.

Findings show no significant differences between young women exposed and unexposed to the intervention on all three measures. About half of all young women, irrespective of exposure to the intervention, already had at least one birth at the time of the interview (48-52\%). Among women with at least one birth, the first birth interval (from marriage to the birth of the first child) was relatively short, and differences between young women in intervention and control sites were mild (20.5-20.7 months). Moreover, of women with at least one birth, about as many young women from intervention sites as from control sites reported having a second or higher order birth (17\% and $18 \%$, respectively).

Table 6.7: Pace of childbearing, married young women

Percentage of currently married women reporting one or more live births, the mean first birth interval (marriage to first child) among women who had at least one birth, and mean second birth interval (between first and second birth) among women who had more than one birth, according to study arm

\begin{tabular}{lcccc}
\hline Pace of child bearing & Control & \multicolumn{3}{c}{ Intervention } \\
\cline { 3 - 5 } & & Combined & Standalone & Comprehensive \\
\hline $\begin{array}{l}\text { Women who never got pregnant or pregnant } \\
\text { for the first time }\end{array}$ & 53.1 & 47.9 & 44.5 & 51.0 \\
$\begin{array}{l}\text { Number of currently married women } \\
\begin{array}{l}\text { Average interval from marriage to first birth } \\
\text { (in months) }\end{array}\end{array}$ & $\mathbf{3 2 8}$ & $\mathbf{6 1 7}$ & $\mathbf{2 9 5}$ & $\mathbf{3 2 2}$ \\
$\begin{array}{l}\text { Women who had a second or higher } \\
\text { order birth }\end{array}$ & 20.5 & 20.7 & 20.8 & 20.6 \\
$\begin{array}{l}\text { Number of women who had at least one } \\
\text { live birth }\end{array}$ & 18.3 & 16.9 & 16.8 & 17.1 \\
\hline
\end{tabular}

Notes: Differences between control and intervention (combined) blocks, control and standalone blocks, and control and comprehensive blocks are significant at ${ }^{*} p<0.05,{ }^{* *} p<0.01,{ }^{* *} p<0.001$.

\section{Multivariate associations}

The associations between many of the variables discussed above and our contraception outcome variables remained statistically significant among young women (and non-significant among young men) even after adjustment for age, educational attainment, and other potentially confounding covariates (Tables 6.8 and 6.9).

\section{Among unmarried and married young men and women reporting pre-marital or extra-marital sexual experience}

Regression analyses comparing young men and women who had been exposed to the intervention with those in comparison areas suggest that those trained in the PRACHAR programme were significantly more likely than others, even after potentially confounding factors were controlled, to have used a modern method of contraception in their last pre-marital or extra-marital sexual encounter, and to have practiced consistent condom use. The odds that sexually experienced young men and young women had used a modern method of contraception in their last sexual encounter were higher among those who had been exposed to the PRACHAR programme than among those who were not so exposed (odds ratios, 1.99 for young men, 7.40 for young women). With regard to consistent condom use, among young women, once confounding factors were controlled, the odds were higher for those in intervention than control sites (odds ratio, 12.70); corresponding odds ratios for young men suggested no difference between those exposed and not exposed to the PRACHAR programme. 


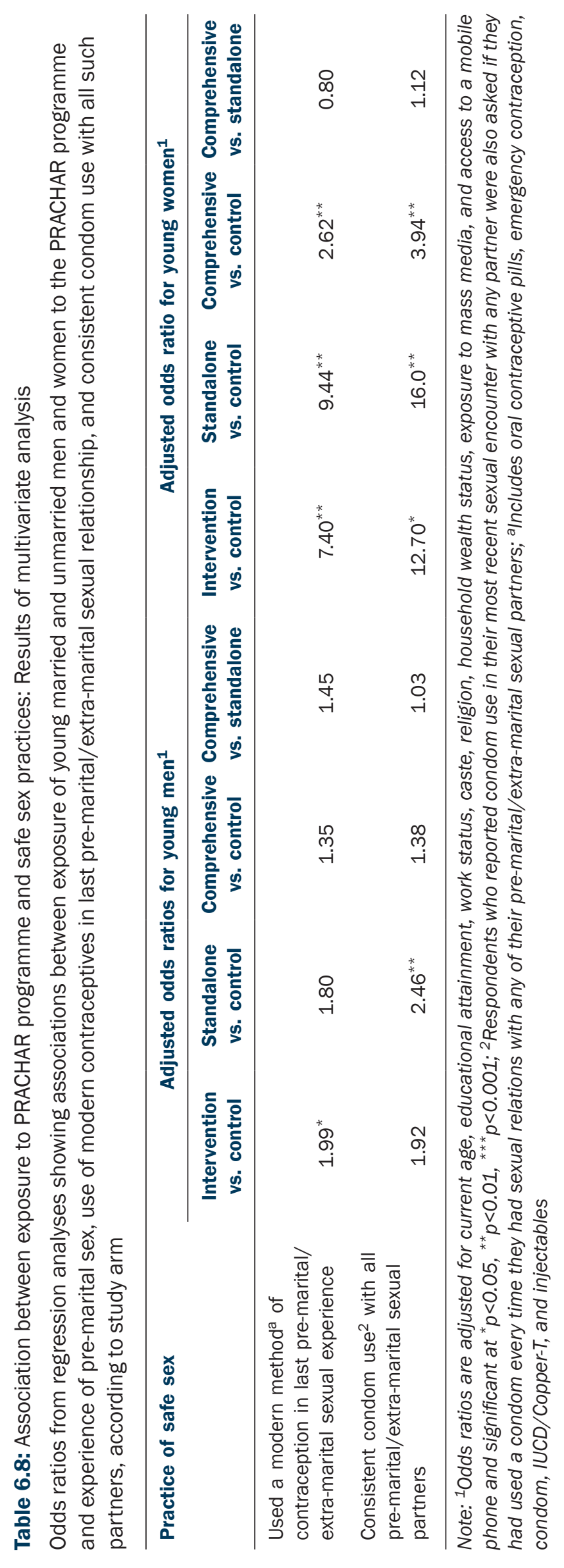




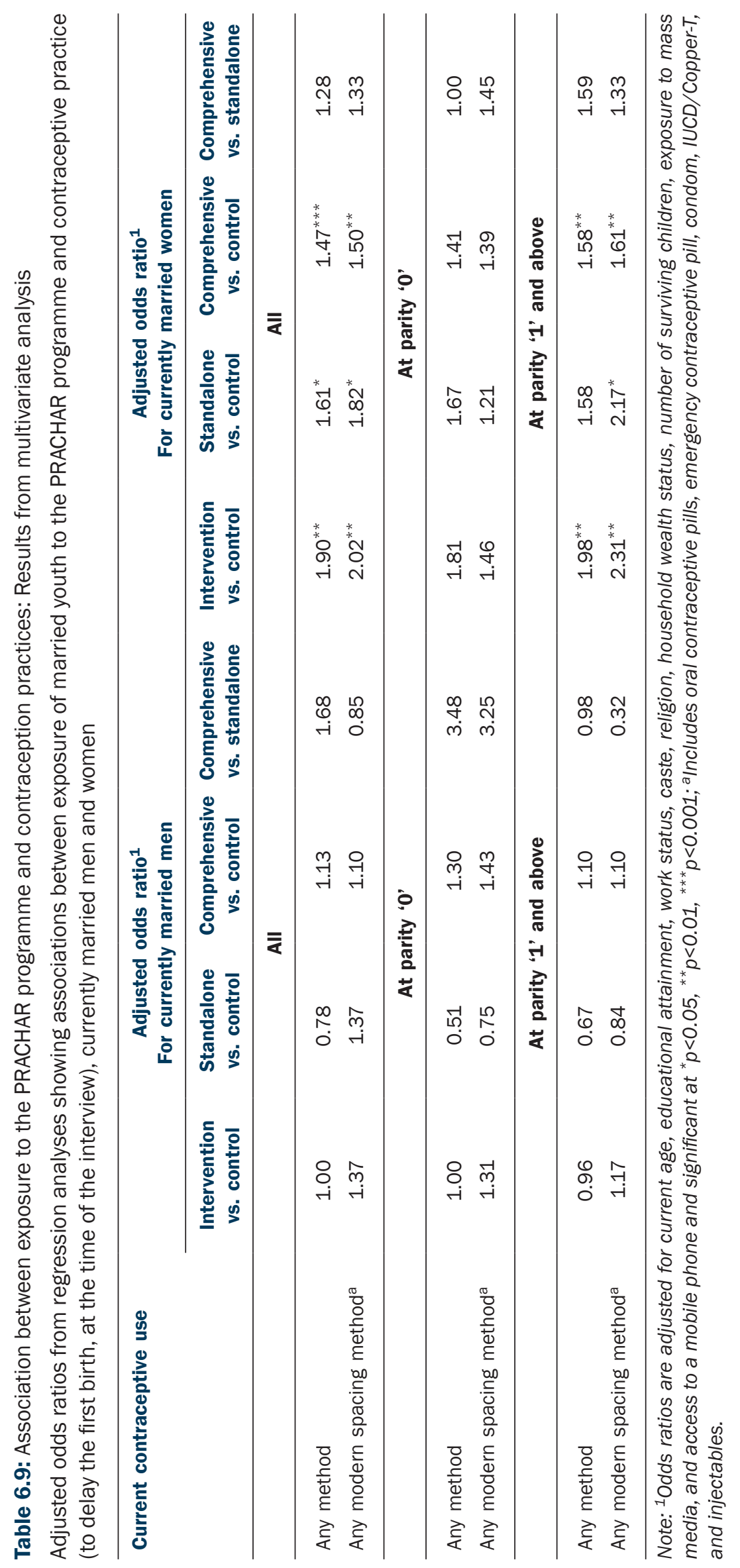




\section{Among the married}

Even once confounding factors were controlled, young women who had been exposed to the PRACHAR intervention areas had greater odds of having practiced contraception to delay the first birth (odds ratios, 1.90), as well as having used a modern spacing method of contraception to do so (2.02) (Table 6.9). Differences were negligible among young men.

Among nulliparous young women however, there was no evidence to suggest that those exposed to the PRACHAR programme were more likely to have practised contraception than those from control sites. Among those with one or more live births, however, odds ratios confirm that young women exposed to the PRACHAR programme were more likely than others to be practicing contraception in general and a modern spacing method of contraception in particular at the time of the interview (odds ratio, 1.98 and 2.31, respectively).

In contrast, exposure to the PRACHAR programme had no effect on contraception indicators among young men. Likewise, there was no evidence, among young women or young men that for those exposed to the intervention, the ones residing in comprehensive intervention areas were more likely than those in standalone areas to be practicing contraception at the time of the interview or to have initiated contraception prior to the first birth.

\section{Summary}

This chapter assessed the extent to which young men and women who had been exposed to the PRACHAR training intervention were more likely than those in control sites, three to four years following the training, to report protected pre-marital or extra-marital sexual relations, and the extent to which the married who had been exposed to the PRACHAR training intervention were more likely to report that they were aware of married life, contraception, and birth spacing at the time of the marriage than were those in control sites, and the extent to which those in the two intervention arms differed from each other in these respects. Findings were mixed.

With regard to protected pre-marital or extra-marital sexual relations, findings suggest that protected sex in such relationships was far from universal. Among young men, for example, just under one-half of those from intervention sites had used contraception at the time of their last sexual encounter, compared to significantly fewer of their counterparts from control sites. Similarly, consistent condom use in all pre-marital and/or extra-marital sexual encounters was reported by about one-quarter of young men from intervention sites and one-sixth of those from control sites. Once confounding factors were controlled, however, differences between those in intervention and comparison areas were no longer observed. Among young women who had experienced pre-marital and/or extra-marital sex, those in intervention sites were significantly more likely to have practised contraception at last sex than were those in control sites; indeed, two-fifths versus one-eighth of young women had done so. Differences were significant and as stark with regard to consistent condom use in all their sexual encounters, with one-quarter of those from intervention sites, compared to fewer than one in 20 of those from control sites reporting consistent condom use in all their sexual encounters. Even after confounding factors were controlled, young women who had been exposed to the PRACHAR programme were more likely than others to have practised contraception and consistent condom use. Finally, we note that among young people exposed to the intervention, differences between those in standalone versus comprehensive project sites were generally negligible on all issues about which we probed.

With regard to preparedness for married life, significantly more young men and women from intervention than control sites reported that prior to or around the time of their marriage, someone had discussed with them the importance of delaying the first pregnancy.

Contraceptive practice at the time of the interview (largely oral contraceptives and condoms) suggests that exposure to the PRACHAR intervention had little effect on men's contraceptive prevalence, but a strong effect among young women; effects remained significant even after confounding factors were controlled. A similar picture emerged with regard to contraceptive practice to postpone higher order births among women (but not men) with one or more births. In contrast, while women in intervention sites were significantly more likely to have practised contraception to postpone the first pregnancy, effects were not significant when confounding factors were controlled. Indeed, although large proportions of young women with one or more births had wished to postpone their first pregnancy, most had 
failed to do so. Reasons for failure to use contraception typically included pressure from the husband and family, suggesting a need for a greater focus on addressing family-level obstacles to contraception among newlywed women.

Also unaffected by the intervention was the pace of childbearing. For example, about half of all young women already had one or more births, the interval from marriage to first birth was short-just 21 months-and of those who had at least one birth, similar proportions (17-18\%) had gone on to have a second or higher order birth. 


\section{Chapter 7 \\ Young people's agency and gender role attitudes}

This chapter presents findings with regard to young people's agency and gender role attitudes. The intention is to assess the extent to which young men and women who had been exposed to the PRACHAR intervention reported more agency and gender egalitarian attitudes than did those in control sites, and the extent to which those in the two intervention arms differed from each other in these respects. We note that the PRACHAR training programme did not directly address these issues, however, its focus on exercise of choice with regard to marriage and contraception, for example, may have had a strong spillover effect on other aspects of their life.

\section{Agency}

To assess differences among young people in intervention and control sites with regard to agency, we explore four outcomes-young people's involvement in decision-making on matters relating to their lives, self-efficacy, access to economic resources, and mobility or freedom to visit selected places unescorted.

\section{Decision-making}

In order to assess young people's involvement in decision-making, we asked them about their involvement in decisions on several matters relating to their lives: spending their own money, making major household purchases, seeking health care for themselves, marriage timing and spouse selection, and their own education and employment. Those who reported that they were involved in decision-making on any issue were probed about whether they made the decision entirely on their own or together with other family members.

Findings, presented in Table 7.1, confirm that few young people were involved in independent decision-making on many matters, but that far more young men than women made decisions on every single item probed. With regard to differences between young people in intervention and control sites, findings were mixed. Among young men, those in intervention sites were significantly more likely than those in control sites to make decisions about their own health care ( $40 \%$ versus $29 \%$ ), but were significantly less likely to make their own decisions with regard to taking up work (54\% versus $67 \%$ ) and making major household purchases (3\% versus $1 \%$ ). Among young women, those from intervention sites were significantly more likely than those in control sites to report several dimensions of decision-making: they were more likely to make independent decisions on spending money (66\% versus 60\%), major household purchases ( $5 \%$ versus $<1 \%$ ), and taking up employment ( $16 \%$ versus $8 \%$ )

In order to summarise young people's decision-making ability, an index was created that summed the number of issues on which they reported making independent decisions. This additive index ranges from 0 , implying that the young person did not make any decisions independently, to 6 , suggesting independent decision-making on all six matters. On average, young people showed limited decision-making ability: among young men, the mean number of decisions made was similar for both groups (2.3-2.4). Among young women in contrast, those in intervention sites made significantly more decisions than did those in control villages (1.1 versus 0.9 ). No differences were apparent between those in standalone and comprehensive intervention sites.

\section{Self-efficacy}

In order to measure young people's sense of self-efficacy, a number of questions were asked about whether they had experienced difficulty in expressing their opinions to elders in the family, and in confronting a person who had said or done something wrong to them, and whether they would be able to confront their parents if they disagreed with their parents' decisions about further education, taking up a job, early marriage, and choice of spouse. Young men demonstrated self-efficacy on most indicators, with more than half, irrespective of whether they had undergone training or not, reporting self-efficacy on each of the six items. Young women, in contrast, were far less likely than 
Table 7.1: Decision-making

Percentage of young men and women who made decisions independently on different matters related to them, according to study arm

\begin{tabular}{|c|c|c|c|c|}
\hline \multirow[t]{2}{*}{ Independent decision-making } & \multirow[t]{2}{*}{ Control } & \multicolumn{3}{|c|}{ Intervention } \\
\hline & & Combined & Standalone & Comprehensive \\
\hline \multicolumn{5}{|c|}{ Young men } \\
\hline \multicolumn{5}{|l|}{ Took independent decision on } \\
\hline Spending money & 92.5 & 92.4 & 92.8 & 91.8 \\
\hline Major household purchases & 3.2 & $1.3^{*}$ & 1.5 & $1.0^{*}$ \\
\hline Own health care & 29.0 & $39.5^{* * *}$ & $38.6^{* *}$ & $40.5^{* * *}$ \\
\hline Own marriage & 9.4 & 10.4 & 10.1 & 10.6 \\
\hline Pursuing education & 39.6 & 37.8 & 37.4 & 38.2 \\
\hline Taking up a job/work & 67.2 & $53.5^{* * *}$ & $52.7^{* * *}$ & $54.3^{* * *}$ \\
\hline $\begin{array}{l}\text { Index of decision-making (ran } \\
\text { Cronbach's alpha 0.54) }\end{array}$ & 2.4 & 2.3 & 2.3 & 2.4 \\
\hline Number of respondents & 371 & 789 & 404 & 385 \\
\hline \multicolumn{5}{|c|}{ Young women } \\
\hline \multicolumn{5}{|l|}{ Took independent decision on } \\
\hline Spending money & 59.8 & $65.6^{*}$ & $66.8^{* *}$ & 64.4 \\
\hline Major household purchases & 0.2 & 0.4 & 0.3 & 0.6 \\
\hline Own health care & 0.3 & $5.1^{* * *}$ & $5.3^{* * *}$ & $5.0^{* * *}$ \\
\hline Own marriage & 0.4 & 1.0 & 1.0 & 1.0 \\
\hline Pursuing education & 17.8 & 20.6 & 22.0 & 19.2 \\
\hline Taking up a job/work & 7.7 & $16.1^{* \star *}$ & $16.4^{* * *}$ & $15.8^{* * *}$ \\
\hline $\begin{array}{l}\text { Index of decision-making (ran } \\
\text { Cronbach's alpha } 0.38 \text { ) }\end{array}$ & 0.9 & $1.1^{* * *}$ & $1.1^{* * *}$ & $1.1^{* * *}$ \\
\hline Number of respondents & 679 & 1382 & 695 & 687 \\
\hline
\end{tabular}

Notes: Differences between control and intervention (combined) blocks, control and standalone blocks, and control and comprehensive blocks are significant at ${ }^{*} p<0.05,{ }^{* *} p<0.01,{ }^{* *} p<0.001$.

young men to report self-efficacy, but for each situation posed, those who had undergone training were significantly more likely than those who had not to express self-efficacy on every matter: expressing their opinion to elders of the family (38\% versus 26\%), convincing a parent about pursuing their education ( $23 \%$ versus $14 \%$ ), and conveying their feelings to their parents if they disagreed with the proposed timing of marriage or partner (37\% versus $27 \%$; $29 \%$ versus 19\%).

An index summarising young people's sense of self-efficacy was created by summing the number of five situations in which young people perceived that they would always display self-efficacy (we excluded reported ability to convince parents about taking up a job as almost all respondents reported that they were able to do so). The index thus created ranges from 0 , implying that they would be unable to express themselves on any of the five issues, to 5 , suggesting that they would be able to do so on all five matters. The index suggests that while young men expressed self-efficacy on an average of four matters, young women did so in just 1-2 matters. Among young men, those from intervention and control sites reported similar scores on the index (3.5-3.6); young women in intervention sites reported significantly higher scores than did those in control sites (1.8 versus 1.4).

No differences were apparent between those in standalone and comprehensive intervention sites. 
Table 7.2: Self-efficacy

Percentage of young men and women who expressed self-efficacy in different situations, according to study arm

\begin{tabular}{|c|c|c|c|c|}
\hline \multirow[t]{2}{*}{ Self-efficacy } & \multirow[t]{2}{*}{ Control } & \multicolumn{3}{|c|}{ Intervention } \\
\hline & & Combined & Standalone & Comprehensive \\
\hline \multicolumn{5}{|c|}{ Young men } \\
\hline \multicolumn{5}{|l|}{ Did not find it difficult to: } \\
\hline Express their opinion to elders in the family & 55.2 & 51.3 & 52.7 & 49.7 \\
\hline Confront a person who says or does anything wrong & 72.8 & 77.7 & 78.7 & 76.5 \\
\hline Convince parent/or find away to continue education & 72.0 & 76.0 & 77.2 & 74.6 \\
\hline Convince parent/or find away to continue work & 99.7 & 99.7 & 99.5 & 100.0 \\
\hline Convey feeling about early marriage to parents & 79.2 & 80.2 & 80.7 & 79.7 \\
\hline Convey feeling about proposed spouse to parents & 72.0 & 75.2 & 73.6 & 77.1 \\
\hline $\begin{array}{l}\text { Index of self-efficacy (range } 0-5 \text {, Cronbach's } \\
\text { alpha } 0.66 \text { ) }\end{array}$ & 3.5 & 3.6 & 3.6 & 3.6 \\
\hline Number of respondents & 371 & 789 & 404 & 385 \\
\hline \multicolumn{5}{|c|}{ Young women } \\
\hline \multicolumn{5}{|l|}{ Did not find it difficult to: } \\
\hline Express their opinion to elders in the family & 26.2 & $37.6^{* * *}$ & $39.6^{* * *}$ & $35.7^{* * *}$ \\
\hline Confront a person who says or does anything wrong & 52.2 & 56.7 & $57.6^{*}$ & 55.7 \\
\hline Convince parent/or find away to continue education & 13.9 & $23.2^{* * *}$ & $24.9^{* * *}$ & $21.5^{* * *}$ \\
\hline Convince parent/or find away to continue work & 99.8 & 99.9 & 100.0 & 99.7 \\
\hline Convey feeling about early marriage to parents & 27.3 & $36.8^{* * *}$ & $37.9^{* *}$ & $35.7^{* \star *}$ \\
\hline Convey feeling about proposed spouse to parents & 19.1 & $29.4^{* * *}$ & $28.6^{* * *}$ & $30.2^{* * *}$ \\
\hline $\begin{array}{l}\text { Index of self-efficacy (range } 0-5 \text {, Cronbach's } \\
\text { alpha } 0.65 \text { ) }\end{array}$ & 1.4 & $1.8^{* * \star}$ & $1.9^{* * *}$ & $1.8^{* * *}$ \\
\hline Number of respondents & 679 & 1,382 & 695 & 687 \\
\hline
\end{tabular}

Notes: Differences between control and intervention (combined) blocks, control and standalone blocks, and control and comprehensive blocks are significant at ${ }^{*} p<0.05,{ }^{* *} p<0.01,{ }^{* * *} p<0.001$.

\section{Access to economic resources}

In order to assess the extent to which young people had access to economic resources, we inquired about whether respondents had any money saved, whether they owned a bank or post office account, and whether they operated the account independently. The large majority of young people reported having savings; while more young men in intervention than control sites reported savings, differences were negligible among young women ( $86 \%$ versus $74 \%$ among young men; $84 \%$ for both groups of young women). More young people in intervention than control sites reported owning a bank or post office account (58\% versus $49 \%$ among young men; $54 \%$ versus $44 \%$ among young women), and reported operating the account they owned (55\% versus $45 \%$ among young men; $41 \%$ versus $35 \%$ among young women).

No differences were apparent between those in standalone and comprehensive intervention sites.

\section{Mobility or freedom of movement}

Questions on mobility or freedom of movement were posed only to young women and unmarried young men, since married young men typically exhibited freedom of movement on all issues. It was measured by a number of questions on whether the respondent was permitted to visit places and events unescorted within and outside the village. Places within the village included a meeting or programme, and a shop or market. Places outside the village 
Table 7.3: Access to economic resources

Percentage of young men and women who reported having savings, owning bank/post office accounts, and operating their account on their own, according to study arm

\begin{tabular}{lcccc}
\hline Access to economic resources & Control & \multicolumn{3}{c}{ Intervention } \\
\cline { 3 - 5 } & & Combined & Standalone & Comprehensive \\
\hline & Young men & & \\
\hline Had some savings & 73.7 & $86.1^{* * *}$ & $85.6^{* * *}$ & $86.5^{* * *}$ \\
Had own/joint account in a bank/post office & 48.5 & $57.7^{*}$ & 51 & $65.1^{* * *+}$ \\
Operated account on their own & 44.8 & $55.1^{*}$ & 47.8 & $63.2^{* * *+}$ \\
Number of respondents & $\mathbf{3 7 1}$ & $\mathbf{7 8 9}$ & $\mathbf{4 0 4}$ & $\mathbf{3 8 5}$ \\
\hline & Young women & & & \\
\hline Had some savings & 84.1 & 84.3 & 84.2 & 84.4 \\
Had own/joint account in a bank/post office & 43.8 & $54.1^{* *}$ & $58.9^{* * *}$ & 49.4 \\
Operated account on their own & 34.9 & $40.6^{* *}$ & $44.5^{* *}$ & 36.7 \\
Number of respondents & $\mathbf{6 7 9}$ & $\mathbf{1 3 8 2}$ & $\mathbf{6 9 5}$ & $\mathbf{6 8 7}$ \\
\hline
\end{tabular}

Notes: Differences between control and intervention (combined) blocks, control and standalone blocks, and control and comprehensive blocks are significant at ${ }^{*} p<0.05,{ }^{* *} p<0.01,{ }^{* *} p<0.001$; Differences between standalone and comprehensive blocks are significant at ${ }^{+} p<0.05$.

included the home of a relative or friend, and a mela or other place of entertainment. Findings presented in Table 7.4 confirm that almost all young men had freedom of movement. Among young women, in contrast, mobility was limited even within their own village, but even so, those exposed to the PRACHAR programme were significantly more likely to report freedom of movement to each of the four places and events about which we probed.

An index of mobility reflecting young people's freedom of movement was created by adding the number of places (out of four) they were allowed to visit unescorted. An index value of 0 implies that the young person was not allowed to visit any of the four places unescorted, while a maximum value of 4 suggests that they were permitted to visit all of the four places unescorted. The average number of places that young men were allowed to visit unescorted was 3.9, irrespective of whether they were exposed to the intervention. Among young women, in contrast, those exposed to the intervention were permitted to visit an average of 1.6 places or events, compared to significantly fewer (1.2) among those in control sites.

No differences were apparent between those in standalone and comprehensive intervention sites.

\section{Gender role attitudes}

Ten questions were posed that probed young people's attitudes to gender roles (Table 7.5). Questions ranged from whether educating boys is more important than educating girls to whether only men should make decisions about whether to use a condom. Findings suggest a mixed scenario, in terms of gender differences in reporting of gender role attitudes. For example, young men reported more egalitarian attitudes than young women with regard to the acceptability of girls having male friends and doing away with dowry. In contrast, young women reported more egalitarian attitudes than young men with regard to the acceptability of girls deciding about their own marriage, and of women participating in decisions about condom use and spending household money.

Differences between young people in intervention and control sites were evident on several gender-role attitudes. Where differences were evident, it was always young people in intervention sites who expressed more egalitarian attitudes than did those in control sites. For example, young men in intervention sites were more likely than their counterparts in control sites to report egalitarian attitudes about the acceptability of girls having male friends $(90 \%$ versus $82 \%$ ), of girls deciding about their own marriage (79\% versus $66 \%)$, of women participating in decisions on 
Table 7.4: Mobility

Percentage of young men and women who were allowed to visit different places inside and outside their village alone, according to study arm

\begin{tabular}{|c|c|c|c|c|}
\hline \multirow[t]{2}{*}{ Mobility } & \multirow[t]{2}{*}{ Control } & \multicolumn{3}{|c|}{ Intervention } \\
\hline & & Combined & Standalone & Comprehensive \\
\hline \multicolumn{5}{|c|}{ Young unmarried men } \\
\hline \multicolumn{5}{|l|}{ Allowed to visit alone: } \\
\hline To attend any meeting/programme & 97.9 & 97.2 & 98.2 & 96.2 \\
\hline To a relative outside the village & 95.2 & 96.5 & 96.8 & 96.2 \\
\hline To an entertainment show/mela & 93.9 & 93.7 & 93.4 & 94.0 \\
\hline To a shop or market inside the village & 100.0 & 99.8 & 100.0 & 99.6 \\
\hline $\begin{array}{l}\text { Index of mobility (range } 0-4 \text {, Cronbach's } \\
\text { alpha 0.49) }\end{array}$ & 3.9 & 3.9 & 3.9 & 3.9 \\
\hline Number of respondents & 299 & 649 & 334 & 315 \\
\hline \multicolumn{5}{|c|}{ Young women } \\
\hline \multicolumn{5}{|l|}{ Allowed to visit alone: } \\
\hline To attend any meeting/programme & 35.2 & $49.1^{* * *}$ & $50.9^{* * *}$ & $47.3^{* * *}$ \\
\hline To a relative outside the village & 17.8 & $26.1^{* * *}$ & $27.2^{* * *}$ & $25.0^{* *}$ \\
\hline To an entertainment show/mela & 6.0 & $10.9^{* * *}$ & $11.1^{* * *}$ & $10.7^{* *}$ \\
\hline To a shop or market inside the village & 59.3 & $72.0^{* * *}$ & $72.1^{* * *}$ & $71.8^{* * *}$ \\
\hline $\begin{array}{l}\text { Index of mobility (range } 0-4 \text {, Cronbach's } \\
\text { alpha } 0.71 \text { ) }\end{array}$ & 1.2 & $1.6^{* * *}$ & $1.6^{* * *}$ & $1.6^{* * *}$ \\
\hline Number of respondents & 679 & 1,382 & 695 & 687 \\
\hline
\end{tabular}

Notes: Differences between control and intervention (combined) blocks, control and standalone blocks, and control and comprehensive blocks are significant at ${ }^{*} p<0.05,{ }^{* *} p<0.01,{ }^{* * *} p<0.001$.

household spending ( $74 \%$ versus $61 \%)$, of women participating in decisions on condom use (62\% versus $52 \%$ ), as well as of men performing household chores (72\% versus 56\%). Young women in intervention sites were more likely than those in control sites to report egalitarian attitudes on almost all the questions posed. They were more likely than those in control sites to report egalitarian attitudes on four of the five issues about which young men reported egalitarian attitudes: the acceptability of girls having male friends ( $72 \%$ versus $60 \%$ ), of girls deciding about their own marriage ( $41 \%$ versus $33 \%$ ), of women participating in decisions on condom use (69\% versus $56 \%$ ), and of men performing household chores (63\% versus 54\%). In addition, young women from intervention sites expressed more egalitarian attitudes than those in control sites with regard to giving dowries (41\% versus $33 \%$ ) and to the ability of girls to support their parents in their old age (85\% versus $79 \%)$.

As in the case of indexes representing agency, an index of gender role attitudes was constructed by summing the number of statements (of a maximum of 10) for which young people expressed egalitarian attitudes. This index takes values between 0 and 10; 0 if young people did not express egalitarian attitudes regarding any of the 10 statements posed and 10 if they expressed such attitudes in all 10 statements. The average number of statements in which young people expressed gender egalitarian attitudes was significantly higher among those in intervention than control sites: 7.4 versus 6.6 among young men, 7.1 versus 6.4 among young women.

No differences were apparent between those in standalone and comprehensive intervention sites. 
Table 7.5: Gender role attitudes

Percentage of young men and women expressing egalitarian gender role attitudes, according to study arm

\begin{tabular}{lclc}
\hline Gender role attitudes & Control & \multicolumn{2}{c}{ Intervention } \\
\cline { 3 - 4 } & & Combined Standalone Comprehensive & S \\
\hline
\end{tabular}

\section{Young men}

\section{Expression of gender egalitarian attitudes}

Educating boys is more important than educating girls (disagree)

\begin{tabular}{|c|c|c|c|}
\hline 96.0 & 93.6 & $92.3^{*}$ & 95.0 \\
\hline 93.2 & 94.4 & 94.8 & 93.8 \\
\hline 81.6 & $90.2^{* * *}$ & $91.3^{* * *}$ & $89.0^{* *}$ \\
\hline 65.5 & $79.4^{* * *}$ & $80.4^{* * *}$ & $78.2^{* * *}$ \\
\hline 63.3 & 66.3 & 65.5 & 67.1 \\
\hline 79.4 & 83.9 & 82.4 & $85.6^{*}$ \\
\hline 15.8 & 19.0 & 18.0 & 20.0 \\
\hline 60.9 & $73.6^{* *}$ & $72.9^{* * *}$ & $74.3^{* * *}$ \\
\hline 56.4 & $72.4^{* * *}$ & $70.8^{* * *}$ & $74.2^{* * *}$ \\
\hline 52.4 & $62.3^{* *}$ & $60.5^{*}$ & $64.2^{* * *}$ \\
\hline 6 & $7.4^{* * *}$ & $7.3^{* * *}$ & $7.4^{* * *}$ \\
\hline 371 & 789 & 404 & 385 \\
\hline
\end{tabular}

Since girls have to get married, they should not be sent for higher education (disagree)

It is wrong for a girl to have male friends (disagree)

Girls should be allowed to decide when they want to marry (agree)

It is necessary to give dowry (disagree)

Only a son can provide support to his parents in their old age (disagree)

A woman should obtain her husband's permission for most things (disagree)

Husband alone/mainly should decide how household money is to be spent (disagree)

Giving the kids a bath and feeding the kids are responsibilities of only female members of household (disagree)

It is the man who should decide whether to use a condom or not(disagree)

Index of gender-role attitude (range 0-10, Cronbach's alpha 0.67)

Number of respondents

Young women

\section{Expression of gender egalitarian attitudes}

Educating boys is more important than educating girls (disagree)

\begin{tabular}{llll}
96.3 & $99.0^{* * *}$ & $99.0^{* *}$ & $99.0^{* *}$ \\
93.8 & 96.0 & $96.9^{* *}$ & 95.2 \\
60.0 & $71.9^{* * *}$ & $73.4^{* * *}$ & $70.4^{* * *}$ \\
70.4 & $80.3^{* * *}$ & $80.5^{* * *}$ & $80.0^{* *}$ \\
32.7 & $40.9^{*}$ & $40.4^{* *}$ & $41.3^{* *}$ \\
78.6 & $84.7^{*}$ & $87.0^{* * *}$ & $82.5^{+}$ \\
& & \multicolumn{2}{c}{ Cont'd on next page... }
\end{tabular}




\begin{tabular}{|c|c|c|c|c|}
\hline \multirow[t]{2}{*}{ Gender role attitudes } & \multirow[t]{2}{*}{ Control } & \multicolumn{3}{|c|}{ Intervention } \\
\hline & & Combined & Standalone & Comprehensive \\
\hline $\begin{array}{l}\text { A woman should obtain her husband's permission for } \\
\text { most things (disagree) }\end{array}$ & 15.8 & $23.4^{*}$ & $22.4^{\star \star}$ & $24.5^{* \star *}$ \\
\hline $\begin{array}{l}\text { Husband alone/mainly should decide how household } \\
\text { money is to be spent (disagree) }\end{array}$ & 79.8 & 84.5 & $84.6^{*}$ & $84.3^{*}$ \\
\hline $\begin{array}{l}\text { Giving the kids a bath and feeding the kids are } \\
\text { responsibilities of only female members of household } \\
\text { (disagree) }\end{array}$ & 54.0 & $62.6^{* * *}$ & $63.4^{* * *}$ & $61.9^{* *}$ \\
\hline $\begin{array}{l}\text { It is the man who should decide whether to use a } \\
\text { condom or not(disagree) }\end{array}$ & 55.5 & $69.3^{* * *}$ & $72.0^{* \star *}$ & $66.6^{* *+}$ \\
\hline $\begin{array}{l}\text { Index of gender-role attitude (range } 0-10 \text {, Cronbach's } \\
\text { alpha } 0.68 \text { ) }\end{array}$ & 6.4 & $7.1^{* * *}$ & $7.2^{* * *}$ & $7.1^{* * *}$ \\
\hline Number of respondents & 679 & 1382 & 695 & 687 \\
\hline
\end{tabular}

Notes: Differences between control and intervention (combined) blocks, control and standalone blocks, and control and comprehensive blocks are significant at ${ }^{*} p<0.05,{ }^{* *} p<0.01,{ }^{* * *} p<0.001$; Differences between standalone and comprehensive blocks are significant at ${ }^{+} p<0.05$.

\section{Multivariate analyses}

The associations between many of the variables discussed above and our outcome variables remained statistically significant even after adjustment for age, educational attainment, and other potentially confounding covariates (Table 7.6). As in the bivariate associations, effects were far stronger among young women than among young men. For example, among young men, agency, self-efficacy, and mobility were not associated with exposure to the PRACHAR programme. In contrast, among young women, all of these indicators of agency were clearly greater among those in intervention areas. For example, measured against young women in comparison areas, those in intervention areas were more likely to have decision-making authority (0.22), mobility (0.32), and self-efficacy (0.35). Moreover, effects remained significant when comparisons were drawn on each of these indicators between young women residing in comparison villages and those trained by the PRACHAR programme and residing in standalone and comprehensive programme sites, respectively (coefficients ranged from 0.10 to 0.39). However, differences in effects were not observed when young women in standalone sites were compared with those in comprehensive intervention sites.

The longer-term effects on gender role attitudes were significant for both young men and young women. For example, compared with respondents in comparison areas, those in intervention areas scored higher on the index of gender egalitarian attitudes, even after confounding factors were controlled ( 0.38 and 0.50 among young men and women, respectively). Effects remained significant among young women when comparisons were drawn between respondents residing in comparison villages and those trained by the PRACHAR programme and residing in standalone and comprehensive programme sites, respectively (coefficients of 0.39 and 0.31 , respectively); among young men they remained significant only in comparison with those in comprehensive project sites (0.24). As in the case of measures of agency, differences in effects were not observed when young men and women in standalone sites were compared with those in comprehensive intervention sites. 


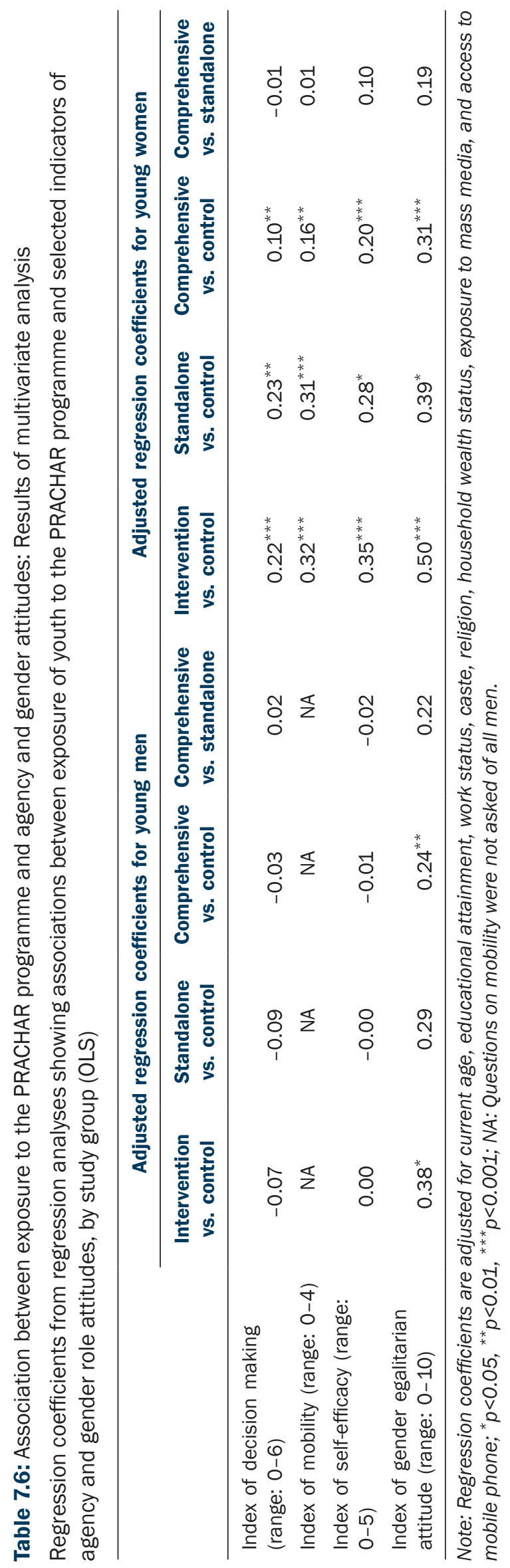




\section{Summary}

As expected, young men were more likely than young women to display most dimensions of agency, in terms of decision-making, self-efficacy, access to economic resources, and freedom of movement. Findings confirm, however, that young people exposed to the PRACHAR intervention were indeed more likely than those in control sites to display agency. Among young men, differences between those in intervention and control sites were evident on just a few outcomes, for example, decision-making about health seeking practices and access to and control over economic resources. In contrast, among young women, differences between those in intervention and control sites were consistently significant, and remained significant even after controlling for a host of potentially confounding factors such as age, education, and exposure to mass media. Indeed, among young women, those in intervention sites displayed greater agency on every dimension; they reported significantly higher levels of decision-making authority, self-efficacy, access to and control over economic resources, and freedom of movement, as revealed by responses on several individual matters about which we probed, as well as in summary measures relating to each dimension of agency.

With regard to the expression of egalitarian gender role attitudes, we sought respondents' attitudes on ten issues, ranging from whether girls should be educated as much as boys to whether it is the man who should decide on condom use. Patterns exhibited by young men and young women differed, and differences between those exposed to the intervention and those in control sites were significant on a larger number of attitudes among young women than among young men. Even so, overall, the summary measure reveals that egalitarian gender role attitudes were significantly more likely to have been expressed by those who had been exposed to the PRACHAR intervention than others, and effects continued to be strong among both young men and young women even after confounding factors were controlled.

Finally, we note that among those exposed to the intervention, no differences were discerned in terms of both agency and gender role attitudes among those in standalone versus comprehensive project sites. 


\section{Chapter 8}

\section{Pregnancy related care and nature of married life}

This chapter explores the extent to which other dimensions of married life-pregnancy related care, spousal relations, and marital violence-differed between those exposed to the PRACHAR programme and other youth. We focus on the nature of married life among those in intervention and control sites who had married in the period 2010-11 to 2014, and assess the extent to which young men and women who had been exposed to the PRACHAR intervention were more likely, three to four years following the training, to report appropriate pregnancy related care and egalitarian marital relations, including the absence of marital violence, than were those in control sites, and the extent to which those in the two intervention arms differed from each other in these respects.

\section{Pregnancy related care}

To assess pregnancy-related care, we focus on births to women in our sample in the three years preceding the survey. These included a total of 340 births in intervention sites, and 198 in control sites. We explored, for each birth, the extent of pregnancy related care. Findings, presented in Table 8.1, suggest that young women had registered for antenatal care for almost every birth, irrespective of whether they belonged to intervention or control sites (95-96\%), and that the large majority of births had been attended by a trained provider ( $87-88 \%)$ or had been conducted in a health facility $(79-81 \%)$.

Fewer-for two-thirds of all births-women made the first antenatal visit during the first trimester of pregnancy, and again, differences between young women in intervention and control sites were negligible (66\% for both groups). Postpartum care was rarely sought. Indeed, for just 11-13 percent of all infants born in the intervening period did women report the recommended three or more postpartum visits.

Differences between young women in intervention and control sites emerged with regard to just one indicator-the extent of male participation in women's pregnancy-related care. We assessed, for each pregnancy, whether the husband had accompanied the pregnant young women for her check-ups. Findings show that significantly more husbands of women in intervention than control sites had done so (54\% versus $44 \%$ ).

Among young women in intervention sites, differences were also observed with regard to institutional deliveries and postpartum care among those in standalone versus comprehensive intervention sites. Indeed, more births of young women from standalone than comprehensivesites had taken place in an institution (84\% versus $75 \%)$. In contrast, fewer women from standalone than comprehensive intervention sites had obtained three or more postpartum checkups following the birth of their infants in ( $7 \%$ versus $14 \%$ ).

\section{Marital relations}

While the PRACHAR intervention had not directly stressed, among adolescents, the importance of equitable gender relations within marriage, and the importance of husband-wife communication and violence-free conflict resolution, it had stressed contraception and childbearing related communication and negotiation. Our survey probed the extent to which these skills had spilled over into marital relations of married young men and women in intervention sites. Findings are presented in Table 8.2. They highlight, in general, that changing gender norms in gender stratified settings such as rural Bihar is challenging.

Spousal intimacy was far from universal. Indeed, relatively few young men reported that they had gone out with their spouse for purposes of entertainment: more young men in intervention than control sites (38\% versus 15\%), but identical proportions of young women from intervention and control sites (29\%) reported such outings. Spousal communication on such matters as the number of children to have and whether to practice contraception or which type of contraception to adopt was reported by considerably more young women than young men. However, differences between those in intervention and control sites were narrow with regard to communication about how many children to have, although somewhat more young people in intervention than control sites reported having 
discussed this topic with their spouse ( $76 \%$ versus $65 \%$ among young men; $89 \%$ versus $85 \%$ among young women). Differences were wider with regard to spousal discussion about contraception, again with more of those from intervention than control sites reporting communication; significant differences were observed among young men (58\% versus $28 \%$ ), while minor differences were apparent among young women (75\% versus $70 \%$ ).

Table 8.1: Pregnancy related care, all births in the three years preceding the survey to married young women Percentage of births in the period 2010-11 to 2014 for which married young women reporting antenatal, delivery and postnatal care for births taking place in the three years preceding the survey, according to study arm

\begin{tabular}{|c|c|c|c|c|}
\hline \multirow[t]{2}{*}{ Pregnancy related care } & \multirow[t]{2}{*}{ Control } & \multicolumn{3}{|c|}{ Intervention } \\
\hline & & Combined & Standalone & Comprehensive \\
\hline \multicolumn{5}{|l|}{$\begin{array}{l}\text { Of all infants born in the period } 2010-2011 \\
\text { to 2014: }\end{array}$} \\
\hline Women registered for antenatal care & 96.0 & 95.0 & 96.0 & 94.1 \\
\hline $\begin{array}{l}\text { Women who obtained antenatal care in the first } \\
\text { trimester of pregnancy }\end{array}$ & 66.0 & 66.1 & 69.1 & 63.6 \\
\hline $\begin{array}{l}\text { Women who were accompanied by their husband for } \\
\text { check-ups during pregnancy }\end{array}$ & 44.1 & $53.5^{*}$ & 54.0 & 53.1 \\
\hline Deliveries attended by a trained healthcare provider & 87.6 & 87.0 & 88.2 & 86.0 \\
\hline Births that took place in an institution & 81.1 & 79.0 & 84.2 & $74.9^{+}$ \\
\hline $\begin{array}{l}\text { Women who received three or more postnatal check } \\
\text { ups }\end{array}$ & 12.7 & 11.2 & 7.2 & $14.3^{+}$ \\
\hline $\begin{array}{l}\text { Number of births in three years preceding the } \\
\text { survey }\end{array}$ & 198 & 340 & 152 & 188 \\
\hline
\end{tabular}

Notes: Differences between control and intervention (combined) blocks, control and standalone blocks, and control and comprehensive blocks are significant at ${ }^{*} p<0.05,{ }^{* *} p<0.01,{ }^{* * *} p<0.001$. Differences between standalone and comprehensive blocks are significant at ${ }^{+} p<0.05$.

Table 8.2: Marital relations

Percentage of married young men and women reporting spousal interaction and communication, and perpetration (husbands) or experience (wives) of marital violence, according to study arm

\begin{tabular}{llll}
\hline Marital relations & Control & Intervention \\
\cline { 3 - 4 } & & Combined & Standalone Comprehensive \\
\hline & Currently married young men & \\
\hline
\end{tabular}

\section{Spousal interaction and communication}

Men who had gone on an outing (picnic, movie, other celebration) with their wife in last six months

\begin{tabular}{rrrr}
14.8 & 38.1 & 32.5 & 43.8 \\
64.8 & 75.5 & 75.2 & 75.7 \\
27.8 & $58.4^{* * *}$ & $62.0^{* * *}$ & $54.6^{* *}$ \\
& & & \\
53.2 & 56.0 & 57.6 & 54.3 \\
15.9 & 18.0 & 22.9 & 13.0 \\
$\mathbf{6 9}$ & $\mathbf{1 0 5}$ & $\mathbf{5 2}$ & $\mathbf{5 3}$ \\
\hline
\end{tabular}

Men who had discussed the number of children to have with their wife

Men who had discussed contraception with their wife

\section{Perpetration of marital violence}

Men who had ever perpetrated physical violence against their wife

Men who had forced sex on their wife

Number of currently married respondents

Currently married young men 


\begin{tabular}{|c|c|c|c|c|}
\hline \multirow[t]{2}{*}{ Marital relations } & \multirow[t]{2}{*}{ Control } & \multicolumn{3}{|c|}{ Intervention } \\
\hline & & Combined & Standalone & Comprehensive \\
\hline \multicolumn{5}{|c|}{ Currently married young women } \\
\hline \multicolumn{5}{|l|}{ Spousal interaction and communication } \\
\hline $\begin{array}{l}\text { Women who had gone on an outing (picnic, } \\
\text { movie, other celebration) with their husband in } \\
\text { last six months }\end{array}$ & 28.7 & 28.5 & 33.4 & 24.1 \\
\hline $\begin{array}{l}\text { Women who had discussed the number of } \\
\text { children to have with their husband }\end{array}$ & 85.3 & 88.5 & 88.2 & 88.8 \\
\hline $\begin{array}{l}\text { Women who had discussed contraception with } \\
\text { their husband }\end{array}$ & 69.8 & 75.2 & 76.0 & 74.5 \\
\hline \multicolumn{5}{|l|}{ Experience of marital violence } \\
\hline $\begin{array}{l}\text { Women who had ever experienced physical } \\
\text { violence perpetrated by their husband }\end{array}$ & 48.9 & 44.7 & $40.9 *$ & 48.2 \\
\hline $\begin{array}{l}\text { Women who had experienced forced sex in } \\
\text { marriage }\end{array}$ & 50.6 & 47.9 & 46.6 & 49.1 \\
\hline Number of currently married respondents & 328 & 617 & 295 & 322 \\
\hline
\end{tabular}

Notes: Differences between control and intervention (combined) blocks, control and standalone blocks, and control and comprehensive blocks are significant at ${ }^{*} p<0.05,{ }^{* *} p<0.01,{ }^{* *} p<0.001$.

Marital violence persisted as reported by young men and women, and in both intervention and control sites. Indeed, 53-56 percent of young men reported perpetrating physical violence against their wife, and 45-49 percent of young women reported having experienced physical violence perpetrated by their husband. With regard to sexual violence within marriage, considerably more young women than men acknowledged that they had experienced (women) or perpetrated (men) such violence. However differences were not observed between young men and women in intervention and control sites (16-18\% among young men; 48-51\% among young women).

\section{Summary}

This chapter assessed the extent to which young men and women who had been exposed to the PRACHAR training intervention were more likely, three to four years following the training, to report pregnancy related care and egalitarian marital relations, including the absence of marital violence than were those in control sites, and the extent to which those in the two intervention arms differed from each other in these respects.

While the PRACHAR training programme did not focus on pregnancy-related care, we hypothesised that its focus on seeking contraceptives from the health system may have influenced young people to link with the health system on other matters, notably pregnancy related care, as well. There was no evidence, however, to suggest that pregnancy related care varied between married young women in intervention and control sites. Similar proportions had registered for antenatal care, made their first antenatal visit in the first trimester, had an institutional or professionally attended delivery, and received postpartum care. Those in intervention sites were however significantly more likely than those in control sites to report their husband's involvement in pregnancy related care.

Likewise, the PRACHAR training programme did not focus on spousal relations within marriage; however we sought to explore whether the focus on communication and negotiation had resulted in more egalitarian marital relations and less marital violence among those in intervention than control sites. Such associations were not observed. Spousal intimacy was far from universal, although young men and women from intervention sites were indeed somewhat more likely than those from control sites to have communicated about the number of children to have and whether and when to practise contraception. And despite the more egalitarian gender role attitudes expressed by those in intervention than control sites, there was no evidence to suggest that marital violence, both physical and sexual, was less likely to have been perpetrated (young men) or experienced (young women) among those from intervention than control sites. 


\section{Chapter 9 Summary}

Although a number of programmes have been implemented in India to support adolescents in making a successful transition to marriage and parenthood, evaluations of these programmes have typically comprised investigations of adolescents' knowledge, attitudes, and practices at the conclusion of the intervention, sometimes compared to a similar investigation at its initiation. Not a single evaluation, to our knowledge, has assessed the situation of those exposed to the programme in comparison with those not exposed, some years following the conclusion of the programme.

The objective of our study was to better understand the longer-term effects of one such programme, namely a three-day training programme offered by Phase III of Pathfinder's PRACHAR (Promoting Change in Reproductive Behaviour)programme among adolescents in rural areas of selected districts of Bihar. Pathfinder's PRACHAR programme was implemented in various districts of Bihar, and focused on addressing adolescents' need for information, contraceptive supplies, parental and community support, and a youth-friendly health system. Briefly, in 2010-11, Pathfinder International implemented a three-day non-residential training programme for a total of almost 40,000 adolescents aged 13 to 21 years in selected villages of Gaya district. The project aimed specifically at raising awareness and understanding of sexual and reproductive matters, the importance of delayed childbearing and spacing of pregnancies, and sources of services among unmarried adolescents. Adolescents were also taught communication skills to negotiate with partners and parents in order to achieve their reproductive goals. The training programme was implemented in villages in which no other PRACHAR programme existed, as well as those in which other activities for communities more generally were also implemented.

With support from the David and Lucile Packard Foundation, the Population Council followed up adolescents aged 13-21 trained in this programme some 3-4 years following its conclusion-that is, when they were aged 17-25 years-to assess whether their reproductive health situation differed from that of a cohort of similar young people not exposed to the programme.

We note that the training programme was short, but reached large proportions of young people in project settings. It focused directly on raising awareness and changing attitudes and practices with regard to such specific outcomes as delaying marriage and promoting contraception, including contraception to delay the first pregnancy. It did not aim to build girls' agency, promote gender egalitarian attitudes among girls and boys, or address safe pre-marital sex and pregnancy related care. Hence, the direct longer-term effects of the programme should be viewed in terms of changes in young people's awareness of reproductive health matters, their marriage-related experiences (and specifically marriage age), and their contraception behaviours. While our report also discusses other outcomesagency, marital relations, and pregnancy-related care-these are presented as likely indirect outcomes; that is, those attributable to the improved communication and negotiation skills, on the one hand, and the emphasis on contact with the health system for obtaining contraceptives, on the other, which were imparted by the programme.

A major limitation of our study is that the training programme was not evaluated and hence no baseline data were available for assessing longer-term changes among trainees. Our design therefore relied on comparisons,3-4 years following the implementation of the programme, of youth who had been trained in the programme as adolescents and a matched group of youth residing in villages of a non-intervention block who had not been exposed to such training; it makes no claim to have assessed change over time.

A second limitation that must be noted is the selectivity of the trainee sample. Although villages selected as control sites resembled those from which the intervention sample was drawn, we noted considerable differences between the background characteristics of the control and intervention samples. The sample of youth listed in control sites tended to be less educated, more likely to have been married, and more likely to have migrated out of the village in the period 2010-11 to 2014. As such, it was evident that the sample of young people trained in the PRACHAR project were self-selected among the better off in intervention villages, and our matching exercise required ensuring that the sample selected from the control villages matched the background characteristics of the intervention sample. Thus we note that our sample, in both intervention and control sites, was not representative of the settings from which they were drawn. 
The study, conducted in 2014, tracked adolescent trainees aged 13-21 in 2010-11 and aged 17-25 in 2014, and compared them to a matched sample of similarly aged youth in 2014. A survey was conducted of 371 and 679 young men and women from control areas, and 789 and 1,382, respectively, from intervention areas.

\section{Acceptability of the programme}

Findings confirm that the PRACHAR programme for adolescents was both acceptable and useful to the young people exposed to it. The overwhelming majority had attended the entire three-day session and recalled every topic covered in the programme. Large proportions found topics relating to RTI/HIV/STIs, contraception, and delaying marriage and childbearing to have been important; almost all young people had discussed the programme with someone, and almost all found the training useful in making subsequent decisions in their life, ranging from the timing of marriage and childbearing to contraception and health-seeking.

Gender differences were apparent. More young women than men reported having attended the entire three-day programme, could recall topics addressed, and considered such topics as marriage and childbearing important. Also different were assessments about how the programme had helped them make decisions in their subsequent life: while both young men and young women reported that it helped them in making decisions about health care seeking, marriage timing, and contraception, young women also reporting that it helped them to make decisions about pregnancy planning, a perception rarely made by young men.

\section{Direct effects of the programme}

As mentioned above, the training programme focused on raising awareness about reproductive health matters, and notably about delaying marriage and appropriate use of contraception. Hence we consider, as direct effects of the programme, differences between young people trained in the PRACHAR programme and those in control sites in terms of reproductive health awareness and marriage and contraception practices. Overall, findings in these three areas were mixed, and on balance were much stronger for young women than young men.

\section{Awareness about sexual and reproductive health matters}

With regard to awareness about sexual and reproductive health matters, findings confirm that young people exposed to the PRACHAR intervention were consistently and significantly more likely than those not so exposed to be aware of all sexual and reproductive health matters about which we probed-how pregnancy happens, ideal ages for initiation of pregnancy and ideal inter-birth intervals, contraception, HIV/AIDS, the legal minimum age at marriage for males and females, and the risks of early childbearing for mothers and infants. In addition, gender differences in young people's awareness of sexual and reproductive health was evident on several matters: by and large young women were better informed than young men about pregnancy related topics and risks associated with early childbearing, while young men were better informed than young women about HIV related matters. Both young men and young women were similarly informed about the legal minimum age at marriage for males and females, and, in general, about contraception and the ideal pace of childbearing. Multivariate analyses controlling for a range of potentially confounding factors reiterate that those in intervention areas, including from both standalone and comprehensive project areas, were more likely to report awareness about contraception and HIV/AIDS than were those in comparison areas.

With regard to exposure to family life or sexuality education, including the PRACHAR programme, as expected, almost all those in intervention sites recalled their participation in the PRACHAR programme, and were thus exposed to at least one, and sometimes more than one family life or sexuality education programme. In contrast, fewer than two in five young men and women from control sites had been so exposed. Among those exposed to any programme, almost all had been informed about HIV related matters. However, those from intervention sites were significantly more likely than those from control sites to have been informed about such other key issues as nocturnal emission, menstruation, pregnancy, and boy-girl relationships.

Finally, we note that among those exposed to the intervention, differences between those in standalone versus comprehensive project sites were generally negligible on all issues about which we probed, but in the few instances in which differences were observed, those in the standalone intervention sites reported greater awareness than did those in comprehensive intervention sites. 


\section{Marriage delay and marriage related decision-making}

There is no evidence that young people's exposure to the PRACHAR intervention succeeded in delaying marriage or enhancing young people's participation in marriage related planning.

Early marriage was evident in both intervention and control sites. Mean ages at marriage among the married ranged from 19 years among young men to 17 among young women. Differences in marriage ages between those from intervention and control sites were not observed. For example, of young women aged 18-25, one-third had married before they were aged 18, and one in 20 had married before they were aged 15. Among young men aged 21-25, one-fifth had married before they were 21. Differences between intervention and control sites were not observed.

Among the unmarried, marriage related discussions had been initiated for between one-sixth and one-fifth of young men, and between two-fifths and one-half of young women. About ten percent of young men, and 15-19 percent of young women reported, moreover, that a potential spouse had been proposed for them, and two percent and 6-7 percent, respectively, reported that their marriage had been fixed, that is, that they were engaged to be married. While differences between young men and women in intervention and control sites were not observed, those in intervention sites were considerably more likely than those in control sites to intend to practice contraception to delay their first birth after marriage.

For married young people, marriages had largely been arranged by parents with no involvement of the young person, and this was particularly so among young women. About half of young men and almost three-quarters of young women had no say in the selection of their spouse; fewer than five percent had selected their own spouse. Most young people met their spouse for the first time on the wedding day and hardly any reported that they were well acquainted with their spouse before marriage. Differences between intervention and control sites were negligible.

\section{Contraception in pre-marital and extra-marital sexual relations}

Protected sex in pre-marital and extra-marital relationships was far from universal. Among young men, for example, just under one-half of all young men from intervention sites had used contraception at the time of their last sexual encounter, compared to significantly fewer of their counterparts from control sites. Similarly, consistent condom use in all pre-marital and/or extra-marital sexual encounters was reported by about one-quarter of young men from intervention sites and one-sixth of those from control sites. Significant differences were observed, moreover, among unmarried young men in intervention and control sites, but once confounding factors were controlled, this advantage was no longer observed.

Among young women who had experienced pre-marital and/or extra-marital sex too, those in intervention sites were significantly more likely to have practised contraception at last sex than were those in control sites; indeed, two-fifths versus one-eighth of young women had done so. Differences were significant and as stark with regard to consistent condom use in all their sexual encounters, with one-quarter of those from intervention sites, compared to fewer than one in 20 of those from control sites reporting consistent condom use in all their sexual encounters. Even after confounding factors were controlled, young women who had been exposed to the PRACHAR programme were more likely than others to have practised contraception and consistent condom use.

\section{Contraception in married life}

Significantly more young men and women from intervention than control sites reported that prior to or around the time of their marriage, someone had discussed with them the importance of delaying the first pregnancy, and significantly more of those from intervention than control sites had intended, around the time of their marriage, to delay the first pregnancy.

Contraceptive practice at the time of the interview (largely oral contraceptives and condoms) suggests that exposure to the PRACHAR intervention had little effect on men's contraceptive prevalence, but a strong effect among young women; effects remained significant even after confounding factors were controlled. A similar picture emerged with regard to contraceptive practice to postpone higher-order births among women (but not men) with one or more births. In contrast, while women in intervention sites were significantly more likely to have practised contraception to postpone the first pregnancy, effects were not significant when confounding factors were controlled. Indeed, although large proportions of young women with one or more births had wished to postpone their first pregnancy, most had 
failed to do so. Reasons for failure to use contraception typically included pressure from the husband and family, suggesting a need for a greater focus on family-level obstacles to contraception among newlywed women.

\section{Pace of childbearing among the married}

Also unaffected by the intervention was the pace of childbearing. For example, about half of all young women already had one or more births; the interval from marriage to first birth was short-just 21 months; and of those who had at least one birth, almost one-fifth of young women in both intervention and control sites had gone on to have a second or higher-order birth.

\section{Indirect effects of the programme}

Our evaluation also explored several indirect effects of exposure to the training programme-indirect because they were never explicitly addressed in the training programme-on the situation of young people 4-5 years following exposure. We hypothesised that the focus of the training programme in promoting communication and negotiation about marriage and contraception may have affected young people's agency, their gender role attitudes, and husband-wife relations, and that the emphasis on seeking contraceptive services would additionally have influenced their pregnancy related practices.

\section{Agency}

Although building agency was not part of the PRACHAR intervention, we hypothesised that the focus on communication and negotiation likely had a spillover effect on agency, particularly among young women. Findings confirm that young people exposed to the PRACHAR intervention were indeed more likely than those not so exposed to display agency in terms of decision-making, self-efficacy, access to economic resources, and freedom of movement. Wide gender differences were observed, however. As expected, young men were more likely than young women to display most dimensions of agency, and differences between young men in intervention and control sites were evident on just a few outcomes, for example, decision-making about health-seeking practices and access to and control over economic resources. Differences between intervention and control sites were consistently significant among young women, and remained significant even after controlling for a host of potentially confounding factors such as age, education, and exposure to mass media. Indeed, among young women, those in intervention sites displayed greater agency on every dimension. They reported significantly higher levels of decision-making authority, self-efficacy, access to and control over economic resources, and freedom of movement, as revealed by responses on several individual matters about which we probed, as well as in summary measures relating to each dimension of agency.

\section{Gender role attitudes}

As in the case of measures to promote agency, fostering egalitarian gender role attitudes was not part of the PRACHAR intervention. However, we hypothesised that efforts made by the intervention to promote communication and negotiation would also have a spillover effect on promoting egalitarian gender role attitudes. We sought respondents' attitudes on ten issues, ranging from whether girls should be educated as much as boys to whether it is the man who should decide on condom use. Although attitudes exhibited by young men and young women differed, differences between those in intervention and control sites were significant on a large number of attitudes among young women ( 8 of 10 ) and young men (5 of 10). A summary measure of all attitudes explored reveals that egalitarian gender role attitudes were significantly more likely to be expressed by those who had been exposed to the PRACHAR intervention than others, and effects continued to be strong among both young men and young women even after confounding factors were controlled.

\section{Marital relations}

Likewise, the PRACHAR training programme did not focus on spousal relations within marriage; however we sought to explore whether the focus on communication and negotiation had resulted in more egalitarian marital relations and less marital violence among those in intervention than control sites. Such associations were not observed. Spousal intimacy was far from universal, although young men and women from intervention sites were indeed somewhat 
more likely than those from control sites to have communicated about the number of children to have and whether and when to practise contraception. And despite the more egalitarian gender role attitudes expressed by those in intervention than control sites, there was no evidence to suggest that marital violence, both physical and sexual, was less likely to have been perpetrated (young men) or experienced (young women) among those from intervention than control sites.

\section{Pregnancy related care}

While the PRACHAR training programme did not focus on pregnancy-related care, we hypothesised that its focus on seeking contraceptives from the health system may have influenced young people to link with the health system on other matters, notably pregnancy related care, as well. There was no evidence, however, to suggest that pregnancy related care varied between married young women in intervention and control sites. Similar proportions had registered for antenatal care, made their first antenatal visit in the first trimester, had an institutional or professionally attended delivery, and received postpartum care. Those in intervention sites were however significantly more likely than those in control sites to report their husband's involvement in pregnancy related care.

\section{Differences between those trained in settings in which other PRACHAR activities were implemented and those in which no other PRACHAR activities existed}

The PRACHAR intervention for adolescents was implemented in two types of intervention settings: 'standalone' settings in which no other PRACHAR activity was conducted, and 'comprehensive' settings in which the PRACHAR programme implemented a range of activities at the community level as well. Outcomes were by and large similar among those trained in both types of settings, and indeed, where differences emerged, there was no indication that those who resided in comprehensive programme settings were consistently better off than those who resided in settings in which no programme other than the training intervention was conducted.

\section{Conclusion}

The longer-term effects of the three-day training programme for adolescents that was implemented by the PRACHAR programme in 2010-11 to more than 39,000 adolescents and youth, provided mixed results but suggested that on several issues, even 3-4 years following exposure to the intervention, those who had been exposed to it displayed significantly different experiences than those not exposed. We note however that our sample of youth was not representative of the communities from which they were drawn, in fact, they were likely more educated than the rest, and findings, therefore, may not be held to be entirely generalisable to the communities from which the sample of young people was drawn.

Notwithstanding these caveats, findings appear to confirm that even a short-duration programme delivered at scale may create sufficient momentum among the young to sustain differences in some behaviours between those exposed to the training and other youth even several years following such exposure. Sustained differences were observed only in some aspects of youth life-knowledge about reproductive health matters, contraceptive practice following the birth of the first child, and agency of young women. No differences were observed in other and perhaps more intransigent key practices that the programme attempted to address, namely delaying marriage and delaying the first pregnancy. Nor were differences observed in all aspects of young women's agency, for example, their role in marriage- related decision-making or the perpetration of violence by husbands on their wife.

Findings demonstrate the promise of a scaled intervention implemented among large proportions of adolescent and young people, but suggests that a training programme lasting just three days or one focused only on adolescents may not be sufficient to sustain longer-term effects in the more difficult-to-change aspects of young people's reproductive health-child marriage and early pregnancy-in a conservative setting such as Bihar. Findings relating to the failure of the intervention in effecting changes in these behaviours call into question the need for a more sustained intervention on the one hand, and for programmes that address other stakeholders as well, notably parents, community leaders, and the health system more generally. 


\section{References}

Acharya, R., S. Kalyanwala and S. J. Jejeebhoy. 2009. Broadening Girls' Horizons: Effects of a Like Skills Education Programme in Rural Uttar Pradesh. New Delhi: Population Council.

Bearinger, L. H., R. E. Sieving, J. Ferguson et al. 2007.'Global perspectives on the sexual and reproductive health of adolescents: patterns, prevention, and potential,'The Lancet, 369(9568): 1220-1231.

Daniel, E.E and R. Nanda. 2012. 'The Effect of Reproductive Health Communication Interventions on Age at Marriage and First Birth in Rural Bihar, India: A retrospective study.' Research and Evaluation Working Papers, Watertown, MA: Pathfinder International.

International Institute for Population Sciences (IIPS). 2010a. District Level Household and Facility Survey (DLHS-3), $2007-08$. Mumbai: IIPS.

International Institute for Population Sciences (IIPS). 2010b. District Level Household and Facility Survey (DLHS-3), 2007-08. Key Indicators: States and Districts. Mumbai: IIPS.

International Institute for Population Sciences (IIPS) and Macro International. 2007. National Family Health Survey (NFHS-3), 2005-06: India, Volume 1. Mumbai: IIPS.

International Institute for Population Sciences (IIPS) and Population Council. 2009. Youth in India: Situation and Needs 2006-2007, Bihar. Mumbai: IIPS.

Office of the Registrar General and Census Commissioner, India. n.d.a. Census of India 2011: B-1 Main workers, Marginal workers, Non-workers and those marginal workers, non-workers seeking/available for work classified by age and sex. Accessed on 16 October, 2015 at http://www.censusindia.gov.in/2011census/B-series/B-01/DDW-1000B-01-Census.xls.

Office of the Registrar General and Census Commissioner, India. n.d.b. Annual Health Survey 2011-12: Factsheet, Bihar. Vital Statistics Division. New Delhi: Office of the Registrar General and Census Commissioner, India. Accessed on 16 October, 2015 at http://www.censusindia.gov.in/vital_statistics/AHSBulletins/AHS_Factsheets_2011_12/Bihar_Factsheet_2011-12.pdf.

Office of the Registrar General and Census Commissioner, India. 2013. Primary Census Abstract, Data Highlights, India, Series 1. New Delhi: Office of the Registrar General and Census Commissioner, India. Accessed on 16 October, 2015 at http://www.censusindia.gov.in/2011census/PCA/PCA_Highlights/pca_highlights_file/India/Chapter-3.pdf.

Pathfinder International. 2007a. Facilitator's Guide: Reproductive Health Training for Adolescents Pathfinder International Module 3a: My Family: Making My Own Choices (15-19 year old Girls). New Delhi: Pathfinder International.

Pathfinder International. 2007b. Facilitator's Guide: Reproductive Health Training for Adolescents Pathfinder International Module 3b: My Family: Making My Own Choices (15-19 year old Boys). New Delhi: Pathfinder International.

Pathfinder International. 2011. PRACHAR Project: Promoting Change in Reproductive Behaviour in Bihar. Summary Report of Phase II Evaluation Findings. New Delhi: Pathfinder International.

Planning Commission. 2013. Press note on poverty estimates, 2011-12. Accessed on 16 October, 2015 at http:// planningcommission.nic.in/news/pre_pov2307.pdf.

Population Council. 2010. Consultation on meeting challenges in measuring youth transitions to adulthood. New Delhi: Population Council (Unpublished).

Prakash, R., S.J. Jejeebhoy and R. Acharya. 2013a. Improving the sexual and reproductive health of married women and men: Effects of the PRACHAR-III project. New Delhi: Population Council (Unpublished).

Prakash, R., S.J. Jejeebhoy and R. Acharya. 2013b. Improving the sexual and reproductive health of married women: Long-term effects of the PRACHAR-I and PRACHAR-II project. New Delhi: Population Council (Unpublished).

Prakash, R., S.J. Jejeebhoy and R. Acharya. 2013c. Knowledge and attitudes of adolescents on reproductive health matters: sustained effects of the PRACHAR-I and PRACHAR-II intervention. New Delhi: Population Council (Unpublished).

UNICEF. 2011. The State of the World's Children 2011: Adolescence An Age of Opportunity. New York: UNICEF. 


\section{Authors}

Neelanjana Pandey, Programme Officer I, Population Council, New Delhi

Shireen J. Jejeebhoy, Senior Associate, Population Council, New Delhi

Rajib Acharya, Associate II, Population Council, New Delhi

Santosh Kumar Singh, Assistant Programme Officer II, Population Council, New Delhi

Mahesh Srinivas, Director, Programs, Pathfinder International, New Delhi 


\title{
LIST OF INVESTIGATORS
}

\author{
Household Listers \\ Deepak Kumar Pandey \\ Hrishikesh Pandey \\ Brhamanand Saraswati \\ Anil Kumar Sinha \\ Jaishankar Tiwari
}

\section{Field Supervisors/Editors}

Sarita Ram Deshbhratar

Md. Tasnim Faruque

Arsi Fatima

Madhulata Gupta

Ruchi Kumari

Bhaskar Mishra

Dipu Kumar Sharma

Preeti Verma

\section{Field Investigators}

Sayra Bano

Saraswatiben Chaudhari

Salma Khanam

Kamlesh Kumar

Chanda Kumari

Rinki Kumari

Diwakar Maji

Dhirendra Rathore

Nanda Sahu

Laxmi Saini

Poonam Saini

Anju Sharma

Rajnikant Shukla

Rachana Singh

Ragini Sinha

Priyanka Vaishnav

Zahida 
Printed at :

Systems Vision

Email:systemsvision@gmail.com 
